\title{
Ernährungsbiologie der Garnele (Crangon vulgaris Fabr.).
}

\author{
Von Johannes Plagmann, Hamburg.
}

(Aus der Hydrobiologischen Abteilung des Hamburgischen Zoologischen Museums und Instituts.)

(Mit 10 Abbildungen und 3 Karten im Text.)

\section{Inhalt.}

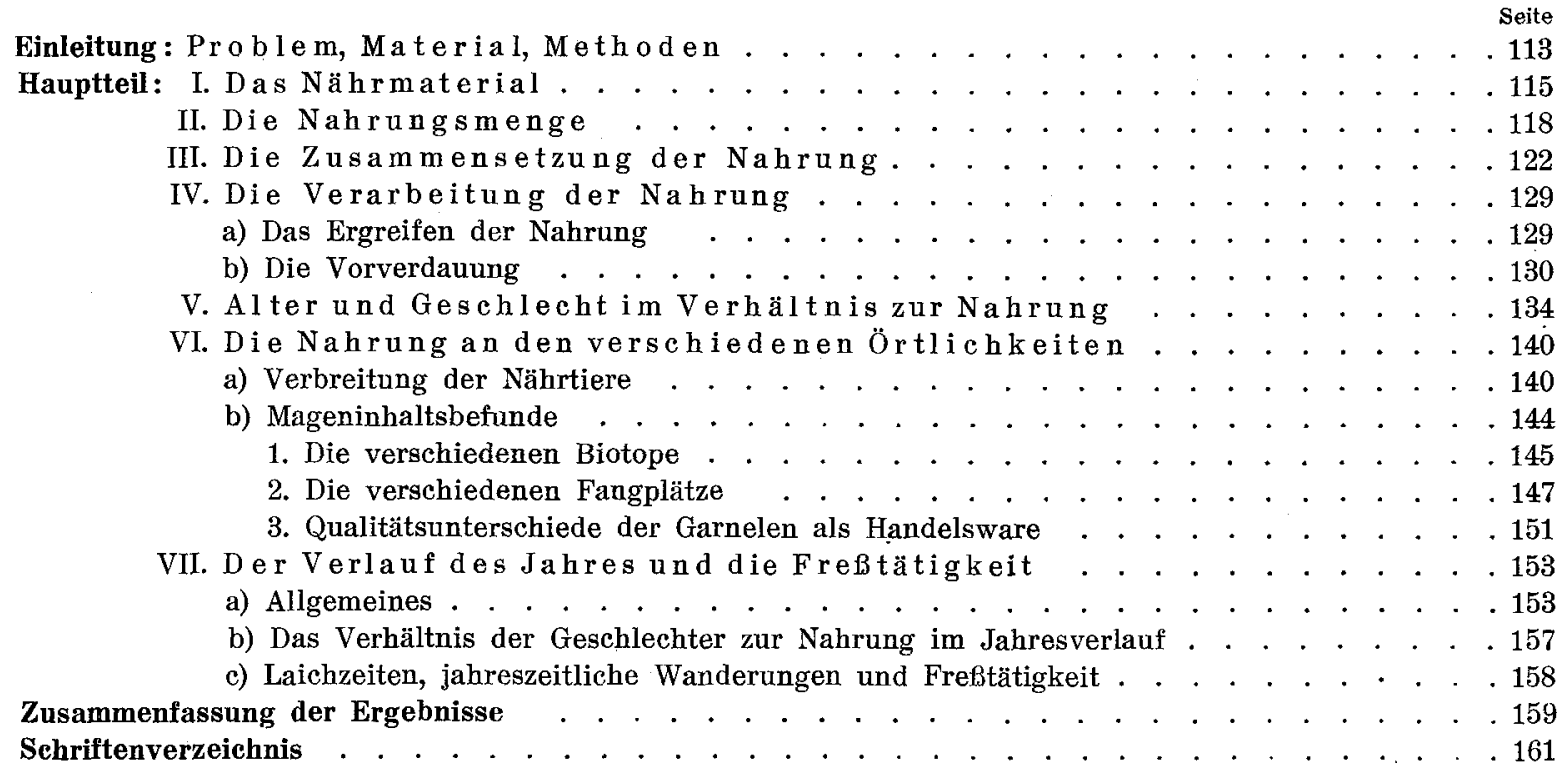

\section{Einleitung.}

\section{Problem, Material, Methoden.}

Die großen Bestandsschwankungen der Garnelen in den deutschen Garnelenfanggebieten lenkten das Interesse der Fischereiwissenschaft in erhöhtem Maße auf den Fragenkomplex der Ökologie dieses an Bedeutung ständig zunehmenden Fischereigegenstandes. Es gilt, innere und äußere Faktoren der Lebensweise der Garnelen zu erforschen, um vielleicht Maßnahmen treffen zu können, die eine stetige Ausnutzung der Bestände zu gewährleisten vermögen. Die vorliegende Arbeit nun versucht, einen Einblick in das Ernäh rungsleben der Garnele zu vermitteln. Die Lösung dieser Frage ist nicht nur aus wirtschaftlichen Rücksichten von Bedeutung, insofern nämlich, als die Grundlage zur Beurteilung der Veränderungen der Bestände in Dichte und Qualität breiter wird, sondern auch in allgemein marinbiologischer Hinsicht. Es wird nämlich versucht, eine Lücke in 
jener großen Schau C. G. J. Petersen's zu schließen, die den Aufbau der Nahrung von pflanzlichen Meeresprodukten bis zu den Nutzfischen sieht und in gegenseitige Abhängigkeit bringt. Weiter wird so ein Beitrag geliefert zur Ökologie der Küstenlebensgemeinschaften.

Das Material für diese Untersuchungen ist dem Elbmündungsgebiet, von Cuxhaven bis zur Insel Scharhörn, entnommen, welches Gebiet durch den Besitz fast aller jener Biotope ausgezeichnet ist, die sich innerhalb größerer Räume auch auf den übrigen Garnelenfanggebieten der deutschen Nordseeküste wiederfinden.

Rauschenplat (1901) stellt die These auf, daß ,von den Methoden zur Bestimmung der Nahrung von Meerestieren die Darmuntersuchung die exakteste" sei. Ich stellte also die Mageninhaite von Garnelen fest, die ich an verschiedenen Orten und Zeiten folgendermaßen gewann. AuI dem Watt verwendete ich die übliche, in der Krabbenfischerei seit langen Zeiten angewandte Krabbenzille; für die kleinen Pfützen des Wattes benutzte ich einen kleinen Schiebehamen, wie er als Kinderspielzeug verkauft wird. An den Watträndern und in den Prielausgängen fischte ich Garnelen mit dem Hamburger MotorbootTrawl nach LÜBBERT vom Motorboot der Fischmarkt-Cuxhaven G. m. b. H. aus, welches mir freundlicherweise zur Verfügung gestellt wurde. Die meisten der zur Untersuchung gelangten Garnelenproben aber entnahm ich den Baumkurrenfängen der Cuxhavener Krabbenkutter. Einige Proben stammen aus dem Beifang der Stinthamenfischer, und zur Lebenduntersuchung nahm ich einige aus den Gammelanlandungen bei den Darrenbetrieben. Lebende Garnelen zur Fütterung im Aquarium transportierte ich entweder, für kürzere Strecken, in einem mit Seewasser beschickten Zinkkanister oder in einer Wasserflasche, der, für längere Strecken, Sauerstoff zugeführt war. Die Proben wurden konserviert durch $4 \%$ iges Seewasserformalin, welches die Garnelen meist so tötete, daß ein Erbrechen während des Sterbens nur selten auftrat. Proben, die durch den Bodensatz der Flasche erkennen ließen, daß sich Garnelen erbrochen hatten, wurden von vornherein ausgeschieden. Die Kutterproben bestanden durchschnittlich aus 50 bis 60 Stück Garnelen, von denen soviel untersucht wurden, bis das Untersuchungsbild sich nicht mehr wesentlich veränderte; das war meistens bei etwa 15 Stück der Fall. Erwies sich die Nahrung innerhalb einer Probe als sehr heterogen, so wurde die ganze Probe untersucht. Von den Motorbootfängen wurden außer den Garnelen auch Beifangtiere konserviert und von diesen Fische und Brachyuren gelegentlich auf ihren Mageninhalt geprüft. Dies erwies sich als vorteilhaft, zumal sich in den Mägen der Tiere solche Nahrungstiere fanden, die mit Bodenproben, Brutnetz- und Planktonfängen nicht erbeutet worden waren. Ich versuchte nämlich, das Gebiet dadurch zu bonitieren, daß ich gleichzeitig mit Garnelenfängen und auch getrennt, Bodenproben nahm, entweder mit einem Petersen-Bodengreifer in Gebieten größerer Wasserbedeckung oder auf dem während der Ebbe freiliegenden Watt mit einem Bodenstecher von $25 \mathrm{qcm}$ etwa $7-10 \mathrm{~cm}$ tief. Die Bodengreiferproben wurden durch einen Siebsatz gegeben, der bei Bodenuntersuchungen (HAGmeIER) üblich ist, und die Bodenstecherproben wurden durch die Gaze des Brutnetzes gespült, so daß die Organismen die sich im Wattboden aufhalten, auf der Gaze zurückblieben. Das Brutnetz setzte ich 15 Minuten aus, während das Oberflächennetz (Gaze 25) mit 50 l Oberflächenwasser beschickt wurde. Die Ergebnisse der Zählungen aber erwiesen sich als derartig uneinheitlich, daß sie zu einem unmittelbaren Vergleich mit den Mageninhaltsbefunden nicht herangezogen werden konnten; ich beschränkte mich daher darauf, eine qualitative Übersicht über die Besiedlung des Gebietes mit Garnelennahrungstieren zu bekommen und zog die Feststellungen und Abstraktionen anderer Untersucher ähnlicher Biotope zur Vervollkommnung des Bildes heran. So hielt ich mich zu Untersuchungen an Ort und Stelle in Duhnen für das Duhner Watt auf und auf Neuwerk und Scharhörn, um von diesen Operationsbasen aus Schnitte durch das Watt zu legen.

Die Mageninhalte der Garnelen untersuchte ich in $\mathrm{Cuxh}$ aven im Fischereimuseum des Heimatvereins und in Hamburg in der Hydrobiologischen Abteilung des Zoologischen Museums und Instituts. Durch Abnahme des Kopfbruststückes legte ich den Magen der Garnele frei, riß ihn mit einer Pincette unmittelbar hinter den Mandibeln heraus und breitete seinen Inhalt unter Zusatz eines Wassertropfens auf einem Objektträger aus. Der meist stark zerkleinerte Inhalt wurde zuerst makroskopisch geprüft, dann unter einem Binokular mit zehnfacher Vergrößerung und, nach weiterer Aufschwemmung und Isolierung einzelner Teile, mikroskopisch, zunächst mit Lupenvergrößerung und weiter, je nach Beschaffenheit der Teile, mit stärkeren Vergrößerungen. Auf diese Weise war eine fast lückenlose Feststellung der Beutetiere der Garnele gewährleistet. Die Art-, ja selbst Gattungsbestimmung aber war eine der Hauptschwierigkeiten, da in den meisten Fällen 
die Beutestücke zu stark zerrieben waren. Durch Fütterungsversuche, durch Herstellung von Zeichnungen und Präparaten einzelner Teile des Mageninhaltes einerseits und andererseits der möglichen Nahrungstiere versuchte ich sie zu erkennen. Es stellte sich im Laufe der immer wieder angestellten Vergleiche heraus, daß die Art und Weise des Zerbrechens der verschiedenen Formen den Gattungen, ja zuweilen gar den Arten eigentümlich war, sodaß fast jeder Mageninhalt eine Rekonstruktion seiner Teile zu ganzen Tieren usw. zuließ. Schizopodenteile fanden sich anders zerbrochen als Amphipodenteile und unter diesen wieder Gammarus anders als Bathyporeia usw. Zum mindesten aber konnte festgestellt werden, ob Malacostraken oder Entomostraken die Urheber eines Gemisches von Chitinteilchen waren. Unterstützt wurde diese Rekonstruktion der Teile durch Einzelheiten wie Mandibeln, Augen, Beinteile, Borsten, bei Schnecken und Muscheln durch Spindeln und Schlösser, während bei Würmern entweder Mandibeln oder meist die Borsten zur Bestimmung herangezogen werden konnten. Für seltener auftretende Tiere ist es selbstverständlich, daß Irrtümer auftreten, es gelang aber, rund 2000 Garnelen einigermaßen einwandfrei inbezug auf ihren Mageninhalt zu bearbeiten und für die folgenden Erörterungen auszuwerten. Die Länge der einzelnen Garnele wurde gemessen vom Ende der Antennenschuppen bis zum Ende des zusammengelegten Schwanzfächers auf den nächstliegenden Millimeter. ${ }^{1}$ ) Außer der Länge wurden eine Reihe von Zuständen der Garnele und des Darmtraktus mitregistriert, die, soweit sie zur Verwendung kamen, in den betreffenden Abschnitten vorher erklärt werden. Ebenso werden im Anfang jeden Abschnittes die Methoden zur Berechnung auseinandergesetzt. ${ }^{2}$ )

\section{Das Nährmaterial.}

Gelegentlich sind an verschiedenen Orten von einer Reihe von Autoren Mageninhalte von Garnelen untersucht worden. In den Mägen von Garnelen aus dem ostfriesischen Wattenmeer fand ЕнRENBaum (1890) neben Meeresalgen (Ulva und Enteromorpha) hauptsächlich Ueberreste von polychaeten Würmern (Nereis pelagica) und meint, "daß die Garnele zeitweise auch nur Schlick frißt, wie viele andere auf und im Schlick lebende Tiere". Im Sommer nimmt sie vor allem Crustaceen, weil enorme Mengen von Amphipoden und Schizopoden zur Verfügung stehen (Corophium volutator, Gammarus locustá, Mysis vulgaris, Podopsis slabberi) (S. 105). Teile von Heringslarven (Wirbelsäule von $23 \mathrm{~mm}$ Länge) und vom Stint wurden vorgefunden und die Neigung der Garnele zum Kannibalismus beobachtet. Weibchen fraßen Zoëen ihrer eigenen Brut, eben gehäutete Artgenossen wurden angefressen, und selbst ganze, kleine Garnelen waren in Mägen größerer (S. 85). Rauschenplat (1901) gibt an, daß er vorwiegend Polynoidenborsten, Nereidenborsten, Crustaceenteile (2 mal Ostracoden), außerdem eine kleine Schnecke und zerbrochene Muschelschalen in Mägen von Garnelen der Kieler Bucht vorfand. Pflanzenteile füllten einen Magen so, daß sie wohl zum Zwecke der Ernährung aufgenommen waren. Dem vereinzelten Vorkommen der Diatomeen legt er keine Bedeutung bei (S. 33). Havinga's Untersuchungen im Jahre 1930 an Garnelen aus den holländischen Gewässern decken sich in ihren Ergebnissen im wesentlichen mit denen von EHrEnbaum. An Würmern gibt er Nereis succinea und Nereis diversicolor als die belangreichste Nahrungsquelle an, "neben noch einigen anderen Arten und Gattungen, die aber an den oft spärlichen Resten nicht immer einwandfrei zu bestimmen waren". Auf die Würmer folgen der Häufigkeit nach die Kruster (an erster Stelle Corophium, viel weniger Gammarus und vereinzelt Neomysis und Praunus). Von den Mollusken fand er die Schnecke Hydrobia und die Muschel Mya arenaria (eine unverletzte Schale von $1,4 \mathrm{~mm}$ Länge). Selten stellte er junge Fische und Fischlarven fest. Schlick und Detritus bemerkte er zwar, ohne bestimmen zu können, "ob dieses von Würmern stammt oder direkt von dem Granat gefressen war". Von allen Garnelen, die er im Laufe des Jahres untersuchte, hatten $38 \%$ nur Würmer gefressen, $31 \%$ nur Crustaceen, $9 \%$. Würmer und Crustaceen und $22 \%$ Detritus. A. MeschKat (1936) prüfte die Mageninhalte von Garnelen aus dem Bereich der Vestmannainseln Islands, und von „13 Stück hatten 12 Bodenorganismen, und zwar Polychaeten, Ophiuren, Crangon, Philine und Crustaceeneier gefressen. Planktontiere, Calaniden und Amphipoden kamen

1) Wie Ehrenbaum und Havinga; P. F. Meyer maß vom Ende des Rostrums bis zum Ende des Telsons.

2) Meinem verehrten Lehrer, Herrn Prof. Dr. E. Hentschel, Hamburg, bin ich zu großem Dank verpflichtet für Anregungen und Ratschläge, die mir während der Untersuchungen zuteil wurden. 
in zwei Fällen vor, Detritus war in 5 Mägen enthalten. Einmal eine Bodenforaminifere. Eine Melosira-Kette und eine Paralia-Kolonie sind die Planktondiatomeen“ (S. 13).

Wir sehen aus dieser Zusammenstellung, daß wir die Garnele wohl als einen Allesfresser mit erheblicher Nahrungsbreite bezeichnen können. Unter den Garnelen, deren Mageninhaltsbefunde in vorliegender Untersuchung verarbeitet worden sind, fraßen

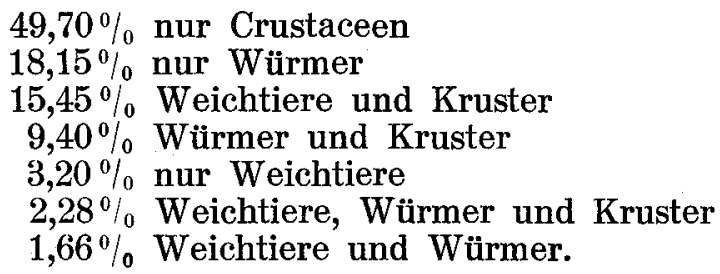

Der Wert der verschiedenen im Magen vorgefundenen Gegenstände wechselt sehr mit den Unterschieden von äußeren und inneren Bedingungen der Garnele. Deshalb habe ich in folgender Übersicht die Beutetier-Formen nebst den sonstigen Beifunden einzeln aufgeführt und in Anlehnung an SchIEMENZ (1905) eine Unterteilung in Haupt- und Nebennahrung vorgenommen, wo als ordnendes Prinzip die Qualität der Nährtierform und die Häufigkeit, in der sie an den Befunden des Gesamtmaterials Anteil hat, benutzt wurde. Es ist dabei zu beachten, daß mehrere Formen gleichzeitig in einem Magen vorzukommen pflegen. Außerdem ist wegen der gelegentlichen Schwierigkeit, die Nahrungstiere näher $\mathrm{zu}$ bestimmen, die Möglichkeit in Rechnung zu ziehen, daß noch mehr verschiedene Formen gefressen worden sind, als angegeben werden.

Hauptnahrung:

1. Amphipoden (Gammarus, Bathyporeia, Corophium)

2. Würmer (Polychaeten und Oligochaeten)

3. Schizopoden

4. Muscheln

5. Copepoden (mit Harpacticiden)

6. Schnecken

7. Cyprislarven von Balanus

$28,00 \%$ $27,30 \%$ $16,80 \%$ $16,35 \%$ $15,50 \%$ $12,40 \%$ $9,14 \%$

Nebennahrung:

8. Grünalgen

9. Crangon, also Artgenossen

10. Fischteile

11. Balanus-Teile

12. Nematoden

13. Blütenpflanzenteile

14. Insektenteile

15. Ostracoden

16. Cumaceen

17. Naupliuslarven von Balanus

18. Hydroidenteile

$8,20 \%$
$5,80 \%$
$5,04 \%$
$2,80 \%$
$2,80 \%$
$2,80 \%$
$2,10 \%$
$1,50 \%$
$0,70 \%$
$0,50 \%$
$0,50 \%$

Be if unde:

19. Seeigelstacheln

20. Foraminiferen

21. Schlick und Detritus

22. Bodendiatomeen

23. Planktondiatomeen

24. Cercarien, schwanzlos

25. Eikokons von Pygospio

26. Sand (vereinzelt Glaukonit-Stückchen)

$15,70 \%$ $13,60 \%$ $13,60 \%$ $7,60 \%$ $5,10 \%$ $1,10 \%$ $0,30 \%$ 
Unbestimmtes:

Crustaceenteile
Muskulatur
Ungeformtes
Eier

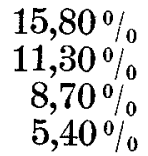

Von den Amphipo den waren außer Corophium volutator uud Gammarus locusta vor allem Bathyporeia-Arten zu erkennen, die ich nach einem Material identifizierte, welches Herr Prof. Schellenberg-Berlin mir freundlicherweise bestimmte. Ob sich auch Hyperiiden an der Nahrung beteiligen, konnte nicht ausgemacht werden, ist aber wahrscheinlich, weil sie sich oft zwischen den Garnelen eines Fangzuges zeigten. Nur in einem Falle konnte ich eine Idothea lineata aus dem Garnelenmagen hervorholen, die in höheren Schichten des Wassers stellenweise zahlreich vorhanden sind. Das I s op od en-Vorlagematerial bestimmte mir Herr Dr. PANnING-Hamburg. Die Schizopoden waren vertreten durch Praunus flexuosus, Neomysis vulgaris und Schistomysis ornata. Auch hier besteht die Möglichkeit sehr wohl, daß andere, kleinere Arten genommen worden sind, wie z. B. Podopsis slabberi. Da sich auch gewisse Eu phausiden, zeitweise sogar massenhaft, einstellen, werden sie auch gefressen worden sein; sie wurden zu den Schizopoden gerechnet. An Würmern ist mit Sicherheit Nereis diversicolor, Arenicola marina und eine Tubifex-Art erkannt, außerdem Terebelliden und Sabelliden. Von letzteren Sabellaria spinulosa, welche Art den sogenannten „Salpetergrund“ der Fischer bildet. Eine ganze Reihe anderer Wurmarten fallen weiterhin den Garnelen noch zum Opfer, die Reste aber waren zumeist unbestimmbar, wenigstens kostete es zuviel Zeit, die vielen verschiedenen Borstenformen zur Artbestimmung $\mathrm{zu}$ verwenden. Das Vorlagematerial war von Herrn Dr. AugenERHamburg bestimmt worden. An Muscheln kommen die Jugendformen und kleineren Stücke von Mytilus edulis, Macoma baltica, Cardium edule und Mya arenaria in Betracht, wahrscheinlich auch Scrobicularia plana. Die Jugendformen wie geschlechtsreifen Formen der Schnecke Hydrobia ulvae wurden in gleicher Weise genommen; Littorina war nur vereinzelt vorhanden. Die Mollusken-Vorlageformen waren von Herrn Prof. DEGNERHamburg bestimmt. Neben den bodenbewohnenden Ha rp a cti c iden, kleinen und größeren Formen, erschienen nicht selten auch Cyclopiden und Centropagiden. Jüngere Stadien als Copepoditen wurden nicht gefunden, dafür aber recht oft Copepoden-Spermatophoren und -Eier. Größere Stücke von Grünalgen, wahrscheinlich von Ulva und bestimmt von Enteromorpha compressa, machten gelegentlich den ganzen Mageninhalt aus. Meist mit Grünalgen zusammen traten schwanzlose Cercarien auf, die in unkonserviertem Material noch lange am Leben blieben, auch wenn die Alge schon ausgedaut war. Recht oft waren die Sprossen von Grünalgen abgegrast worden und fanden sich dann mit 2-5 Zellreihen. Wie stark mazerierte Blütenpflanzenteile traten Fucus-Teile und Hydroidenstöckchen auf, oft mit jungen Mytilus zusammen, die sich daran festgesponnen haben mochten. Cumaceen und Ostracoden habe ich unbestimmt gelassen. Zu den Fischmahlzeiten waren verschiedene Fische genommen: Pleuronectes sp., Clupea sp. sp. (Wirbelsäule, Schuppen, Sprott-Otolithen), Osmerus eperlanus, Gobius minutus. Teile größerer Fische, wie Muskulatur, Schuppen und Wirbel, deuten darauf hin, daß auch A as gefressen wird, während im allgemeinen die Tiere anscheinend lebend erbeutet waren. RAUSCHENPLAT hat gar an Menschenleichen Garnelen sich mästen gesehen. Die im Magen wohlerhaltenen $\mathrm{Ne}$ m a to d e n waren durchweg freilebende Arten, daneben aber auch offenbar parasitische, die sie sich in lebenden Mägen noch heftig bewegten, sich aufrollten, während die ersteren gestreckt erstarrten. Beide sind unbestimmt geblieben. Von In sekt en waren sowohl Coleopteren wie Dipteren in den Bereich der Garnele gekommen und gefressen worden. Die beiden Formen Polystomella und Rotalia, die erstere bedeutend überwiegend, unter den For a min if eren und Seeigels tachelnbruchstücke sind augenscheinlich als Sedimente aufgenommen. Es wurde nur in einem Falle eine einzige Pedicellarie vorgefunden und von Foraminiferen selten glasige aus dem Plankton. Die Bodendiatomeen (Navicula, Pinnularia usw.) wie auch wohl herabgesunkene Coscinodiscen, Cyclotellen, Biddulphien, die oft mit kleinen Bodendiatomeen besetzt waren, waren oft mit anderen Bodenteilchen vorhanden. Planktonische Diatomeen waren vertreten durch Bellerochea malleus, Melosira sulcata, Coscinodiscus sp. sp., Biddulphia sp. sp. Weit ere Planktonten waren Sagitta sp. (nur die Greifhaken), Hydrobia-Larven, Muschellarven, Cyprislarven und Naupliuslarven von Balanus sp., ebenso Crangon-Zoëen. Bellerochea überwog merkwürdigerweise gegenüber den anderen Planktondiatomeen so erheblich, als 
ob sie besonders ausgewählt würde. In einem einzigen Falle wies sich ein Tintenfisch (Alloteuthis?) durch seinen glasigen Rückenschulp aus. Kokons von Pygospio waren immer leer und meist an Sandkörnern angeklebt. Der vorgefundene Schlick und Detritus war durchweg mit Wurm- und Crustaceenteilchen untermischt. In nur 5 Fällen waren Garnelenmägen nur mit Schlick angefüllt und einige nur mit Sand. Eine Entscheidung über die Frage, ob die Garnele bei Nahrungsmangel auf Schlickfraß übergeht, kann ich an Hand meiner Befunde nicht treffen. Im Aquarium jedenfalls fraßen hungernde Garnelen solange keinen Schlick, wie sie keine Witterung irgendwelcher Nahrungstiere darin hatten.

Es ist sehr gut möglich, daß die Garnelen die Spoli en von ihren Artgenossen und anderen Crustaceen fressen, besonders von Schizopoden. Gerade die letzteren finden sich zu Zeiten massenhaft im Angeschwemmsel der Küste. Aber auch die Reste anderer Tiere werden aufgenommen, sodaß bei der Bestimmung der Nahrung die Möglichkeit im Auge behalten werden muß, daß gewisse Tiere als sedimentierte Reste aufgenommen worden sind, ebenso wie die Möglichkeit des Übersehens von Protozoen wie z. B. Noctiluca.

\title{
II. Die Nahrungsmenge.
}

In den meisten Fällen ließ der Zustand des Nährmaterials eine Zählung der aufgenommenen Nährtiere nicht mehr zu. Sobald aber die Zerstörung noch nicht so weit vorgeschritten war, daß die Bestandteile $\mathrm{zu}$ sehr gegeneinander verlagert waren, wurde eine Zählung versucht und hierbei neben den noch ganzen Stücken wesentliche Merkmale dieser Stücke herangezogen. Als solche dienten Augenpaare, Telsonteile, Mandibeln von Krustern und Würmern, Schlösser der Muscheln, Operculen der Schnecken oder ihre Spindeln, bei den Schizopoden spielten die Statolithen eine wichtige Rolle.

Schon die große Anzahl der verschiedenen Arten von Beutetieren beweist die außerordentliche Gefräßigkeit der Garnele. Dabei ist sie imstande, verhältnismäßig große Mengen in ihren Magen aufzunehmen, der von beträchtlicher Ausdehnungsfähigkeit ist. Man kann sehr oft Garnelen finden, die nicht nur ihren Magen prall mit einem Teil eines großen Wurmes angefüllt haben, sondern auch solche, denen der größere Teil dieses Wurmes, der oft noch erheblich länger ist als der Fresser, zur Mundöffnung herausragt, um auch noch langsam einverleibt zu werden. Ein Weibchen von $64 \mathrm{~mm}$ Lä̈nge hatte im Magen etwa 50 Segmente einer Nereis, in Stücken von je 10 Segmenten, die offenbar langsam aufeinanderfolgend in den Magen gelangt waren, sobald das vorhergehende Stück genügend ausgepreßt war und für ein neues Platz gemacht hatte. Ein anderes Weibchen von $60 \mathrm{~mm}$ Länge fraß im Aquarium, dem ein Brutnetzfang hinzugesetzt war, folgende Organismen, ohne damit den höchsten Grad der Magenfüllung erreicht zu haben:

\author{
700 Copepoden \\ 220 Balanus-Nauplien \\ 25 Cyprislarven \\ 8 Crangon-Zoëen \\ 4 Mytilus-Larven \\ 1 kleine Idothea lineata \\ und mehrere Melosira-Fäden.
}

Eine so große Menge von Nährorganismen habe ich in Mägen von Garnelen aus der Natur nicht wieder angetroffen, natürlich weil hier die Dichte an Nahrung geringer als im Aquarium ist.

Gewiß ist es das Bestreben jeden Fressers, möglichst die Höchstfassungskraft seines Magens auszufüllen, diese aber ist naturgemäß bei den verschiedenen Größen der Garnelen sehr unterschiedlich. Außerdem wird auch die Mundöffnung eine gewisse Auswahl unter den Größenordnungen der Nahrungsmittel notwendig machen. Dies vor allem, wenn es sich um sehr widerstandsfähige Nahrungsmittel handelt, z. B. um Crustaceen.

In der Tabelle I ist eine Auswahl von zählbaren Nährtieren in Beziehung gesetzt zu den verschiedenen Größen der Garnele. Die erste senkrechte Spalte enthält diese nach Gruppen geordnet mit einem Spielraum von $5 \mathrm{~mm}$ Unterschied, von oben nach unten anwachsend. Die erste waagerechte Spalte führt die Nährorganismen auf, in zwei Gruppen zusammengestellt: die erste Gruppe enthält die „mikroskopischen“, die zweite die „makroskopischen" Beutestücke. Die Zahlen innerhalb der Tabelle geben die durchschnittliche Menge gezählter Nahrungstiere für die betreffende Längengruppe, auf einen Magen umgerechnet. Die 
Tabelle I.

Anzahl der Nahrungstiere, auf einen Magen berechnet.

\begin{tabular}{|c|c|c|c|c|c|c|c|c|c|c|c|c|c|c|c|c|}
\hline $\mathrm{mm}$ & $\begin{array}{l}\text { Fora- } \\
\text { mini- } \\
\text { feren }\end{array}$ & $\begin{array}{l}\text { Cope- } \\
\text { poden }\end{array}$ & $\begin{array}{l}\text { Nema- } \\
\text { toden }\end{array}$ & $\begin{array}{c}H y- \\
\text { drobia } \\
\text { juv. }\end{array}$ & $\begin{array}{l}\text { Har- } \\
\text { pacti- } \\
\text { ciden }\end{array}$ & $\begin{array}{c}\mathrm{Mu}- \\
\text { scheln } \\
\text { juv. }\end{array}$ & $\mid \begin{array}{c}\text { Cypris } \\
\text { larven } \\
\text { von } \\
\text { Balanus }\end{array}$ & $\begin{array}{l}\text { Coro- } \\
\text { phium } \\
\text { volu- } \\
\text { tator }\end{array}$ & $\begin{array}{c}\text { Stato- } \\
\text { li- } \\
\text { then }\end{array}$ & $\begin{array}{l}\text { Cer- } \\
\text { carien }\end{array}$ & $\begin{array}{c}\text { Wür- } \\
\text { mer }\end{array}$ & $\begin{array}{c}\mathrm{Mu}- \\
\text { scheln } \\
\text { ad. }\end{array}$ & $\begin{array}{c}H y- \\
\text { drobia } \\
\text { ad. }\end{array}$ & $\mid \begin{array}{c}\text { Am- } \\
\text { phi- } \\
\text { poden }\end{array}$ & $\begin{array}{c}\text { Schi- } \\
\text { zopo- } \\
\text { den }\end{array}$ & $\begin{array}{c}\text { Cran- } \\
\text { gon }\end{array}$ \\
\hline $6--10$ & 1.0 & - & - & - & - & $\ldots$ & - & - & - & - & - & - & - & - & - & - \\
\hline $11-15$ & 1.4 & 1.4 & 10.0 & $\ldots$ & - & 1.0 & 2.5 & 0.6 & - & - & - & - & - & - & - & - \\
\hline $16-20$ & 3.2 & 3.0 & 1.0 & 12.0 & 2.0 & 10.4 & - & 0.7 & - & - & - & - & + & - & - & - \\
\hline $21-25$ & 4.0 & 3.0 & - & 3.5 & 1.0 & 3.0 & 3.0 & 0.8 & - & - & - & - & $t$ & - & - & - \\
\hline $26-30$ & 33.0 & 3.0 & - & + & 1.0 & - & 0.5 & 0.2 & 2.0 & $\ldots$ & 0.2 & - & 1 & - & - & - \\
\hline $31-35$ & 10.0 & 1.6 & 3.0 & + & 1.7 & 1.5 & 2.4 & - & 3.0 & - & 0.2 & 0.2 & + & 0.2 & - & - \\
\hline $6--40$ & 0.5 & 5.5 & 8.0 & 2.0 & 1.5 & 6.7 & 3.8 & - & 1. & - & - & 0.3 & 0.2 & 0.3 & - & - \\
\hline $41-45$ & 0.8 & 2.3 & 1.1 & + & 3.0 & 12.0 & 5.4 & 0.4 & 3.2 & - & 0.2 & 0.6 & 0.7 & 0.3 & 0.2 & - \\
\hline $46-50$ & 1.0 & 3.0 & 3.6 & 1.0 & 1.8 & 5.0 & 2.6 & 0.2 & 3.7 & - & 0.3 & 0.7 & 3.3 & 0.3 & 0.2 & - \\
\hline $51-55$ & 0.7 & 0.3 & 1.0 & 6.0 & 1.0 & 3.1 & 8.8 & - & 2.2 & 14.3 & 0.3 & 0.1 & 4.8 & 0.5 & 0.1 & - \\
\hline $6--60$ & 0.8 & 0.3 & 1.0 & 3.3 & 1.0 & 12.2 & 6. & 0.1 & 2.2 & 10.0 & 0.4 & 0.5 & 2.3 & 0.5 & 0.3 & - \\
\hline $61-65$ & 1.1 & 1.0 & 2.7 & 3.5 & 5.0 & 5.0 & 6.3 & - & 1.9 & 10.0 & 0.5 & 0.5 & 7.0 & 0.6 & 0.3 & 0.1 \\
\hline $66-70$ & 0.7 & 0.3 & 1.0 & 1,0 & - & 1.0 & 3.0 & - & 2.0 & 3.0 & 0.6 & 0.8 & 1.6 & 1.8 & 0.7 & 0.5 \\
\hline $71-75$ & 1.6 & - & 1.0 & - & - & 3.0 & 11.0 & _- & 2.0 & - & 0.3 & - & 7.5 & 1.8 & 1.0 & 0.7 \\
\hline $76-80$ & 1.5 & - & - & $\ldots$ & $\ldots$ & - & - & - & 3.0 & - & - & 1.0 & - & 1.0 & 1.0 & 1.0 \\
\hline LM : & 31.5 & 33.8 & 33.3 & 36.8 & 43.8 & 43.0 & 52.2 & 25.2 & 52.3 & 55.9 & 55.7 & 58.2 & 60.8 & 64.0 & 70.0 & 73.2 \\
\hline
\end{tabular}

letzte waagerechte Spalte enthält die mittlere Crangon-Länge für jede Beutetier-Form. Diese mittleren Längen folgen einander innerhalb der beiden Gruppen wachsend von links nach rechts. Auf diese Weise stellt die erste waagerechte Spalte die Rangordnung der Nährmittel für die verschiedenen Garnelengrößen dar. Wenn wir die Höchstwerte der Beutetiere fett drucken, so zeigt sich deutlich, daß diese in der Gruppe der mikroskopischen Nahrungsmittel auf der Skala der Garnelenlängengruppen zwei und drei Mal vorkommen. Das kommt wohl daher, daß die kleineren Zehrer die kleineren Beutestücke bevorzugen, während die größeren Garnelen sammelnd eine größere Anzahl kleinerer nehmen können. Hierbei spielten allerdings nicht nur das Magenvolumen und die Mundöffnung allein eine Rolle, sondern vielmehr auch die ökologischen Verhältnisse der Beutetier-Formen. Denn wir sehen z. B., daß auch Corophium, trotz seines Erscheinens in hoher mittlerer Größe auf seinem Wohngebiet des Watts von geringerer mittlerer Crangon-Länge bevorzugt wird, eben weil auch die kleineren Garnelen ihr Wohngebiet fast ausschließlich auf dem Watt haben. In der Gruppe der makroskopischen Nahrungsmittel lagern sich, wenn man von den Cercarien und Statolithen absieht, die Höchstwerte einigermaßen gleichmäßig um eine hohe mittlere Crangon-Länge.

Cercarien und Statolithen fallen etwas heraus; sie sind nämlich deswegen in die Reihe der makroskopischen Nahrungsmittel anfgenommen, weil man von ihnen auf die Größe bzw. Menge von Nährorganismen schließen kann. Je größer die Anzahl der Cercarien ist, umso größer wird auch das Algenstück gewesen sein, auf dem diese gelebt haben. In einem Falle eines Männchens von $54 \mathrm{~mm}$ Länge zählte ich mehr als 50 Stck. Cercarien. Die Grünalgen waren verdaut, und nur einige farblose Reste im Magen und die grüne "Leber" wiesen sie aus. Grünalgen traten aber auch in großen Ballen auf und dementsprechend mit vielen Cercarien untermischt. Wenn Sprossen gefressen waren, fanden sich niemals Cercarien. Zuweilen konnten Algenstücke von 13-18 mm Länge unzerstört aus Mägen herausgefaltet werden. Auch Sprosse mit mehr oder weniger Zellreihen in Längen von mehreren cm kamen in Form von Fadengewirr zum Vorschein.

Die Statolithen sind zumeist Rückstände von Schizopodenmahlzeiten. Vereinzelt konnten sie auch mit dem Sand, der sich in den Mägen in verhältnismäßig großer Menge findet, als Sediment aufgenommen worden sein. Dann waren sie gelblich und verwittert, gerade so, wie sie sich in einigen Sandproben zeigten. Eine andere Möglichkeit ist, daß sie von Schizopoden-Spolien stammten, die evtl. von der Garnele zum Panzerersatz bei der Häutung gefressen werden (? vergl. H. Mann und E. Pieplow, 1938). Diese Frage habe ich geprüft durch Messung der Statolithen, von deren Durchmesser auf die Größe der Schizopoden geschlossen werden kann. Die Möglichkeit des Spolienfraßes wäre dann gegeben, wenn auch die kleinen Garnelen viele große Statolithen im Magen haben würden 
Sie werden wohl die Spolien bewältigen können, aber kaum große lebende Schizopoden, sofern sie diesen nicht die Abdomen abbeißen. Folgende Übersicht zeigt aber, daß mit wachsender Crangon-Länge auch die Statolithendurchmesser größer werden:

\begin{tabular}{l|l|l|l|l|l|l|l|l|l|l}
\hline \hline Crangon-Länge & -40 & -45 & -50 & -55 & -60 & -65 & -70 & -75 & -80 \\
\hline $\begin{array}{c}\text { mittl. Statolithen- } \\
\text { Durchmesser: }\end{array}$ & 0,16 & 0,12 & 0,16 & 0,22 & 0,21 & 0,27 & 0,21 & 0,24 & 0,23
\end{tabular}

Einige ausgewählte Befunde geben ein Bild vom Statolithenvorkommen und ihren Durchmessergrenzen:

\begin{tabular}{c|c|c}
\hline Crangon-Länge & $\begin{array}{c}\text { Statolithen } \\
\text { Stck. }\end{array}$ & $\begin{array}{c}\text { Variationsbreite } \\
\text { mm: }\end{array}$ \\
\hline $410^{*}$ & 25 & $0,123-0,228$ \\
$420^{*}$ & 10 & $0,088-0,140$ \\
$470^{x}$ & 8 & $0,088-0,315$ \\
$470^{x}$ & 14 & $0,105-0,245$ \\
$490^{*}$ & 8 & $0,140-0,193$ \\
589 & 8 & $0,158-0,220$
\end{tabular}

Demnach können wir wohl annehmen, daß vorwiegend lebende Schizopoden die Statolithenrückstände liefern. Es können sehr wohl nacheinander mehrere Schizopoden aufgenommen worden sein, wie der Zustand des Mageninhaltes mancher Garnele zeigte. Die Rubrik "Statolithen“ der Tabelle I beginnt mit ihren Zahlen schon bei 26-30 mm Crangon-Länge, während die der „Schizopoden“ erst bei $41-45 \mathrm{~mm}$ anfangen. Leider liegen von den ersteren keine Messungen vor. Immerhin zeigt die Rubrik, daß auch kleinere Garnelen sich am Schizopodenfraß beteiligen, und zwar können es sehr wohl kleinere Arten oder Individuen sein, die sich in den Wattpfützen oft zahlreich vorfinden, oder auch es beteiligen sich an einem Nährtier mehrere Zehrer, wie man auf dem Watt und im Aquarium beobachten kann. Wenn man in Betracht zieht, daß gleichzeitig drei und vier Schizopoden im Garnelenmagen Platz finden und sich doch so große Zahlen von Statolithen ansammeln, so kann man daraus schließen, daß die Garnele sich eine längere Zeit in dem Wohngebiet der Schizopoden aufhält. Dann haben wir wohl immer die von den Fischern sogenannten "Wohnkrabben“ vor uns, die im Gegensatz zu den „W an derkrabben" sich an einem Fangplatz halten, solange sie nicht weggefischt sind oder durch die andauernde Befischung verscheucht werden. Daß ihre Freßtätigkeit recht intensiv ist, zeigt folgender Befund: Eine Garnele von $71 \mathrm{~mm}$ Länge hatte ihren Magen prall voll von zwei Praunus flexuosus und zwei Neomysis vulgaris. Die beiden ersteren hatten Statolithen von $0,315 \mathrm{~mm}$ und waren etwa $20 \mathrm{~mm}$ lang, die beiden anderen waren etwa $15 \mathrm{~mm}$ lang und hatten Statolithen von $0,22 \mathrm{~mm}$ Durchmesser. Neben diesen vier Schizopoden lagen in demselben Magen noch 11 weitere Statolithen mit Durchmessern von 0,123 mm bis $0,385 \mathrm{~mm}$. Einige Befunde mit ganzen Schizopoden zeigen die Beliebtheit dieses Nahrungsmittels bei den Garnelen:

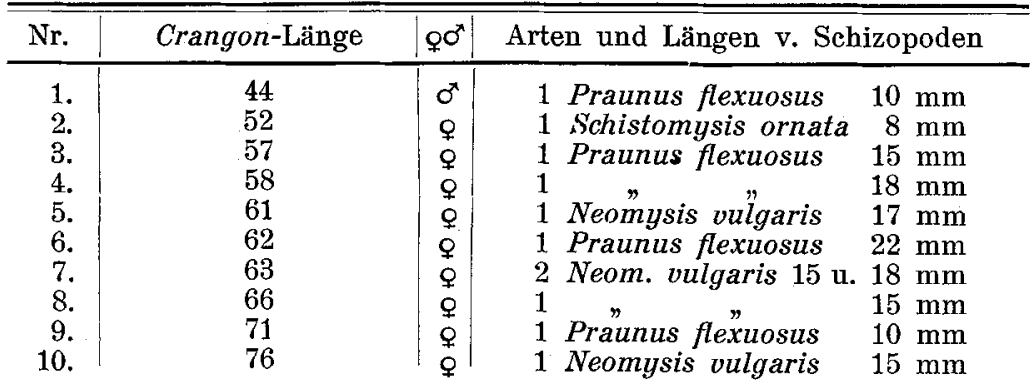

Die Längenangaben der Schizopoden zeigen ihrerseits, daß durch die Garnelen eine Auswahl stattfindet, wenn sie eine Schizopodenschar vor sich haben, die meistens aus sehr großen Tieren bis $\mathrm{zu} 40 \mathrm{~mm}$ und darüber besteht, welche mit kleineren untermischt sind und von den Fischern als "Ködergarnelen" bis zu $50 \mathrm{~kg}$ gefangen werden können. 
Die übrigen Formen der Tabelle $I$ sind in ihrem mengenmäßigen Vorkommen eindeutiger über die Größengruppen der Garnelen verteilt. Die Foraminiferen, die im allgemeinen recht vereinzelt als Beifunde vorkommen, zeigen in der Tabelle durchschnittliche Höchstwerte bei $26-35 \mathrm{~mm}$ langen Garnelen. Diese Eigenart ist anscheinend wiederum eine Folge der ökologischen Verhältnisse dieser Längengruppen. Während die Höchstwerte meist 5 bis 6 Stück nicht übersteigen, erreichen diese in Wattgarnelen 26 bis 80 Stück. Diese Garnelen stammen fast alle vom Schlickwatt und in ihren Mägen waren wenig oder gar keine Steinchen vorhanden, so daß die Annahme berechtigt ist, die Foraminiferen ersetzten den Mangel an Steinchen, die die Garnelen aus einem später zu erläuternden Grunde nötig haben, im Schlickwatt. Die Größen der Foraminiferen schwanken innerhalb folgender Grenzen: $0,14 \mathrm{~mm}$ bis $0,385 \mathrm{~mm}$, der Mittelwert aller Größen liegt bei $0,23 \mathrm{~mm}$.

Dem obengenannten Höchstwert an Copepoden von 700 Stück, gefressen von einem $60 \mathrm{~mm}$ langen Tier im Aquarium, ist ein anderer eines Männchens aus der Natur von $36 \mathrm{~mm}$ Länge mit 63 Stück bei vollem Magen an die Seite zu stellen. Andere Zahlen sind 10 und 30 Stück in einem Magen, während bei allen übrigen Fällen die Anzahl 5 und 6 nicht überschritten wird. Die Größen aller dieser Copepoden bewegen sich um $1,00 \mathrm{~mm}$ herum. Neben den Cyclopiden und Centropagiden unter den Copepoden erschienen in den Mägen allgemein Harpacticiden, die wegen ihres bodenbewohnenden Lebens den Garnelen leicht zur Beute werden können. Bei ihnen waren Höchstwerte von 15-20 Stück; sie bestanden aus einer kleineren Art von etwa $0,2 \mathrm{~mm}$ und einer größeren von etwa $0,8 \mathrm{~mm}$. Mit den Copepoden fanden sich natürlich auch oft Eier und Spermatophoren. Eier kamen immer nur vereinzelt vor, während Spermatophoren höhere Werte von 10 und 15 Stück in einem Magen erlangten und zwei Formen von $0,3 \mathrm{~mm}$ und $0,5 \mathrm{~mm}$ Länge hatten.

Nach SchuURMANS-STEKHOvEN hat der Biotop des Schlickwatts einen hohen Nematodenindex (Verhältnis von Sediment- zu Nematodenmenge), und auch Wattbodenproben enthielten große Mengen von $\mathrm{Nem}$ a toden. Höchstwerte haben auch Wattgarnelen in einigen Mageninhalten. Eine Garnele von $12 \mathrm{~mm}$ Länge enthielt mehr als 10 Stück Nematoden, eine andere aus dem Prielsystem südlich von Neuwerk von $40 \mathrm{~mm}$ Länge hatte 15 Stück gefressen. In fast allen anderen Fällen waren nicht mehr als zwei, höchstens vier Nematoden aufgenommen worden. Zum größten Teil stammten sie aus dem Biotop des "Mulms" (vergl. ERICH Schulz), wie die Beifunde im Magen ausweisen.

Die Tabelle I enthält zweimal die Angabe „Schnecken“, einmal bei den "mikroskopischen" Beutetieren und zum anderen bei den "makroskopischen". Die Schnecken der ersten Gruppe sind Jugendformen, die entweder aus dem Plankton genommen sein mögen als Larven oder kurz nach dem Brutfall vom Boden. Die Schnecken der zweiten Gruppe sind immer geschlechtsreife Tiere gewesen. Die jungen Hydrobien bewegen sich in ihrer Größe etwa um $0,3 \mathrm{~mm}$ herum, während die letzteren die Länge von $1,5 \mathrm{~mm}$ nicht überschreiten. Nach MEYER und MöBIUs sind die Larven im Plankton noch 0,4 mm lang (cit. aus Simroth, Nordisches Plankton). Nur in einem Falle enthielt der Magen einer Garnele von $54 \mathrm{~mm}$ Länge eine Hydrobia von $2,3 \mathrm{~mm}$. Sowohl die jungen wie auch die ausgewachsenen Schnecken werden von der Garnele in erheblichen Mengen gesammelt und sind bis zu 45 Stück in einem Magen vorhanden. Sogar größere Hydrobien finden sich oft in großer Zahl, 18 bis 20 . Stück in Mägen von 50-60 mm langen Garnelen sind keine Seltenheit.

Die aus den Mägen hervorgeholten Muscheln waren durchweg 0,35 mm lang, die kleinsten $0,175 \mathrm{~mm}$ und die größeren $0,53 \mathrm{~mm}$. Hier ist interessant, daß einige Autoren (Delsman, WILsON, KäNDLER) im Plankton noch Mytilus mit den Höchstmaßen von 0,26, 0,28 und $0,29 \mathrm{~mm}$ fanden und daß sich bei Mytilus das erste Blau ansetzt mit 0,35 mm. Daneben waren auch größere Muscheln von 0,7 und $0,8 \mathrm{~mm}$ und von 1,6 bis 2,5 mm verzehrt. Bei den größeren handelte es sich vorwiegend um Macoma und Cardium. In einem Falle enthielt der Magen einer Garnele von $46 \mathrm{~mm}$ Länge vier Mytilus von ca. $2,3 \mathrm{~mm}$, in anderen Fällen eine von $83 \mathrm{~mm}$ ein Muschelschloß von $2 \mathrm{~mm}$ und eine von $57 \mathrm{~mm}$ Länge ein Muschelschloß von 0,5 mm. Ein Männchen von $43 \mathrm{~mm}$ hatte 6 ganze Cardien im Magen mit einer Größe von 1,66:1,40 mm. An jungen Muscheln waren durchweg, wenn überhaupt, 15 bis 30 Stück vorhanden, aber auch nicht selten mehr als 100 Stüick.

Die Cyprislarven von Balanus sp. kommen meist vereinzelt vor, erreichen aber auch hohe Zahlen wie 20 bis 90 Stück (die Männchen höchste Zahlen), gelegentlich auch noch mehr in einem Garnelenmagen. Thre Größen schwanken zwischen 0,63 und 1,05 mm bei einer Breite von durchschnittlich $0,4 \mathrm{~mm}$. 
Der Amphipode Corophium volutator ist gewiß ein Hauptnahrungsmittel der Garnele, und ich habe aus großen und kleinen Garnelen oft so viele hervorgeholt, dafi es schien, als ob dieses Nährmittel begierig vor allen anderen bevorzugt würde. In größeren Garnelen fanden sich zuweilen bei praller Füllung des Magens 7 bis 8 Stück große Corophien von mindestens $10 \mathrm{~mm}$ Länge, in kleineren aber auch 4 bis 5 Stück von 2,3 und 1,5 mm Länge. Die Angabe der Zahlen kann kein genügendes Bild vermitteln, weil alle Größen von Corophium auf engem Gebiet erscheinen und dann auch von den Garnelen genommen werden, sodaß sich in Mägen Teile von großen und kleinen miteinander vermischt unzählbar vorfinden. Anders ist es mit den Bathyporeia-Arten. Diese finden sich in den Mägen, sofern sie noch meßbar waren, zumeist in Größen von 4 bis $5 \mathrm{~mm}$ und erreichen dann die Anzahl von 10 Stück (Garnelen um $55 \mathrm{~mm}$ herum) und im Durchschnitt etwa 5 Stück.

Ganze Würmer waren fast niemals vorhanden, so daß nur Teile zur Zählung benutzt wurden. Einige Beispiele zeigen, wie Würmer vorkamen:

1. $61 \mathrm{~mm}$ : Nereis $20-30 \mathrm{~mm}$ lang.

2. $59 \mathrm{~mm}$ : Nereis über $25 \mathrm{~mm}$ lang.

3. $50 \mathrm{~mm}$ : Tubifex $20 \mathrm{~mm}$ lang.

4. $58 \mathrm{~mm}$ : Nereis $7 \mathrm{~mm}$ lang, $2 \mathrm{~mm}$ breit.

5. $58 \mathrm{~mm}: 8$ Stück Nereis-Kiefer.

6. $61 \mathrm{~mm}$ : 2 Stück Nereis-Kiefer (5 mm lang).

7. $66 \mathrm{~mm}$ : 2 Stück Nereis-Kiefer (4,5 mm lang).

Ganze Sedentarier traf ich nicht an, erkannte sie aber an den Borstenformen.

Einen Ka n nibalismus können sich naturgemäß nur die größeren Garnelen leisten, obwohl sich in den Mägen kleinerer ebenfalls Teile von Artgenossen finden. Diese Teile sind wohl dann gefressen worden, wenn sich mehrere an einer Mahlzeit beteiligt hatten. So fanden sich in einer Garnele von $70 \mathrm{~mm} 3$ verschiedene CrangonMandibeln $(0,7: 0,25)$, in anderen Teile eines fremden Magens, Telson von $7 \mathrm{~mm}$ Länge, das auf eine Garnele von $40 \mathrm{~mm}$ schließen läßt. Es kam eine subchelate Schere von $6 \mathrm{~mm}$ Länge vor, ganze Vorderteile und Abdomen mit verschiedener Anzahl von Segmenten. Eine Garnele von $77 \mathrm{~mm}$ Länge hatte sich einen Artgenossen von etwa $40 \mathrm{~mm}$ Länge einverleibt, eine andere gar zwei dieser Größe, hier waren aber leider nur noch die vier Augen, die Mandibeln und die Telson vorhanden. Daß die Garnelen ihren Kannibalismus auch auf die arteigenen Eier ausdehnen, habe ich in zwei Fällen beobachten können, wo ein Männchen von $30 \mathrm{~mm}$ Länge seinen Magen prall mit über 100 Eiern angefüllt hatte und ein Weibchen von $67 \mathrm{~mm}$ mit "Laichgewebe" (P. F. MEYER) neben anderen Dingen etwa 80 unreife Eier irgendeines anderen Weibchens gefressen hatte.

Außer den in der Tabelle I genannten Nährtieren hatten die Garnelen neben Skeletteilen und Muskulatur von größeren Fischen, auch oft Larven im Magen. Die Lebendgröße der Fische kann man sich rekonstruieren an den Linsendurchmessern. Diese schwankten zwischen 0,49 und $0,11 \mathrm{~mm}$. Es fand sich unter anderen ein Otolith von $5,42 \mathrm{~mm}$, Prae maxillare von $2 \mathrm{~mm}$ Länge und Wirbelsäulen mit verschiedener Anzahl von Wirbeln, deren Breiten 0,3 bis $1,0 \mathrm{~mm}$ maßen.

Ostracoden kamen immer nur einzeln vor und hatten Längen von 0,39 bis $0,88 \mathrm{~mm}$. Bei den $\mathrm{Cu}$ macee $\mathbf{n}$ handelte es sich immer um eine kleine Form von etwa 3 mm Länge.

\section{Die Zusammensetzung der Nahrung.}

Die meisten Mägen der untersuchten Garnelen enthielten die Nährtiere nicht nur in verschiedener Menge, sondern es fanden sich auch verschiedene Formen nebeneinander. Die Anzahl an verschiedenen Typen wechselt zwischen 1 und 10 und beträgt im Durchschnitt etwa 2,6 je Magen.

Die Variabilität im Auftreten verschiedener Stückzahlen, verschiedener Typen und im Zusammentreffen verschiedener Typenkategorien, wie z. B. Planktonten mit EpifaunaMitgliedern u. ä., ist derartig groß, daß auf den ersten Blick schwerlich öfter wiederkehrende Gesellschaften von Beutetieren erkannt werden können. Dennoch gewinnt man den Eindruck der Existenz von solchen Gesellschaften in den Mägen, besonders wenn man die Zusammensetzung der Mageninhalte mit gewissen ökologischen Umständen in Verbindung bringt, denen die beteiligten Nährtiere unterworfen sind. Um solchen etwa vorhandenen Regelmäßigkeiten auf die Spur zu kommen, begehe ich folgenden statistischen Weg. 
Anstatt etwa drei oder mehr Typen zu Gruppen zu vereinigen, von welchen ich den Eindruck gewonnen haben könnte, sie kehrten öfter wieder, stellte ich Kombination en von nur zwei Typen her. Ein Versuch nämlich, bestimmte Gruppen von vornherein herauszustellen, scheiterte an der großen Mannigfaltigkeit in der Zusammensetzung der Mageninhalte. Die Methode der Kombination zweier Formen birgt außerdem die Vorteile in sich, daf falsche Vorurteile über die Zusammengehörigkeit gewisser Formen ausgeschaltet werden, daß alle verfügbaren Befunde voll ausgewertet werden können, und daß, wie wir sehen werden, die Bedeutung der Vergesellschaftung von Nährtieren unabhängig von jener Häufigkeit beurteilt werden kann, in der die im vorliegenden Material vorgefundenen Nährtiere überhaupt in den Mägen auftreten.

$\mathrm{Zu}$ dieser statistischen Erhebung ziehe ich 1026 Mageninhaltsbefunde heran und berücksichtige 30 der darin vorkommenden Nahrungstypen. Wenn ein Mageninhalt nur von einer einzigen Form gebildet wird, wurde dies als "1 Fall ::Nur die betr. Form ::“ registriert, treten zwei Typen nebeneinander auf, so ergibt das einen Fall von der Kombination :: erste Form plus zweite Form ::, sobald aber mehrere Formen nebeneinander zu einem Mageninhalt vereinigt sind, beispielsweise „Amphipoden “, „Schizopoden“, „Copepoden" und „Seeigelstacheln", könnten folgende Kombinationen je 1 mal verwirklicht werden :
1. Amphipoden-Schizopoden
2. Amphipoden-Copepoden
3. Amphipoden-Seeigelstacheln
4. Schizopoden-Copepoden
5. Schizopoden-Seeigelstacheln
6. Copepoden-Seeigelstacheln

Da von den $30 \times 30$ gleich 900 theoretisch möglichen, verschiedenlautenden Kombinationen nur 316 praktisch hergestellt werden konnten, sind gewisse Formen gegenüber anderen von größerer "Affinität" (in übertragenem Sinne) zueinander. Im Ganzen konnten 2713 Fälle registriert werden, sodaß im Durchschnitt jede Kombination etwa 8,6 mal hat verwirklicht werden können. Die Variationsbreite also im Zusammenvorkommen mit anderen Formen ist für jeden Typ sehr groß, während die Variabilität in den Häufigkeiten der Kombinationen relativ klein ist. Dennoch verspricht die Art und Weise der Verteilung der 30 verschiedenen Formen auf die 316 Kombinationen eine Charakterisierung der Zusammensetzung der Nährorganismen.

Die Häufigkeiten der Kombinationen ordnen wir dergestalt in eine Kombinationstabelle (II, S. 124) ein, daß die Abscisse wie die Ordinate gleicherweise aus der Reihenfolge der Formen gebildet werden. Die Formen folgen einander wie sich die Summen der Fälle $(\Sigma)$ verändern, in denen die betr. Form Komponent war. Die Tabelle II gibt zur Erläuterung nur einen Ausschnitt von der so hergestellten Kombinationstabelle.

Zwischen der Reihe der Muschellarven- und der Reihe der Algen-Kombinationen ist ein Absatz eingeschaltet, weil der Ausschnitt der Gesamtverteilungsübersicht bis hierher reicht. Die Summen der Fälle, wo die betreffende Form Komponent war, sind in der drittletzten waagerechten bzw. senkrechten Spalte aufgeführt [die Summen der senkrechten sind aus der Arbeitstabelle errechnet und bilden darin eine Kathete eines rechtwinkligen Dreiecks]. Die fettgedruckten Zahlen auf der Hypothenuse sind die absoluten Häufigkeiten der „Kombinationen“ :: Nur die betreffende Form ::, welche, illustriert durch das Beispiel "Schizopoden“ als die Kombination „Schizopoden plus Schizopoden“ aufzufassen sind. ${ }^{1}$ )

Die zweitletzte waagerechte bzw. senkrechte Spalte geben die Anzahl der verschieden lautenden Kombinationen an, die die betreffende Form mit den übrigen einging; eingeschlossen ist die Kombination "Nur die betr. Form“. Die letzte waagerechte Spalte (bzw. senkrechte) enthält die durchschnittlichen Häufigkeiten der Fälle, wo die betr. Form Kombinationen einging. Die Häufigkeiten, die den Gesamtdurchschnitt überragen, sind kursiv gedruckt. Naturgemäß sind die Ziffern der absoluten Häufigkeit größer oder kleiner, je nachdem die beteiligten Formen mehr oder weniger für die Garnele von Bedeutung sind. So

1) Da in der Literatur keine Einheitlichkeit besteht über den Begriff „absolute Häufigkeit“, sei er hier von mir definiert: „Die absolute Häufigkeit einer Variante ist die tatsäehlich gefundene Anzahl an Individuen mit der betr. "Eigenschaft unter einer beliebig großen Anzahl von verschieden beschaffenen Individnen.“ Für unsere Untersuchung ist statt "Individuen" "Kombinationen“ zu setzen. Der Gegensatz, die „relative Häufigkeit“, gibt die Menge der Individuen mit einer bestimmten Eigenschaft unter einer bestim m ten Anzahl verschieden beschaffener Individuen an, beispielsweise ausgedrückt in Prozenten oder Promillen. Vergl. hierzu RINGLEB, 1937 pg. 14 und W. JOHANNSEN, 1926 pg. 64. 
Tabelle II.

Absolute Häufigkeit der Kombinationen.

\begin{tabular}{|c|c|c|c|c|c|c|c|c|c|c|c|c|c|c|}
\hline & $\mathbf{A}$ & & & & & & & & & & & & & \\
\hline \multirow{10}{*}{$\begin{array}{l}\text { A Schizopoden } \\
\text { B Würmer } \\
\text { C Amphipoden } \\
\text { D Seeigelstacheln } \\
\text { E Foraminiferen } \\
\text { F Cyprislarven } \\
\text { G Copepoden } \\
\text { H Schnecken } \\
\text { I Muscheln } \\
\text { K Muscheln juv. }\end{array}$} & \multirow{10}{*}{$\begin{array}{r}138 \\
21 \\
30 \\
31 \\
36 \\
34 \\
28 \\
42 \\
20 \\
27\end{array}$} & $\mathbf{B}$ & \multirow[b]{2}{*}{ C } & \multirow[b]{3}{*}{0} & & \multirow[b]{5}{*}{$F$} & \multirow{6}{*}{0} & \multirow{7}{*}{$H$} & \multirow{8}{*}{1} & \multirow[b]{9}{*}{$\mathbf{K}$} & & & & \\
\hline & & 90 & & & \multirow{3}{*}{$\bar{E}$} & & & & & & & & & \\
\hline & & 38 & 60 & & & & & & & & & & & \\
\hline & & 46 & 33 & $\overline{1}$ & & & & & & & & & & \\
\hline & & 33 & 27 & 32 & \multirow{6}{*}{$\begin{array}{c}0 \\
24 \\
19 \\
\cdots 20 \\
17 \\
12\end{array}$} & & & & & & & & & \\
\hline & & 22 & 19 & 22 & & \multirow{5}{*}{$\begin{array}{r}3 \\
20 \\
\cdots 38 \\
12 \\
34\end{array}$} & & & & & & & & \\
\hline & & 22 & 45 & 35 & & & \multirow{4}{*}{$\begin{array}{r}27 \\
17 \\
6\end{array}$} & & & & & & & \\
\hline & & $\therefore 19$ & $21 \cdots$ & $\ldots 18 \ldots$ & & & & \multirow{3}{*}{$\begin{array}{r}3 \\
18 \\
24 \\
\end{array}$} & & & & & & \\
\hline & & 20 & 24 & 26 & & & & & \multirow{2}{*}{$\begin{array}{l}4 \\
8\end{array}$} & & & & & \\
\hline & & 10 & 17 & 12 & & & & & & 4 & & $\Sigma$ & $\mathrm{K}$. & $\boldsymbol{\theta}$ \\
\hline Algen & 15 & 29 & 11 & 22 & 16 & 16 & 5 & 12 & 10 & 5 & 9 & 198 & 23 & 8.6 \\
\hline Detritus & 13 & 33 & 13 & 8 & 9 & 4 & 8 & 6 & 10 & 6 & 7 & 164 & 23 & 7.1 \\
\hline Corophium & 6 & 22 & 2 & 14 & 24 & 10 & 3 & 7 & 6 & 6 & 18 & 152 & 22 & 6.9 \\
\hline Harpacticiden & 8 & 15 & 11 & 6 & 14. & 10 & 3 & 11 & 8 & 5 & 3 & 148 & 24 & 6.2 \\
\hline Crangon & 8 & 7 & 7 & 9 & 12 & 4 & 2 & 6 & 5 & 7 & 27 & 126 & 21 & 6.0 \\
\hline Bellerochea & 22 & 4 & 3 & 7 & 5 & 12 & 5 & 10 & 8 & 9 & 0 & 110 & 24 & 4.6 \\
\hline Coscinodiscus & 8 & $1 \overline{1}$ & 11 & 8 & 9 & 2 & 12 & 3 & 5 & 5 & $\mathbf{0}$ & 101 & 22 & 4.6 \\
\hline Schnecken juv. & 7 & 4 & 3 & 3 & 8 & 11 & 0 & 6 & 4 & 20 & 0 & 93 & 22 & 4.2 \\
\hline Nematoden & 1 & 15 & 3 & 6 & 6 & 3 & 2 & 3 & 5 & 1 & 0 & 70 & 20 & 3.5 \\
\hline Cirripedien & 7 & 2 & 6 & 4 & 3 & 7 & 2 & 3 & 5 & 7 & 8 & 63 & 18 & 3.5 \\
\hline Insekten & 3 & 1 & 9 & 5 & 4 & 5 & 8 & 0 & 2 & 1 & 7 & 55 & 18 & 3.0 \\
\hline Fischteile & 9 & 4 & 2 & 1 & 1 & 3 & 2 & 2 & 2 & $\mathbf{3}$ & 12 & 52 & 18 & 2.9 \\
\hline Ostracoden & 3 & 4 & 4 & 2 & 6 & 3 & 3 & 0 & 3 & 2 & 4 & 51 & 20 & 2.5 \\
\hline Biddulphia & 1 & 3 & 2 & 0 & 1 & 1 & 2 & 2 & 1 & 4 & 0 & 27 & 17 & 1.6 \\
\hline Cumaceen & 5 & 0 & 1 & 1 & 2 & 0 & 1 & 1 & 0 & 0 & 1 & 24 & 13 & 1.8 \\
\hline Sagitta & 6 & 0 & 0 & 0 & 0 & 1 & 1 & 1 & 0 & 2 & $\mathbf{0}$ & 16 & 9 & 1.8 \\
\hline Hydroiden & 0 & 1 & 2 & 2 & 0 & 0 & 1 & 2 & 0 & 2 & $\mathbf{0}$ & 15 & 11 & 1.4 \\
\hline Cerc & 0 & 6 & 0 & 1 & 1 & 0 & 0 & 0 & 0 & 0 & 0 & 13 & 4 & 3.2 \\
\hline Nauplien & 2 & 1 & 0 & 0 & 0 & 2 & 3 & 0 & 1 & 0 & 0 & 13 & 9 & 1.4 \\
\hline Kokons & 1 & 1 & 0 & 0 & 2 & 0 & 0 & $\dot{\gamma} 1$ & 2 & 0 & 0 & 10 & 8 & 1.3 \\
\hline Summe $\Sigma^{1}$ ) & 532 & 484 & 404 & 355 & 343 & 322 & 290 & 287 & 243 & 239 & & & & \\
\hline Kombinationen $n$ & 28 & 28 & 26 & 26 & 20 & 26 & 27 & 26 & 26 & 26 & & & & \\
\hline$\varnothing$ & 19,0 & 17,3 & 15,5 & 13,6 & 13,2 & 12,4 & 10,7 & 11,0 & 9,4 & 9,2 & & & & \\
\hline
\end{tabular}

bildet die Rubrik der Häufigkeiten von „Nur die betr. Form“ eine wertvolle Ergänzung der auf Seite 116 gegebenen Einteilung in Haupt- und Nebennahrung. Wir können nämlich, unter Verwendung der absoluten Häufigkeiten des Alleinvorkommens der Nährorganismen als ordnendes Prinzip, die Hauptnährorganismen noch in drei Gruppen unterteilen, in welchen einige Nebennährorganismen gewisse Berücksichtigung finden. Die Gruppe a besteht aus 1. Schizopoden, 2. Würmer, 3. Amphipoden, 4. Copepoden; die Gruppe b aus 1. Crangon, 2. Fischteile, 3. Algen, 4. Cirripedienteile, 5. Insekten. Diese Gruppe besteht ausschließlich aus sogen. Nebennährorganismen, die aber durch besondere Umweltsbedingungen zu Hauptnährorganismen werden können. Während wir also die Gruppe a als "Absolute Hauptbeutetiere* bezeichnen können, würden die Mitglieder der Gruppe b „Bedingte Hauptbeutetiere“ genannt werden können. Eine dritte Gruppe c wird gebildet durch jene Hauptbeutetiere auf der Seite 116, die zwar selten allein einen Mageninhalt ausmachen, aber als Ergänzung eine bedeutende Rolle spielen. Sie würde also als Gruppe der "Ergänzenden Hau ptbeutetiere" bezeichnet werden können. Zu ihr gehören etwa "die Schnecken, Muscheln und die drei Larvenformen. Eine wertende Reihenfolge der Gruppen müßte lauten, wenn wir die Häufigkeit des Auftretens ihrer Mitglieder in Rechnung ziehen:

$$
\begin{aligned}
& \text { I. "Absolute Hauptbeutetiere" } \\
& \text { II. "Ergänzende Hauptbeutetiere" } \\
& \text { III. "Bedingte Hauptbeutetiere". }
\end{aligned}
$$

Die Anzahl der verschiedenen Kombinationen, die jede Form eingeht, der allmähliche Abfall der Summen der registrierten Fälle, sowie der Durchschnittswerte der registrierten Fälle für die einzelne Form korrespondieren miteinander und zeigen uns die große Variabilität in der Zusammensetzung der Mageninhalte. Wenn wir uns den Häufigkeitsziffern der Tabelle II im Einzelnen zuwenden, bemerken wir allerdings, daß

1) Die Summe $\Sigma$ ist die Gesamtanzahl der Fälle, wo die betr. Form Kombinationen einging; addiert wurden also die Zahlen, wie die Verbindungslinie bei dem Beispiel der Schnecken-Kombinationen angibt. 
manche Typen erheblich häufiger mit der einen als mit der anderen kombiniert werden konnten, oder mit anderen Worten, daß die Streuung weniger gleichmäßig ist, als die obengenannten drei Werte-Reihen vermuten lassen. Beispielsweise konnte die Kombination "Würmer-Detritus" mit 33 Fällen häufiger verwirklicht werden als die Kombination "Schizopoden-Detritus" mit nur 13 Fällen, bei unerheblichem Unterschied der beiden dazugehörigen Gesamtsummen. Die beiden Formen (Schizopoden und Würmer) können auf diese Weise gekennzeichnet werden durch die unterschiedliche Häufigkeit, in der sie mit einer dritten (Detritus) zusammentreffen, zumal, wenn wir von der dritten Form eine einigermaßen feste Vorstellung über ihre ökologischen Umstände haben. Wenn wir diese Kennzeichnung auch auf die übrigen Formen ausdehnen, stellen wir fest, daß sie meistens wegen der allgemeinen großen Variationsbreite und wegen unserer Unkenntnis der ökologischen Umstände, oder weil letztere sehr gleitend sind, nicht scharf umrissen durchgeführt werden kann.

Um aber dennoch einen Überblick zu bekommen über das Verhalten der e inzelnen Formen zueinander im Zusammenvorkommen in den Mägen der Garnelen, multipliziere ich den Hundertsatz, in welchem die einzelne Kombination Anteil hat an der Summe der Fälle, wo die eine Form Komponent war, mit dem Hundertsatz, in welchem der andere Partner Kombinationen mit allen übrigen Formen einging. Ich erhalte so einen Wert, der eine Funktion der relativen Häufigkeiten (Hundertsätze) ist, nämlich

$$
\mathrm{z}=\frac{\mathrm{a} \cdot 100}{\Sigma_{1}} \cdot \frac{\mathrm{a} \cdot 100}{\Sigma_{2}}=\mathrm{a}^{2} \cdot \frac{100}{\Sigma_{1}} \cdot \frac{100}{\Sigma_{2}}
$$

für das Beispiel Schizopoden-Schnecken

$$
\mathrm{z}=\frac{42 \cdot 100}{532} \cdot \frac{42 \cdot 100}{287}=\underline{115}
$$

oder für das Beispiel Schnecken-Cyprislarven

$$
\mathrm{z}=\frac{38 \cdot 100}{287} \cdot \frac{38 \cdot 100}{322}=\underline{156} .
$$

Dieser Wert ist unabhängig von jener Häufigkeit, in der die Garnelen sich, nach dem hier verwendeten Untersuchungsmaterial, den einzelnen Partnerformen zuwenden; es ist also ein „abstrakter" Wert, den wir definieren können als "die sekundäre oder abstrakte relative Häufigkeit" der Kombinationen. Wir können ihn behandeln wie primäre oder konkrete absolute Häufigkeiten, nämlich die Einzelwerte untereinander vergleichen, Reihensummen und Durchschnitte bilden, ja, selbst eine weitere Abstraktionsrechnung vornehmen. Dieses Verfahren hat dieselbe Berechtigung wie die Überhöhung bei Kurvendarstellungen.

Die Tabelle III (S. 126) faßt die Werte zusammen für eine Reihe ausgewählter Formen. Die Höchstwerte sind wiederum kursiv gedruckt und die Werte der Kombination „Nur die betr. Form" sind fettgedruckt; letztere erfahren keine weitere Erörterung und sind nur der Vollständigkeit halber aufgeführt. Die Gesamtheit der Tabelle III stellt also gewissermaßen ein Abbild von der Zusammensetzung der Nahrung der Garnelen des gesamten Untersuchungsgebietes dar, ohne Rücksicht auf die Anzahl der untersuchten Mägen und ohne Rücksicht auf die Anzahl der vorgefundenen Nährtiere, ist andererseits ein Gemenge von verschiedenen Mageninhaltsgesellschaften, die bedingt sein mögen durch örtliche und zeitliche Verhältnisse.

In folgendem soll nun versucht werden, herauszustellen, wie die Tiere, die als Beute dienen, unter sich in den Mägen zusammen vorzukommen pflegen und welche Momente das Zusammenvorkommen oder Nichtzusammenvorkommen bewirken. So stellen wir fest, daß Würmer mit Detritus nach der Tabelle III häufiger in den Mägen der Garnelen zusammentreten als Würmer mit den übrigen Formen, ebenso Würmer und Seeigelstacheln, sodaß der Schluß naheliegt, die gefressenen Würmer stammten vorwiegend von sedimentreichen Örtlichkeiten. Weiter sehen wir aus der Tabelle III an Hand der , abstrakten Häufigkeiten“, wie wir sie kurz nennen wollen, daß Schizopoden oft mit Schnecken und Bellerochea, also einerseits mit typischen Bodenbewohnern und andererseits mit Planktonorganismen zusammen erscheinen.

Amphipoden vereinigen sich meistens mit Copepoden, Corophium mit Foraminiferen, Copepoden mit Seeigelstacheln und sehr bemerkenswerterweise die drei Larvenformen Cyprislarven, Muschellarven und Schneckenlarven miteinander. Cyprislarven und Schneckenlarven 
Tabelle III.

Übersicht über die abstrakten relativen Häufigkeiten der Kombinationen.

\begin{tabular}{|c|c|c|c|c|c|c|c|c|c|c|c|c|c|c|}
\hline & A & & & & & & & & & & & & & \\
\hline A Würmer & 346 & $\mathrm{~B}$ & & & & & & & & & & & & \\
\hline B Schizopoden & 17 & 673 & C & & & & & & & & & & & \\
\hline C Amphipoden & 74 & 42 & 221 & D & & & & & & & & & & \\
\hline $\mathrm{D}$ Corophium & 66 & 4 & 1 & 140 & $\bar{E}$ & & & & & & & & & \\
\hline E Copepoden & 35 & 51 & 173 & 2 & 87 & $F$ & & & & & & & & \\
\hline F Cyprislarven & 31 & 68 & 28 & 20 & 43 & 1 & $\mathbf{a}$ & & & & & & & \\
\hline G Muschellarven & 4 & 57 & 30 & 8 & 5 & $15 \overline{1}$ & 3 & $\mathrm{H}$ & & & & & & \\
\hline H Schneckenlarven & 4 & 10 & 2 & 6 & - & 41 & 180 & - & I & & & & & \\
\hline I Muscheln & 50 & 31 & 59 & 10 & 41 & 18 & 11 & 7 & 3 & $\mathbf{K}$ & & & & \\
\hline K Schnecken & 59 & 115 & 38 & 11 & 8 & 156 & 84 & 13 & 47 & 1 & $\mathrm{~L}$ & & & \\
\hline L Algen & 88 & 21 & 15 & 3 & 4 & 40 & 4 & 1 & 20 & 25 & 20 & $M$ & & \\
\hline M Detritus & 137 & 19 & 26 & 49 & 13 & 3 & 9 & 1 & 25 & 7 & 11 & 18 & & \\
\hline Harpacticiden & 32 & 8 & 20 & 29 & 2 & 21 & 7 & 82 & 18 & 29 & 12 & 2 & $\cdots$ & 4. \\
\hline Ostracoden & 7 & 3 & 8 & 1 & 6 & 5 & 3 & 2 & 7 & - & 4 & 11 & $\cdots$ & 62 \\
\hline Cumaceen & - & 20 & 1 & - & 1 & - & - & - & - & 1 & 2 & 33 & $\ldots$ & 4 \\
\hline Nauplien & 2 & 6 & - & - & 24 & 10 & 一 & 一 & 3 & - & - & - & $\therefore$ & - \\
\hline Cirripedien & 1 & 1 & 14 & - & 2 & 24 & 3 & 2 & 16 & 5 & 7 & - & $\ldots$ & 161 \\
\hline Crangon & 8 & 10 & 10 & 5 & 1 & 4 & 16 & 1 & 8 & 10 & 32 & 48 & $\ldots$ & 458 \\
\hline Bellerochea & 3 & 83 & 2 & - & 8 & 41 & 31 & 4 & 25 & 35 & 5 & 2 & $\ldots$ & - \\
\hline Biddulphia & 7 & 1 & 4 & - & 5 & 1 & 25 & 15 & 1 & 5 & - & 10 & $\ldots$ & - \\
\hline Coscinodiscus & 25 & 12 & 30 & 3 & 50 & 1 & 10 & - & 10 & 3 & 5 & 2 & $\ldots$ & - \\
\hline Nematoden & 66 & 3 & 3 & 4 & 2 & 4 & 1 & 2 & 14 & 4 & 26 & - & $\ldots$ & - \\
\hline Insekten & - & 3 & 37 & 1 & 40 & 14 & 1 & - & 3 & - & 一 & - & $\ldots$ & 161 \\
\hline Sagitta & - & 42 & - & - & 2 & 2 & 10 & - & 一 & 2 & - & - & $\ldots$ & - \\
\hline Cercarien & 57 & - & - & - & - & - & - & - & - & - & 97 & - & $\ldots$ & - \\
\hline Hydroiden & 1 & - & 7 & - & 2 & - & 11 & 7 & 一 & 10 & - & 4 & $\ldots$ & - \\
\hline Kokons & 2 & 2 & - & 7 & - & - & - & 11 & 16 & 3 & - & 一 & $\ldots$ & - \\
\hline Fischteile & 6 & 29 & 2 & 1 & 3 & 5 & 7 & 2 & 3 & 3 & - & 20 & $\ldots$ & 529 \\
\hline Foraminiferen & 66 & 71 & 24 & 110 & 36 & 52 & 18 & 20 & 35 & 41 & 38 & 15 & $\ldots$ & - \\
\hline SeeigelstacheIn & 123 & 24 & 76 & 36 & 119 & 42 & 17 & 3 & 78 & 32 & 69 & 11 & $\ldots$ & - \\
\hline
\end{tabular}

kommen einerseits oft mit Schnecken vor und andererseits mit Bellerochea, während die Schneckenlarven mit Harpacticidén sehr häufig zusammen vorzufinden sind.

Wir sehen so an der vielseitigen, aber in Anbetracht der Lebensweise der Partner typischen Bindung der einzelnen Formen untereinander, daß wir ein G emenge von verschiedenen Biotopen vor uns haben, welche Biotope sich in ihrer je nach den besonderen zeitlichen und örtlichen Umständen in den Zusammensetzungen der Mageninhalte abzuzeichnen scheinen.

Um eine weitere Analyse der Tabelle III in dieser Richtung vornehmen zu können, legen wir einer Betrachtung die Kombinationsverhältnisse einiger biotopbestimmender Typen zugrunde. Da die Bodenbeschaffenheit eines Biotops diesen weitgehend zu modifizieren vermag, wählen wir die Sedimente „Detritus“, „Foraminjferen" und "Seeigelstacheln" aus. Wir haben schon oben festgestellt, daß Detritus und Würmer häufig miteinander zusammen vorkommen. Wenn wir jetzt die Häufigkeitsziffern des Zusammenauftretens der übrigen Typen der Nährorganismen mit dem Detritus einerseits und den Würmern andererseits vergleichen, können wir aus dem Zahlenverhältnis und der Ökologie der Partnerformen Schlüsse ziehen auf das Zustandekommen von Mageninhaltsgesellschaften. Einige Gesellschaften von grundsätzlicher Bedeutung mögen in diesem Zusammenhang erörtert werden. Daß Würmer mit Detritus zusammen so häufig in den Garnelenmägen erscheinen, liegt aus folgendem Grunde nahe. HAGMEIER nämlich stellte fest, daß Würmer an solchen Stellen in großer Zahl erlangt werden können, wo Schlickboden ist, oder wo der Sand mit Schlick ( Detritus) durchsetzt ist, und zwar wächst diese Zahl mit dem Anteil an Schlick. Naturgemäß gelangt Schlick mit in den Magen der Garnele, wenn sie Schlickbewohner erbeutet. Wir sehen weiter, daß auch Corophium-Detritus von großer Häufigkeit ist. Corophium ist ja zur Endofauna des Schlickwatts zu rechnen. Ebenso finden sich Cumaceen, die Bewohner tiefer, mit Schlick versehener Stellen, oft mit Detritus zusammen. Daß Crangon häufig mit Detritus zusammen in den Mägen erscheint, ist erklärlich, da Kannibalismus aller Wahrscheinlichkeit nach, wie auch die Anzahl und Art der Crangon-Partnerformen vermuten lassen, im wesentlichen eine Folgeerscheinung bei Nahrungsmangel ist, bei welchem der Boden von den Garnelen vermutlich zunächst abgesucht werden wird.

Wie der Detritus können auch die beiden Sedimente Seeigelstacheln und Foraminiferen als Jndikatoren für die Beschaffenheit eines Biotops dienen. Sie 
kommen, wie Bodenproben lehrten, in der Natur zusammen vor und deswegen auch in den Mägen. Hier haben sie, wie die Tabelle III nicht mehr aufführt, die Häufigkeitsziffer 85. Wenn wir uns die beiden Reihen der Tabelle III (die beiden letzten waagerechten Spalten) ansehen, stellen wir fest, daß die Häufigkeitsziffern erheblich um den Wert 85 herum schwanken. Wir können aus folgenden Gründen annehmen, daß die beiden Sedimente eine unterschiedliche mengenmäßige Verteilung im Untersuchungsgebiet besitzen. Die Seeigelstacheln sind im Durchschnitt größer als die Foraminiferen, sie sind im Gegensatz zu den letzteren kompakt, ihre Sinkgeschwindigkeit ist also größer, so daf sie an solchen Orten vorkommen, wo das Wasser tiefer ist und stärker bewegt ist als an den Plätzen, wo die leichteren Foraminiferen sedimentiert werden. Sehr einfach kann man dieses an den Wattrippeln beobachten, bei denen sich die Sedimente auf dem Querschnitt derartig verteilen, daß die kleineren am Scheitel lagern und am Abhang, in Richtung der Sohle größer werdend, sich die größten vorfinden. Wie verhalten sich nun die verschiedenen Formen der Nährtiere zu diesen Sedimenten im Zusammenvorkommen in den Mägen der Garnelen? Wir vergleichen zur Beantwortung dieser Frage die beiden Reihen miteinander.

Würmer sind erheblich häufiger mit Seeigelstacheln zusammen als mit Foraminiferen, sie werden demnach vorwiegend an Orten gefressen, an denen Seeigelstacheln überwiegen, also in Tiefen. Die nächsten beiden Nährtiere verhalten sich im Zusammenvorkommen mit den beiden Sedimenten geradezu umgekehrt proportional. Diese Tatsache läßt eine Deutung zu, die für alle beteiligten Formen bezeichnend, sogar typisch ist. Wir wissen von unseren Amphipoden, daß sie (außer Corophium) einen Biotop haben, welcher ausgezeichnet ist durch grobsandigen, stark beweglichen Boden (HAGMEIER), während unsere Schizopoden einen starken Biotopwechsel vornehmen (ScHLIENZ), sowohl aktiv wie auch passiv durch Tidenversetzung, außerdem haben sie die Gepflogenheit, sich in den Boden einzuwühlen, um die Ebbe zu überstehen (THAMDRUP, KÜNNE). Wo grober Sand vorkommt, überwiegt das gröbere Material der Seeigelstacheln; und wo die Schizopoden den zum Einwühlen nötigen Boden haben, sedimentiert am besten die leichte Foraminifere. Das folgende Beutetierpaar verhält sich ebenfalls umgekehrt proportional in den in Rede stehenden Häufigkeitsziffern und hat dabei ein durch größere Gegensätzlichkeit hervorgehobenes charakteristisches Verhältnis $\mathrm{zu}$ den Sedimenten. Corophium bewohnt das flache, durch wenig Wasserbewegung ausgezeichnete Hochwatt, während Copepoden (außer Harpacticiden) als Planktonten die dieser Kategorie von Tieren eigene Lebensweise haben. Wenn wir die folgenden Typen unter diesem Gesichtswinkel betrachten, kommen wir zu ganz entsprechenden Ergebnissen. Schnecken und Schneckenlarven überwiegen im Vorkommen mit Foraminiferen, da sie ja besonders an flachen Stellen, beispielsweise dem Hochwatt, anzutreffen sind. Muscheln, besonders die hier in Frage kommenden Macoma, gewinnen einen Standort, dessen „Gebietslage" (HAGMEIER) ähnliche Verhältnisse aufweist, wie sie Copepoden und Amphipoden haben. Unter dem Begriff "Algen " sind zusammengefaßt Sprosse und abgerissene Teile älterer Spreiten, erstere findet man meist mit Foraminiferen und letztere mit Seeigelstacheln zusammen, welche sich durch besondere Länge $(>3 \mathrm{~mm})$ auszeichnen.

Wie wir schon bei dem Vergleich der Häufigkeitsziffern der Reihe der DetritusKombinationen mit der Reihe der Würmer-Kombinationen bei Schizopoden der Größenordnung nach gleichgroße Ziffern feststellen konnten, so können wir auch bei den beiden Reihen der beiden Sedimente für die Formen Cyprislarven, Muschellarven und, wenn wir die Größenordnung vergleichsweise in Rechnung ziehen, auch für Schnecken und den Detritus wieder eine auffällige Übereinstimmung der Häufigkeitsziffern erkennen. Diese Tatsache ist in doppelter Hinsicht beachtlich, nämlich in berechnungsmethodischer wie in biologischer. Die berechnungsmethodischen Zusammenhänge mögen an einem anderen Orte mit einem weniger heterogenen Material erläutert werden, in diesem Zusammenhang interessiert uns vor allem die biologische Bedeutung der Übereinstimmung der in Rede stehenden Werte der „abstrakten relativen Häufigkeit“. Die naheliegende Vermutung aus dieser Tatsache, nämlich die, daß wenn eine Beutetierform ebenso häufig mit einer zweiten wie mit einer dritten zusammen vorkommt, sie alle drei zusammen eine Gesellschaft bilden, die den Verhältnissen in der Natur gleichkommt, bedarf natürlich einer Bestätigung durch die Erfahrung. Wie also finden sich die Formen, bei denen sich solche Übereinstimmungen zeigen, in der Natur zusammen vor?

Der Detritus ist, ebenso wie die Seeigelstacheln und Foraminiferen, ein Sediment; daß hier eine übereinstimmende Häufigkeit erscheint, liegt deshalb nahe. Die Schnecke 
Hydrobia bewohnt zwar vorzüglich das hochgelegene Watt, erfährt aber durch folgenden Vorgang eine Verteilung über einen größeren Raum. Bei abfließendem Wasser heften sie sich unter der Oberfläche unter Ausnutzung der Oberflächenspannung fest und werden auf diese Weise in großen Mengen im Gebiet der Schorre angeschwemmt (vergl. RICHTER, Trusheim, ANKel usw.). Die Schorre nun hat alle hydrophysikalischen Voraussetzungen für eine gleichmäßige Ablagerung auch der beiden Sedimente Seeigelstacheln und Foraminiferen. Die Cyprislarven von Balanus leben bis zu ihrem Brutfall planktonisch, danach aber setzen sie sich ab, um an ein geeignetes Substrat zum Ansetzen zu gelangen. Da sie in den Mägen zuweilen in größerer Anzahl vorhanden sind, ist es wahrscheinlich, daß sie von der Garnele dann erbeutet worden sind, wenn der Brutfall bereits stattgefunden hatte, wofür noch die Tatsache spricht, daß sich zwischen den Larven oft nur ihre leeren Schalenklappen fanden. Hinzukommt noch, wie die Tabelle III zeigt, ihr sehr häufiges Zusammentreten mit den Schnecken. Mit diesen bereichern sie das "Angeschwemmsel" der Schorre, wo ja auch die beiden Sedimente gleichermaßen verteilt beisammen sind. Ganz ähnlich wie die Cyprislarven verhalten sich die Muschellarven; allerdings ist hier zu beachten, daß unter dem Begriff "Muschellarven“ die Larven aller vorkommenden Muschelarten zusammengefaßt sind, welche untereinander unterschiedliche Verteilungsformen haben, wie z. B. Mytilus und Macoma. Es wird aber zum mindesten ein Teil an der Schorre angeschwemmt, sobald der Brutfall eintritt und zusammen mit den besagten Sedimenten aufgenommen werden.

Diese kurze Auseinandersetzung zeigt uns, daß die Verhältnisse in der freien Natur auf die obengenannte Deduktion zutreffen. Wir sind dadurch in den Stand gesetzt, dre iglie d erige Gesellschaften von Nährorganismentypen aus der Tabelle zu isolieren. Bei weiterer Anwendung des Prinzips der übereinstimmenden abstrakten relativen Häufigkeiten können wir die Gesellschaften noch durch mehrere Glieder vervollständigen, wodurch jene Biotope näher charakterisiert werden, deren Verhältnisse ein mehr oder weniger häufiges Zusammentreten zweier Formen verursachen. Das Beispiel der Muschellarven-Cyprislarven-Kombination mit ihrer großen Häufigkeitsziffer (151, siehe Tab. III) möge dies erläutern. Wir haben festgestellt, daß Cyprislarven mit Foraminiferen und Seeigelstacheln eine Gesellschaft bilden, ebenso die Muschellarven mit den beiden sedimenten. Beide also werden aus jenem Biotop genommen, wo die beiden Sedimente in gleicher Weise vorzufinden sind. Da aber die Werte der Sedimentkombinationen mit den beiden Larvenformen in der Tabelle III nicht gleichgroß sind, wie wir erwarten dürfen, sobald die Partner von ein und demselben Biotop her aufgenommen worden sind, muß ein anders beschaffener Biotop mit einer anderen Biocönose die so häufige Vereinigung der beiden Larvenformen bewirken. Stellen wir also die Reihen der beiden Formen einander gegenüber, so sehen wir übereinstimmende Werte bei den Kombinationen mit folgenden Typen: AmphipodenBellerochea-Schizopoden-Muscheln. Da die Werte der Tabelle III einer ganzen Reihe von Fehlerquellen unterliegen, welche bedingt sind durch Siedlungsverhältnisse der als Beute dienenden Organismen, durch Ortsveränderungen der Fresser, sowie durch den Zustand des Mageninhaltes, ist es berechtigt, zum Vergleich die Größenordnung der Werte heranzuziehen und diese Größenordnung ihrerseits so weit zu fassen, wie die betr. Häufigkeitsziffer im Vergleich zu den übrigen Ziffern an Bedeutung hat. Je kleiner nämlich die Ziffer ist, desto ungenauer zeigt sie die Bedeutung der betr. Kombination an. Um diesen Umstand in der Darstellung der zusammenzustellenden Gesellschaften zum Ausdruck zu bringen, seien die Formen fettgedruckt, deren Ziffern einigermaßen einwandfrei die Forderungen erfüllen, die nötig sind, die Form zu der Gesellschaft hinzu rechnen zu können. Für unser Beispiel (Cyprislarven-Muschellarven) muß also die Gesellschaft folgendermaßen lauten, welche die Garnele am häufigsten die beiden Larvenformen zusammen aufnehmen läßt: :: Muschellarven-CyprislarvenMuscheln-Bellerochea-Amphipoden-Schizopoden:: Nachdem wir auf rein rechnerischem Wege diese Gesellschaft aus dem Gemenge der Übersicht eliminiert haben, tauchen naturgemäß folgende Fragen auf: 1. Sind in den Untersuchungsbildern der einzelnen Proben in der Tat Muschellarven und Cyprislarven dann am häufigsten zusammen gefunden, wenn auch alle die übrigen Formen der Gesellschaft gegenwärtig waren? 2. Deckt sich die Gesellschaft mit den Nährtierbesiedlungsverhältnissen an dem Orte der Entnahme der Garnelenproben? [Der Entnahmeort muß entweder einen enger umgrenzten Lebensraum darstellen oder, falls sich an mehreren Orten die Gesellschaft in den Mägen findet, müssen die Siedlungsbedingungen ähnliche sein.] Nach Durchsicht meiner Untersuchungsprotokolle kann ich die Fragen bejahen und die Gesellschaft wie folgt lokalisieren. Sie findet sich in den Mägen von Garnelen, die an Fangorten entnommen 
sind, welche nach ihrer „Gebietslage“ (HAGmeier) zu den „Stromsänden“ gehören und außerdem unter der Einwirkung der THIEmannschen Planktonsprungzone (siehe Abs. VI) stehen.

Die Untersuchungsbilder enthalten außer den Mitgliedern der Gesellschaft in verschiedener Weise noch andere Beuteorganismen, welche ihren typischen Standort an anderen Biotopen haben. Wir können also in den Mägen der Garnelen eines bestimmten Fangortes Nährtiere feststellen, die gemischt sind aus a u tochthonen und allochthonen Nährtieren. Während also die errechnete Gesellschaft als Stammgesellschaft zu bezeichnen wäre, könnte an den beigesellten Nährtieren erkannt werden, woher der Zustrom an Garnelen gekommen ist. Dieses wiederum kann uns als Indikator dienen bei der Erforschung der "kleinen Wanderungen" der Garnele, ein Fragenkomplex, der mit darauf zugeschnittenem Material von mir in Angriff genommen ist.

Wenn wir eine derartige Gesellschaftenbestimmung mit allen Formen der Tabelle III vornähmen, würden wir erstens alle möglịchen, von den Garnelen des vorliegenden Materials besuchten Biocönosen herausstellen können und zweitens die Mannigfaltigkeit der Besiedlung des Untersuchungsgebietes erkennen. Wir beschränken uns hier darauf, jene Gesellschaften zu isolieren, die die Höchstwerte unter den Kombinationen bewirken, indem wir die Werte der Reihen der Partnerformen miteinander vergleichen.

1. Muschellarven - Schneckenlarven (180) - Foraminiferen (18:20) - Muscheln (11:7) Würmer (4:4)-Corophium (8:6). Hier finden sich die Nährtiere zusammen, wie sie etwa auf dem Watt vereint zu sein pflegen.

2. Amphipoden-Copepoden (173)-Insekten (37:40)-Coscinodiscus (30:50)-Biddulphia (4:5)-Schizopoden (42:51). Garnelen mit derartig zusammengesetztem Mageninhalt finden sich in der Umgebung des Süderfahrwassers.

3. Cyprislarven - Schnecken (156) - Foraminiferen (52:41) - Seeigelstàcheln (42:32)Bellerochea (41:35)-Harpacticiden (21:29)-Nematoden (4:4)-Amphipoden(28:38). Diese Gesellschaft können wir in den Prielen antreffen.

4. Würmer-Detritus (137)-Schizopoden (17:19). Aus den Tiefen der Flußmündung.

5. Würmer-Seeigelstacheln (123)-Schizopoden (17:24)-Amphipoden (74:76). Großer Vogelsand.

6. Copepoden-Seeigelstacheln (119)- Cyprislarven (43:42) -Detritus (11:13). (Nach der Arbeitstabelle außerdem Bellerochea und Coscinodiscus). Prielöffinung.

7. Schizopoden Schnecken (115) - Amphipoden (42 : 38) - Algen (21 : 25) - Crangon (10:10)-Schneckenlarven (10:13)-Nematoden (3:4). Im Prielsystem der Hundebalje.

8. Corophium-Foraminiferen (110)-Würmer $(66: 66)$. Hochwatt.

Zusammenfassend können wir also über die Zusammensetzung der Nahrung unserer omnivoren Garnele aussagen, daß sie so mannigfaltig ist, wie die Biotope ihres Wohngebiets besiedelt sind.

\section{Die Verarbeitung der Nahrung.}

a) Das Ergreifen der Nahrung.

Garnelen, die kurz nachdem sie aus dem freien Wasser genommen worden sind, in ein Aquarium gesetzt werden, nehmen angebotene Nahrung sehr eifrig. Sobald sie aber eine längere Zeit im Aquarium gehalten worden sind, fressen sie nur sehr spärlich. Bei der Nahrungssuche streifen sie in Zickzackbewegungen auf dem Boden umher und jagen auch in höheren Schichten des Wassers mit gesenktem Carapax, im Gegensatz zu Palaemon, der den Carapax aufwärts richtet. Für die Garnele ist, besonders wenn sie aufgescheucht worden ist, eine ruckartige Bewegung charakteristisch. Diese Bewegung, zu der sie die kräftige Abdominalmuskulatur befähigt, findet sich beim Ergreifen und während des Verzehrens der ergriffenen Nabrung wieder. Wirft man einen lebenden Wurm ins Aquariumbecken, so stößt die Garnele aus ihrem Versteck auf den schwimmenden Wurm direkt hervor, ergreift ihn mit dem ersten Gehfufpaar, das mit kräftigen subchelaten Scheren bewaffnet ist und unter kurzen Rückwärtsstößen, die durch ventralwärts gerichtete Schläge des Abdomens ausgeführt werden, sucht sie den Wurm zu bewältigen. Schwimmend bringt sie den Wurm in eine Lage, in der die Gehfüße ihn umklammern und ihn in unmittelbarer Nähe des Sternums halten. Anscheinend hat dabei der nach vorn gerichtete Stachel eine Stützfunktion. Beihilfe zu dieser Bewältigung leisten die „Stocherfüße“, die zweiten Gehfüße, welche mit einer e cht en Schere versehen sind. Während dieses Vorganges wird offenbar das dritte Kaufußpaar zur Orientierung über die Lage der Beute benutzt, denn dieses folgt dem Wurm in allen seinen Bewegungen. Das zweite und erste Kau- 
fußpaar betasten ebenfalls den Wurm, während die beiden Maxillenpaare in ständiger Hinund Herbewegung verharren. Diese Bewegungen werden aber schneller in dem Augenblick, wo die beiden ersten Kaufußpaare ein Ende, meist das Vorderende, ertastet haben. Unterdessen ist die Garnele mit nachlassenden Schwimmbewegungen langsam auf den Boden gesunken und verzieht sich ruckartig in ein Versteck oder wühlt sich in Ermangelung eines solchen in den Boden ein, sobald die Lippen das Wurmende erfaßt haben. Ganz ähnlich verhält sie sich, wenn man ihr Miesmuschelfleisch zuwirft. Auch hier wird der Brocken aus dem freien Wasser ergriffen, durch die Gangbeine geballt und am Boden verzehrt. Durch die ruckartigen Rückwärtsstöße wird versucht, dem Ballen Teile zu entreißen. In der freien Natur konnteich beobachten, wie 6-7 junge Garnelen einen $8 \mathrm{~cm}$ langen Wurm (Nereis diversicolor), der sich in einer flachen Wattpfütze frei umherschwimmend fand, gemeinsam angriffen und von ihm mit denselben Bewegungen mit mehr oder weniger gutem Erfolg Teile abzureißen suchten. Große Garnelen pflegen sich sogar den Wurm langsam ganz einzuverleiben; sie beißen daher nach erster Magenfüllung das heraushängende Stück des Wurmes nicht ab, und bei auf würmerreichem Grunde gefangenen Garnelen findet man oft solche, denen ein Wurm zur Mundöffnung herausragt. Wenn die Garnele Schizopoden oder Amphipoden zu ergreifen sucht, stößt sie auf sie, schiebt sich über sie und trachtet danach, sie mit ihren Gangbeinen zu umklammern. Die Ruckbewegungen erfolgen dann rück-aufwärts gerichtet. Dieselbe Richtung schlägt die Garnele ein, wenn sie sich inmitten von Planktonten befindet. Anscheinend ist das für die Garnele so eigenartige Hüpfen gegen den Strom in abfließenden Rinnsalen durch diese Art der Nahrungsgewinnung bedingt. Die Art und Weise, Planktonten zu erbeuten, kann man sich etwa wie folgt vorstellen: Wenn sich die Garnele über ihrem Beutestück (Copepoden, Larvenformen usw.) befindet, erzeugt sie durch den Rückstoß einen Strudel in Richtung auf ihre Mundwerkzeuge, wodurch die Nährtiere mitgerissen und ergriffen werden können. Schnecken und Muscheln gelangen den Garnelen in die Mundöffnung dadurch, daß sie sich über sie lagert und sie unmittelbar mit den Maxillen anpackt.

Die Tatsache, daß sich vielfach ganze Nahrungstiere im Magenlumen finden, ordnet die Garnele zu den "Schlingern“.

\section{b. Die Vorverdauung.}

Nachdem das sehr erweiterungsfähige Lumen des Magens mehr oder weniger mit Nahrungsbrocken angefüllt ist, pflegt sich die Garnele in den Sand oder Schlick einzuwühlen, um ruhig zu verdauen. Nur die Augen und Antennen ragen hervor; denn die Garnele belauert jede geeignete Beute und ist stets bereit, noch neue Brocken hinzu zu nehmen.

Der räumlich größte Teil des Decapodenmagens ist der Cardialteil. Dieser ist ein Vorverdauungsraum und als Kaumagen bei den verschiedenen Familien der Decapoden unterschiedlich organisiert. Meist ist nicht nur der Pylorikalteil mit chitinigen Kauapparaten versehen, sondern auch der Cardialteil besitzt Borsten, Reibplatten und vor allem Chitinzähne.

Während bei Potamobius solche Kauinstrumente zu einer sogenannten ,Magenmühle" angeordnet sind, hat der Caridenmagen allgemein nur einen Besatz von schwachen Borsten, die nicht imstande sind, sich an der Zerkleinerung der Nahrungsbrocken unmittelbar zu beteiligen. So läge die Meinung nahe, daß Magensäfte und Mitteldarmdrüsensekrete die Weichteile der Nahrungstiere verdauen, und daß die groben unverdaulichen Rückstände durch den Mund wieder abgegeben werden. Von Potamobius ist dies bekannt, wie ja auch von anderen Tieren, nämlich Raubvögeln, der Corethra-Larve und anderen. Aquariumsversuche lehrten mich, und auch EHRENBAUM stellte schon früher fest, daß Crangon dergleichen nicht zu tun pflegt. Vielmehr werden die Hartteile der Nahrungstiere (Chitinhäute der Crustaceen, Muschel- und Schneckenschalen, Wurmborsten) fast restlos so zerrieben in den Mägen vorgefunden, daß sie sehr wohl durch den Filterapparat des Pylorus hindurch in den Mitteldarm gelangen können. Eine Ausnahme aber stellen die in den meisten Mägen in wechselnder Menge vorhandenen Quarzkörnchen dar. Diese werden durch den Mund wieder abgegeben. Gibt man in ein Aquarium Garnelen mit vollem Magen aus der Natur, um sie für kontrollierte Nahrungszufuhr hungern zu lassen, so ist nach beendigter Verdauung dẹr Boden des Aquariums mit einer dünnen Schicht von Sand bedeckt. Nach erneuter Nahrungsaufnahme findet man bald wieder Quarzkörnchen im Magen, die nur vom Boden herzugenommen sein können. Di e Körnchen sind of fenbar ein Ersatz für die Magenmühle von Potamobius. Es stellt sich weiter heraus, daß mit Hilfe der Körnchen das Nährmaterial stärker zerrieben und somit 
besser ausgenutzt wird, als es z. B. Potamobius kann. Die Garnele besitzt also mit der Aufnahme von Steinchen ein Mittel zur mechanischen Beihilfe bei der Vorverdauung, wie wir es ähnlich bei manchen Vögeln haben, ebenso beim Walroß, beim Krokodil und der verdauenden Holothurie, die Schlund und Kropf mit Sand angefüllt hat. MEIERJÜRgen (1935) berichtet, daß auch Ancylus Quarzstückchen in den Darm aufnimmt zum Zerbrechen der Diatomeenschalen und zur besseren Ausnutzung der Nahrung.

EHRENBAum stellt wohl den Borstenbesatz im Cardialteil des Garnelenmagens fest, mißt ihm aber keine funktionelle Bedeutung bei; er gibt vielmehr den Mandibeln mit den langen Zähnen den hervorragendsten Anteil bei der Zerkleinerung der Nahrung (S. 21) und den Skeletteilen des Magens (S. 77). Da nach Giesbrecht (S. 98) die Zähne im Kaumagen von Potamobius aus Borstengruppen ontogenetisch entwickelte Apparate darstellen, können wir wohl auch von den Crangon-Cardialborsten eine wichtige Funktion erwarten. Diese Borsten sind im Oesophagus und in der Cardia nach hinten gerichtet und im Praepylorikalteil entsprechend nach vorn. Wenn man nun Mägen öffnet, die in ihrer Vorverdauungstätigkeit verschieden weit vorgeschritten sind, so zeigt sich, daß der Nahrungsballen in Borstenrichtung gedreht wird. Als Anzeiger kann man die Lage und Menge der hinzugenommenen Quarzkörnchen heranziehen. Mit den peristaltisehen Bewegungen werden die Borsten abwechselnd aufgerichtet und in den Ballen eingesenkt; so wird er gedreht. Und andererseits verhindert die Sperrklinkenstellung der Borsten ein Zurück- und Herausgleiten des Ballens. Besonders wichtig dabei ist, daß die successiv hinzugenommenen Steinchen einen Ortswechsel erfahren und von allen Seiten den Nahrungsballen in Angriff nehmen können. Die Zerreibewirkung ist umso größer, je dichter der Ballen von Steinchen durchsetzt ist.

Während der Drehung gleitet die Masse über den Pylorikalteil hinweg. Hier sammelt sich der abgepreßte schleimige Chymus, und die zweckmäßig angeordneten Borstengruppen saugen ihn wie ein Schwamm in den Pylorus, ganz wie bei Potamobius.

$\mathrm{Da}$ über die Wirksamkeit der Quarzkörnchen in Krustermägen in der Literatur nichts angegeben ist, möge in folgendem etwas näher darauf eingegangen werden. Die durchschnittliche Größe der Quarzkörnchen ist für alle Crangon-Längen ziemlich gleich. Sie bewegt sich zwischen 0,26 und $0,44 \mathrm{~mm}$ (vergl. Mytilus-Larven 0,23 bis 0,29 mm). Die größten sind 0,53 bis $0,61 \mathrm{~mm}$ und werden keineswegs nur von den größeren Garnelen aufgenommen. Der Körnchenbestand von solchen Garnelen, die offenbar in feinsandigem Boden verdaut haben, weist alle Größen wie wahllos eingeschaufelt auf. Solche von schlickigem oder Kiesgrund hingegen haben Steinchengrößen im Magen mit geringer Variationsbreite und hoher mittlerer Größe.

Die Anzahl der Steinchen schwankt natürlich sehr durch den Rhythmus der Aufnahme und Abgabe und den wechselnden Bedarf je nach Konsistenz der Nahrung. Die mittlere Höchstzahl beläuft sich auf etwa 300 Stück, zuweilen fanden sich erheblich mehr.

Bei der Sektion von Garnelenmägen zum Zwecke der qualitativen Bestimmung des Mageninhaltes wurden der Füllungsgrad des Magens, die relative Steinchenmenge im Magen, so wie der Zerstörungsgrad und der Verdauungsgrad des Nährmaterials meist mitbestimmt. Dabei dienten folgende Abstufungen als Grundlage:

1. Füllungsgrade:

$$
\begin{aligned}
& \text { leer }=0 \\
& \text { fast leer }=5 \\
& \text { wenig }=10 \\
& 1 / 4=25
\end{aligned}
$$

$$
\begin{aligned}
& 1 / 2=50 \\
& 3 / 4=75 \\
& \text { voll }=100 \\
& \text { prall }=125
\end{aligned}
$$

Die Zahlen sollen ein ungefähres Bild von dem Spielraum zwischen den Stufen geben und sollen bei späteren Mittelwertberechnungen als Hilfsmittel dienen. Hier ist "voll“ gleich 100 gesetzt, weil diese Stufe dem normalen Höchstfüllungsgrad am ehesten entspricht. Die Stufen geringerer Füllung sind auf diesen Grad bezogen und nicht auf die Höchstfassungskraft des Magenlumens der jeweils untersuchten Garnelenlänge; dieser kommt die Stufe „prall“ am nächsten.

2. Steinchenmenge :

$$
\begin{aligned}
& \text { nicht vorhanden (n. v.) }=0 \\
& \text { selten }(\mathrm{s} \text {.) }=5 \\
& \text { vorhanden (v.) }=10 \\
& \text { nicht selten (n. s.) }=25
\end{aligned}
$$

$$
\begin{aligned}
& \text { häufig (h:) }=50 \\
& \text { sehr häufig (s. h.) }=75 \\
& \text { massenhaft (m.) }=100
\end{aligned}
$$


Die Steinchenmenge bezieht sich auf den räumlichen Anteil, den die Steinchen an dem Gesamtmageninhalt haben. "Massenhaft" ist hier gleich 100 gesetzt; das hieße also, daß in solchen Fällen nur Steinchen im Magen sind. Das trifft in den meisten Fällen nicht in vollem Umfange zu, zeigt aber an, daß der Anteil an Nährpartikeln gering genug ist, um vernachlässigt werden zu können.

3. Zerreibungsgrad:

$$
\begin{aligned}
& \mathrm{a}=\text { unzerstört } \\
& \mathrm{b}=\text { leicht zerrieben } \\
& \mathrm{c}=\text { stark zerrieben }
\end{aligned}
$$

4. Verdauungsgrad der Weichteile:

$$
\begin{array}{ll}
\mathrm{A}=\text { unzersetzte Weichteile } & \mathrm{C}=\text { stark zersetzte Weichteile } \\
\mathrm{B}=\text { leicht zersetzte Weichteile } & \mathrm{D}=\text { nur Hartgebilde }
\end{array}
$$

Der Fortschritt in der Vorverdauung ist also durch zwei Gesichtspunkte gekennzeichnet. Der Zerstörungsgrad gibt in weiten Grenzen an, wie sehr das Nährmaterial in seinem ursprünglichen Zusammenhang gelöst ist. Der Verdauungsgrad zeigt an, wie weit Verdauungssäfte wirksam gewesen sind. Als ursprünglicher Zustand ist der angenommen, den die Nahrung nach Durchgang durch Mandibeln und Oesophagus gehabt haben mag.

Das hierin verarbeitete Material von etwa 1000 Befunden setzt sich natürlich aus allen möglichen Fällen zusammen. Einerseits birgt die Methode der Schätzung viele Fehlerquellen in sich, und andererseits wird auch in der Natur der Vorgang der Vorverdauung nicht immer so ablaufen, wie ihn die oben gegebene Schilderung darstellt. Es ist also angebracht, das gewonnene Bild z. B. mit Hilfe von variationsstatistischen Methoden auf Richtigkeit zu prüfen. Es gilt, die Frage zu beantworten, ob im Durchschnitt die vier angegebenen Eigenschaften so miteinander variieren, wie die vorgefaßte Meinung vom Vorgang der Vorverdauung ausdrückt.

\section{A. Zerstörungs- bzw. Verdauungsgrad : Steinchenmenge.}

In der Tabelle IV, 1. und 2. sind die Variationsreihen für jeden Grad der Zerstörung und der Verdauung untereinander gestellt. In 1053 Befunden gab es 218 Fälle, in denen der Mageninhalt noch kaum von der Vorverdauung in Angriff genommen war, in 330 Fällen war er leicht zerrieben und in 505 Fällen stark zerrieben. Von den 218 Fällen wiederum waren 40 ohne Steinchenbeigabe, 34 hatten die Steinchenmenge "selten", in 70 Fällen wurdé die Steinchenmenge "vorhanden" festgestellt usf. Die letzte Rubrik zeigt die Mittelwerte (fette Zahlen) für jede Variationsreihe an.

Der Mittelwert M ist der Quotient aus der Summe der Produkte von Variantenzahl mit der Stufenmaaßzahl durch die Gesamtzahl der Varianten: z. B. $M=\frac{40 \times 0+34 \times 5+70 \times 10+\ldots \ldots}{218}$. Der Mittelwert kennzeichnet also die Lage des Schwerpunktes innerhaḷ der Variationsreihe, so daß diese mit Hilfe einiger weniger Zahlen verglichen werden können (W. JoHANNSEN).

Aus den Mittelwerten der Tabelle IV, 1. ersehen wir, daß die mittlere Steinchenmenge mit dem Zerstörungsgrad größer wird. Ebenso zeigt die Tabelle IV, 2., daß die Steinchenmenge umso größer ist, je weiter die Verdauung fortgeschritten ist.

Dieses rechnerisch gewonnene Ergebnis entspricht ganz unserer Vorstellung vom Vorgang der Vorverdauung, welche wir experimentell durch Aquarienversuche bekamen. Erst in Verbindung mit dem Experiment allerdings haben die Mittelwerte in unserem Falle genügend Überzeugungskraft; , es sei denn, man zöge bei jedem Wert die möglichen Fehler in Rechnung, die subjektiv bei der Abschätzung eines Zustandes entstehen und die objektiv durch unnormales Verhalten des toten oder lebenden Untersuchungsgegenstandes auftreten. Da sich die Mittelwerte unserer Anschauung gemäß verändern, obwohl die zugrundeliegenden Daten, ungeachtet der möglichen Fehler; mechanisch und „blindlings" statistisch verarbeitet worden sind, stützen wir uns weiter auf sie.

\section{B. Zerstörungs- bezw. Verdauungsgrad : Füllung des Magens.}

Es ist die Aufgabe der Vorverdauung, das Nährmaterial so zu zerlegen, daß es im Pylorus der weiteren Verflüssigung durch Mitteldarmdrüsensekrete (vergl. JoRDAN-HIRsCH) zugänglich ist. Damit nimmt der Füllungsgrad im Cardialteil des Magens ab. Wenn wir jetzt die Mittelwerte, die ebenso für die Füllungsgrade wie für die Steinchenmengen errechnet sind, graphisch darstellen, so sehen wir, daf die Kurven mit fortschreitender Vorverdauung fallen. Während aber der Füllungsgrad geradlinig abfällt bei wachsender Zerstörung, steigt er mit größerer Zersetzung der Weichteile nach anfänglichem Abfall vorübergehend wieder an. Hiermit macht sich die Hinzunahme der Steinchen augen- 
Tabelle IV.

Der Ablauf der Vorverdauung, dargestellt an den Beziehungen verschiedener Momente in ihrer Veränderlichkeit.

1. Steinchenmengen - Zerstörungsgrade.

\begin{tabular}{l|r|r|r|r|r|r|r|r|r}
\hline \hline & n. v. & s. & v. & n. s. & h. & s. h. & m. & n & M \\
\hline & & & & & & & & & \\
a & 40 & 34 & 70 & 29 & 31 & 9 & 5 & 218 & $\mathbf{1 8 . 6 7}$ \\
b & 29 & 62 & $\mathbf{1 1 4}$ & 60 & 46 & $\mathbf{1 2}$ & 7 & 330 & $\mathbf{2 0 . 7 5}$ \\
c & 18 & 81 & $\mathbf{1 9 4}$ & 44 & $\mathbf{1 0 8}$ & $\mathbf{3 0}$ & 30 & 505 & $\mathbf{2 7 . 9 0}$
\end{tabular}

2. Steinchenmengen - Verdauungsgrade.

\begin{tabular}{|c|c|c|c|c|c|c|c|c|c|}
\hline & n. v. & s. & v. & n. s. & h. & s. h. & $\mathrm{m}$ & $\mathrm{n}$ & M \\
\hline A & 34 & 22 & 34 & 7 & 11 & 4 & 2 & 114 & 14.70 \\
\hline B & 27 & 37 & 49 & 29 & 26 & 7 & 4 & 179 & 20.30 \\
\hline $\mathrm{C}$ & 6 & 25 & 46 & 20 & 30 & 10 & 9 & 146 & 28.99 \\
\hline D & 21 & 76 & 213 & 122 & 105 & 24 & 25 & 586 & 25.80 \\
\hline
\end{tabular}

3. Füllungsgrade - Zerstörungsgrade.

\begin{tabular}{|c|c|c|c|c|c|c|c|c|c|}
\hline & $\begin{array}{l}\text { fast } \\
\text { leer }\end{array}$ & wenig & $1 / 4$ & $1 / 2$ & $3 / 4$ & voll & prall & $\mathrm{n}$ & MI \\
\hline a & 2 & 9 & 19 & 39 & 55 & 70 & 24 & 218 & 76.5 \\
\hline $\mathrm{b}$ & 5 & 17 & 33 & 72 & 84 & 101 & 18 & 330 & 67.6 \\
\hline $\mathrm{c}$ & 35 & 67 & 75 & 133 & 125 & 112 & 18 & 565 & 55.6 \\
\hline
\end{tabular}

4. Füllungsgrade - Verdauungsgrade.

\begin{tabular}{l|r|r|r|r|r|r|r|r|c}
\hline & $\begin{array}{c}\text { fast } \\
\text { leer }\end{array}$ & wenig & $1 / 4$ & $1 / 2$ & $3 / 4$ & voll & prall & n & M \\
\hline & & & & & & & & & \\
A & 1 & 4 & 7 & 11 & 27 & 49 & 15 & 114 & $\mathbf{8 4 . 1}$ \\
B & 4 & 10 & 7 & 25 & 50 & 72 & 11 & 179 & $\mathbf{7 7 . 5}$ \\
C & 4 & 2 & 9 & 27 & 37 & 54 & 13 & 146 & $\mathbf{7 8 . 4}$ \\
D & 34 & 73 & 93 & 151 & 131 & 88 & 16 & 586 & $\mathbf{5 3 . 6}$
\end{tabular}

5.-16. Die Mittelwerte bei drei Nahrungsmitteln mit unterschiedlicher Konsistenz.

\begin{tabular}{|c|c|c|c|c|c|c|c|c|c|c|c|c|}
\hline & & & \multicolumn{3}{|c|}{ Zerstörung } & & & \multicolumn{4}{|c|}{ Verdauung } & \\
\hline & & & a & $b$ & $\mathrm{c}$ & & & A & B & $\mathrm{C}$ & D & \\
\hline Nur Würmer & $\begin{array}{l}\text { Steinchen: } \\
\text { Füllung: }\end{array}$ & $(n=173)$ & $\begin{array}{r}17.1 \\
101.9\end{array}$ & $\begin{array}{l}18.7 \\
78.9\end{array}$ & $\begin{array}{l}31.6 \\
66.1\end{array}$ & $\begin{array}{l}(5) \\
(6)\end{array}$ & $(n=178)$ & $\begin{array}{l}13.7 \\
96.2\end{array}$ & $\begin{array}{l}19.0 \\
73.6\end{array}$ & $\begin{array}{l}26.8 \\
85.8\end{array}$ & $\begin{array}{l}\mathbf{3 3 . 5} \\
\mathbf{5 7 . 3}\end{array}$ & $\begin{array}{l}(7) \\
(8)\end{array}$ \\
\hline Nur Crustaceen & $\begin{array}{l}\text { Steinchen: } \\
\text { Füllung: }\end{array}$ & $(n=492)$ & $\begin{array}{l}11.4 \\
73.2\end{array}$ & 19.2 & $\begin{array}{l}23.2 \\
46.2\end{array}$ & (9) & $(\mathrm{n}=490)$ & $\begin{array}{r}9.2 \\
73.5\end{array}$ & $\begin{array}{l}17.6 \\
76.9\end{array}$ & $\begin{array}{l}22.3 \\
73.5\end{array}$ & 15.6 & (11) \\
\hline Nur Mollusken & $\begin{array}{l}\text { Steinchen : } \\
\text { Füllung: }\end{array}$ & $(\mathrm{n}=32)$ & $\begin{array}{l}21.1 \\
75.3\end{array}$ & $\begin{array}{l}24.0 \\
77.0\end{array}$ & $\begin{array}{l}36.5 \\
75.5\end{array}$ & $\begin{array}{l}\text { (13) } \\
\text { (14) }\end{array}$ & $(n=32)$ & $\begin{array}{l}21.1 \\
75.3\end{array}$ & $\begin{array}{r}50.0 \\
125.0\end{array}$ & $\begin{array}{l}38.0 \\
90.0\end{array}$ & $\begin{array}{l}27.3 \\
62.8\end{array}$ & $\begin{array}{l}(15) \\
(16)\end{array}$ \\
\hline
\end{tabular}

scheinlich räumlich bemerkbar. Der Augenschein während der Untersuchung lehrt uns außerdem, daß die Weichteile nicht stückweise von der Praepylorikalklappe „abgebissen “ (Ehrenbaum) werden, sondern in schleimiger Form in den Pylorus gelangen. Chemische Einwirkung der Verdauungssäfte erweist sich also auch bei der Vorverdauung als nötig.

\section{Verschieden beschaffene Nahrung.}

Naturgemäß setzen die verschiedenen Konsistenzen der Nährkörper dem Zerreiben durch die Steinchen unterschiedlichen Widerstand entgegen und werden auch einen anderen Ablauf der Vorverdauung hervorrufen. In solchen Fällen, wo wir in den Crangon-Mägen n u r Würmer gefunden haben, verläuft die Vorverdauung sehr stetig, wie die betr. Mittelwerte in der Tabelle IV zeigen. Die Mittelwerte von 5. deuten an, daß das weiche Material des Wurmes anfangs von dem Magendrucke genügend ausgepreßt werden kann; 
erst nachdem der zähe Hautmuskelschlauch und die harten Borsten übrig geblieben sind, tritt ein größeres Bedürfnis nach Steinchen ein, wie das plötzliche Ansteigen bei c ausdrückt. Die Veränderung der Werte von 8. unterstreicht diesen Befund noch dadurch, daß der Füllungsgrad von $A$ nach $B$ rasch und tief abfällt und bei $C$ sich wieder erhebt durch die Hinzunahme von Steinchen. Wenn Würmer als Nahrung im Magen gefunden waren, konnte man den Vorgang der Drehung des Ballens, das Einschleimen und das Einsenken der Steinchen an den verschiedenen Stadien am besten verfolgen. Man konnte den Ballen oft noch so auseinanderfalten, daß die Segmente des Wurmes mit den Parapodien gut sichtbar waren. Die Peripherie des Ballens war mit einer Schleimschicht umgeben, von Steinchen umlagert und in Richtung auf den Mittelpunkt je nach Fortschritt der Vorverdauung durchsetzt. So war es immer bei Polychaeten und Oligochaeten, während die wenigen Fälle des Vorkommens von Nematoden sich wegen der widerstandsfähigen Cuticula wie bei Crustaceen verhielten. Die verschiedenen Borsten und auch die Kiefern der Würmer wurden zwischen den Steinchen zerrieben. Die Kiefer allerdings leisten bis zuletzt Widerstand und wurden noch vorgefunden, wenn schon neue andersartige Nahrung aufgenommen war. Crustaceen verlangen durch den Besitz ihres chitinigen Außenskeletts natürlich eine gründlichere mechanische Behandlung als die Würmer. Wenn wir die Würmer-Mittelwerte mit den entsprechenden Crustaceen-Werten vergleichen, sehen wir deutlich den Unterschied. Während 6 rasch abfällt, verändert sich der Füllungsgrad bei Crustaceen zögernd (10). Auch 12 zeigt, daß der Füllungsgrad sich bei fortschreitender Verdauung nur langsam verändert. Gleicherweise verhält es sich mit den Steinchenmengen. Bei Crustaceen ist das Bedürfnis nach mechanischer Beihilfe von Anfang an groß, so daf die Werte 9 rasch ansteigen, wie auch die Wertereihe 11, die bei $\mathrm{C}$ ein ausgeprägtes Maximum hat. Die Steinchen haben zur Zerkleinerung der Crustaceen drei Aufgaben zu lösen. Einmal trennen sie die aufgenommenen Tiere in ihren Ligamenten zu einzelnen Segmenten und Gliedern, zum anderen durchsetzen sie innerhalb der Segmente und Glieder die Muskulatur und zum dritten zerreiben sie zwischeneinander die Chitinhäute. So ergeht es in den meisten Fällen den Malacostraken, die als Nährtiere aufgenommen sind. Die kleinen Entomostraken entgehen den Mahlsteinen anfangs, weil sie in die Zwischenräume gleiten, aber später werden auch sie ergriffen mit Hilfe der Chitinstücke, die von größeren Krustern stammen. Bei Schizopoden und größeren Amphipoden, die ja ganz aufgenommen zu werden pflegen, gelangen die Steinchen von der weicheren Unterseite in den Körper. Besonders bei Crustaceennahrung kann man verfolgen, daß die successive hinzugesetzten Steinchen auch langsam wieder abgegeben werden, während die nötige Menge immerhin bis zuletzt bleibt. Der große Raum, den die Nährtiere anfangs einnebmen, wird durch den energischen Steinchenangriff schnell reduziert, soda $B$ bald viele Steinchen überflüssig sind. Schnecken und Musch eln bilden als Nährmaterial für die Vorverdauung immer ein retardierendes Moment, weil sie für den Angriff der Steinchen sehr unzugänglich sind. Wie auch dje entsprechenden Mittelwertfolgen ausweisen (13-16), ist es offenbar, daß eine starke Hinzunahme der Steinchen hauptsächlich den Zweck verfolgt, an die Weichkörper innerhalb der Schalen heranzukommen. Die Schalen zerreiben und zerdrücken sich, unterstützt von der Magenmuskulatur, gegenseitig. Während die Klappen von Muscheln meist vollkommen verarbeitet werden, finden sich Spindeln von Schnecken und Schlösser von Muscheln oft bis zuletzt und können anscheinend wie Steinchen wieder abgegeben werden.

\section{Alter und Geschlecht im Verhältnis zur Nahrung.}

Während die Larven der Garnelen in stark salzhaltigem Wasser schlüpfen, im Laufe ihrer Entwicklung zu Jugendstadien in brackigem Wasser anlangen und hier ihre Jugend verbringen, kehren die älteren Stadien wieder in salzigeres Wasser zurück.

Die Larven führen ein pelagisches Leben. Ihr Mageninhalt stellt nach EHRENBAum immer eine breiige, Detritus ähnliche Masse dar, in der geformte Teile nicht mehr zu erkennen sind, außer Bruchstücken von Diatomeenskeletten. Er nimmt weiter an, daß Pflanzenreste, der sogenannte „Darg“ des Wattenmeeres, für die Larven als Nahrung eine gewisse Rolle spielen, daneben aber auch Meeresalgen und animalische Kost.

Mir standen 12 Zoëen zur Untersuchung, von denen 9 einen leeren Magen hatten, während 3 von ihnen chitinige Teilchen und in einem Falle noch ein Stückchen von Biddulphia aufwiesen. 5 Tiere des 1. Jugendstadiums, die aus einer Brutnetzprobe stammten, hatten Copepodenspermatophoren, Diatomeen und in einem Falle einen Copepoden gefressen. 


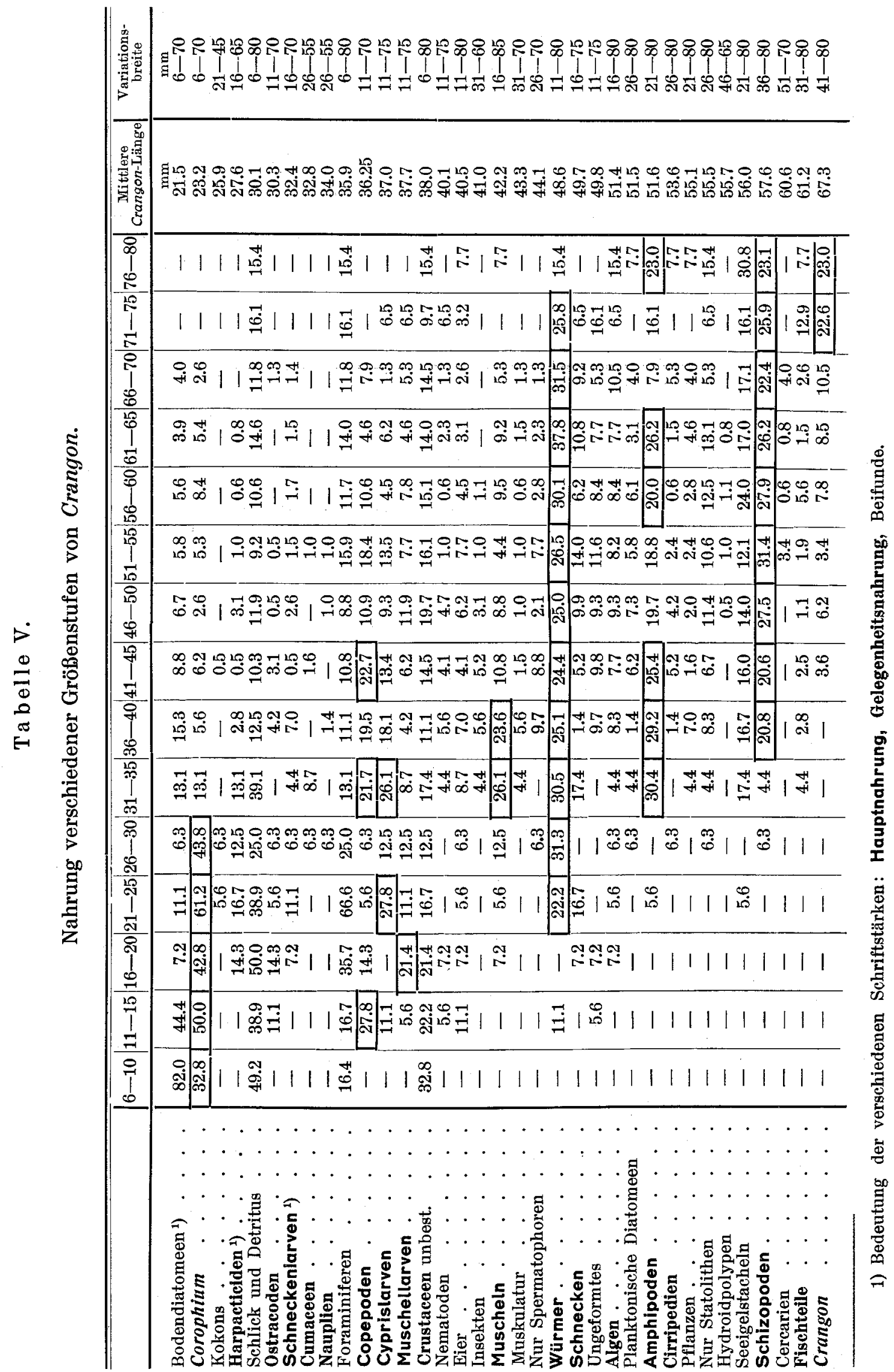


Die jungen Garnelen sind als erste Bodenstadien etwa $5 \mathrm{~mm}$ lang. In der Tabelle $\mathrm{V}$ sind daher von dieser Größe an die Größenstufen aufgeführt. Auf dem brackigen Watt wachsen die Tiere zur Geschlechtsreife heran, die ungefähr bei $40 \mathrm{~mm}$ im Durchschnitt (HAviNGA) eintritt. Die Längenzunahme ist bei Männchen und Weibchen bis zu dieser Größe einander ähnlich, dann aber bleibt das Wachstum der Männchen hinter dem der Weibchen zurück. Die Männchen sind also bei gleichem Alter relativ kleiner als die Weibchen. Nach Havinga's Untersuchungen sind in allen Monaten vorwiegend die Längen $40 \mathrm{~mm}$ und $46 \mathrm{~mm}$ unter den Männchen vorhanden. In einigen Monaten überwiegen daneben auch Längen von 32,36 und $38 \mathrm{~mm}$. Die meisten der laichreifen Weibchen bewegen sich in ihrer Länge um $55 \mathrm{~mm}$ herum. Die Jahreszeiten unterscheiden sich inbezug auf das Vorkommen eiertragender Weibchen darin, daß im Frühjahr diese $52 \mathrm{~mm}$ und $61 \mathrm{~mm}$ lang sind und im Herbst 55, 66 und $73 \mathrm{~mm}$. Diese Ergebnisse von Havinga können auf die Verhältnisse in der Elbmündung im allgemeinen übertragen werden, wie bisher unveröffentlichte Untersuchungen von A. MoLTzaHn ( $\dagger$ ), Cuxhaven, ausweisen.

Die Tabelle $\mathrm{V}$ beleuchtet die Nahrungsverhältnisse bei den verschiedenen Größenstufen der Garnele. Diese folgen sich von links nach rechts mit einem Spielraum von $5 \mathrm{~mm}$ Unterschied. Die in den Mägen vorgefundenen Gegenstände sind durch drei verschiedene Schriftstärken als Hauptnahrung, Gelegenheitsnahrung und Beifunde gekennzeichnet. Die Zahlen in der Tabelle geben an, in wieviel von hundert Mägen der betr. Längengruppe sich der angezeigte Gegenstand befand. Diese folgen einander von oben nach unten, und ihre Reihenfolge ist bestimmt durch die Mittelwerte von Garnelengrößen, die errechnet worden sind für jeden Gegenstand, wie Seite 132 angegeben ist. Die Werte finden sich von oben nach unten wachsend in der vorletzten senkrechten Spalte. Die letzte senkrechte Spalte zeigt, wie schon ein Blick auf die Gesamttabelle lehrt, daß die Längenvariationsbreite für die Gegenstände sehr groß ist. Demnach nimmt die Garnele im Laufe ihres Lebens keinen plötzlichen Nahrungswechsel vor, wie es bei anderen Tieren beobachtet worden ist (vergl. Ladiges 1934, HeRTLING 1930). Von den Hauptbeutetieren sind solche Anteilzahlen umrahmt, die über $20 \%$ der untersuchten Mägen jeder Längengruppe ausmachen. Dadurch stellt die Gesamttabelle deutlicher dar, daß ein langsamer Obbergang zu andersartiger Nahrung stattfindet mit dem Größerwerden der Garnele. In diesem Übergang zeigt sich eine erste Stufe bei etwa $30 \mathrm{~mm}$, eine zweite bei etwa $45 \mathrm{~mm}$, während die großen Tiere die Nahrungsqualität nur noch unwesentlich verändern. Die folgende Übersicht zeigt die Rangordnung, die die verschiedenen Nährorganismen innerhalb der Längengruppen einnehmen. Auch hier sind nur die Anteilzahlen über $20 \%$ herangezogen.

Rangordnung der Hauptbeutetiere:

\begin{tabular}{|c|c|c|c|c|c|}
\hline $\mathrm{mm}$ & 1. & 2. & 3. & 4. & 5. \\
\hline $6-10$ & Corophium & 一 & - & - & - \\
\hline $11-15$ & Corophium & Copepoden & - & - & - \\
\hline $16-20$ & Corophium & Muschellarven & - & - & $\ldots$ \\
\hline $21-25$ & Corophium & Cyprislarven & Würmer & - & - \\
\hline $26-30$ & Corophium & Würrmer & - & - & - \\
\hline $31-35$ & Würmer & Amphipoden & Muscheln & Cyprislarven & Copepoden \\
\hline $36-40$ & Amphipoden & Würmer & Muscheln & Schizopoden & - \\
\hline $41-45$ & Amphipoden & Würmer & Copepoden & Schizopoden & - \\
\hline $46-50$ & Schizopoden & Würmer & - & - & - \\
\hline $51-55$ & Schizopoden & Würmer & - & - & - \\
\hline $56-60$ & Würmer & Schizopoden & Amphipoden & - & - \\
\hline $61-65$ & Würmer & Schizopoden & Amphipoden & - & - \\
\hline $66-70$ & Würmer & Schizopoden & - & - & - \\
\hline $71-75$ & Würmer & Schizopoden & Crangon & - & - \\
\hline $76-80$ & Schizopoden & Amphipoden & Crangon & - & - \\
\hline
\end{tabular}

Für die jungen Garnelen bis $30 \mathrm{~mm}$ Länge steht Corophium an erster Stelle, von $30 \mathrm{~mm}$ bis $45 \mathrm{~mm}$ Würmer und Amphipoden, dann wechseln ab, bis zu den größten, Würmer mit Schizopoden. Die Längen $30-45 \mathrm{~mm}$ weisen gegenüber den anderen Gruppen 
eine bemerkenswerte Nahrungsbreite auf, die wohl auf die Differenzierung der Geschlechter und die Folgen dieser Tatsache zurückzuführen ist. Bei den Größen $70-80 \mathrm{~mm}$ rückt der Kannibalismus weit in den Vordergrund.

Die Männchen unterscheiden sich in der Nahrung schon dadurch von den Weibchen, daß sie wegen durchschnittlich geringerer Körpergröße und der damit verbundenen kleineren Mundöffnung, sich mit Vorliebe den kleineren Nährtieren zuwenden: Die Weibchen überdies bedürfen zur Erzeugung von Nachkommen einer intensiveren Ernährung. An dem Copepoden Eurytemora beispielsweise stellte A. BurckHARDT (1935) fest, daß die Männchen im Mittel $14 \%$ weniger fräßen als die gleichgroßen Weibchen. Dabei haben die ersteren auch eine besondere Vorliebe für kleinere Formen (S. 32). Für Weibchen mit Geschlechtsprodukten ging gegenüber solchen ohne Eier ein Nahrungsüberschuß von 10 bis $12 \%$ hervor (S. 40). Bei der Untersuchung der Mageninhalte männlicher Garnelen fiel immer wieder auf, daß die Nahrung sowohl aus einer größeren Anzahl von Typen wie auch einer größeren Anzahl von Individuen an Beutetieren bestand, als es bei den weiblichen Garnelen der Fall war. Diese Tatsache charakterisiert die Männchen als aktiver in der Sammeltätigkeit; in bezug auf die Qualität der Nahrung ist kein wesentlicher Unterschied festzustellen. Folgende Aufstellung allerdings fördert zutage, daß immerhin einige Nährtiertypen von dem einen Geschlecht mehr bevorzugt werden als vom anderen.

\begin{tabular}{|c|c|c|c|c|c|c|c|c|}
\hline Von & 100 & Cyprislarvenfressern & waren & 31 & männlich & und & 69 & weiblich, \\
\hline " & " & Würmerfressern & 》 & 35 & » & » & 65 & " \\
\hline$\eta$ & $\eta$ & Muschelfressern & ” & 41 & $\eta$ & $\eta$ & 59 & " \\
\hline ” & $\eta$ & Amphipodenfressern & ” & 47 & $\eta$ & 》 & 53 & $n$ \\
\hline$n$ & » & Schneckenfressern & " & 53 & 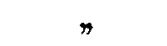 & » & 47 & $"$ \\
\hline 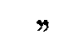 & » & Copepodenfressern & s & 56 & $n$ & » & 44 & $"$ \\
\hline " & $"$ & Schizopodenfressern & $\eta$ & 63 & » & ” & 38 & » \\
\hline
\end{tabular}

Wir sehen, daß bei gleicher Folge der verschiedenen Fresser die Häufigkeit, in der Weibchen Anteil haben, von unten nach oben wächst und der Anteil der Männchen entgegengesetzt von oben nach unten. Bei Schizopodenfressern und Copepodenfressern überwiegen Männchen und bei Cyprislarven-, Würmer- und Muschelfressern die Weibchen. Diese Werte werden in starkem Maße durch die Verschiedenheiten im Auftreten der Nährtiere wie der Zehrer jahreszeitlich und örtlich verändert, und somit wird die Bedeutung der Nährtiere für die beiden Geschlechter gegeneinander verschoben.

Unter den Männchen fanden sich $33 \%$ mit leerem Magen, unter den Weibchen $42 \%$. Der durchschnittliche Füllungsgrad der Mägen erwies sich bei einem geringen Mehr für die Männchen als ziemlich gleich, nämlich 63.5:62.4 (voll $=100)$.

P. F. MEYER (1934) berichtet, daß die Weibchen, die dicht vor der Eiablage stehen, sich in schützende Ecken des Aquariums verkriechen, und daß sie jegliche Nahrungsaufnahme verweigern. Dabei liegt der völlig leere Magen zusammengeschrumpft unter dem Eierstock, sodaß man "durchaus den Eindruck hat, als ob der Magen rein physiologisch keine Nahrung aufnehmen könnte". Nach der Eiablage aber verliert das Weibchen seine Scheu und nimmt wieder Nahrung zu sich, bewegt sich überhaupt so frei wie Weibchen ohne Eibehang. Wieweit nun übt der Grad der Ovarienausbildung einen Einfluß auf die Freßtätigkeit aus? In der Gradeinteilung hielt ich mich an die, welche P. F. MEYER angibt, mit dem Unterschiede, daß ich auf $\mathrm{D}$ erkannte, wenn die Lappen des Ovariums das Ende des zweiten Abdominalsegmentes erreichten, wobei nicht immer der Magen „völlig zusammengefaltet und leer" erschien.

$\begin{array}{lccccc}\text { Ovarienausbildung: } & \mathrm{O} & \mathrm{A} & \mathrm{B} & \mathrm{C} & \mathrm{D} \\ \text { Leere Mägen in \% : } & 32.0 & 32.8 & 27.1 & 20.5 & 62.0 \\ \text { Ovarienausbildung: } & \mathrm{O} & \mathrm{A} & \mathrm{B} & \mathrm{C} & \mathrm{D} \\ \text { Mittlere Magenfüllung (voll }=100): & 55.7 & 58.8 & 58.8 & 63.0 & 44.5\end{array}$

Die beiden Reihen korrespondieren sinngemäß durchaus miteinander und können wie folgt gedeutet werden: Solange die Ovarien noch keinen erheblichen Raum einnehmen, etwa von $\mathrm{O}$ bis $\mathrm{B}$, kommen einerseits ziemlich gleiche Werte an leeren Mägen vor und andererseits hält sich der Füllungsgrad auf ziemlich gleicher Höhe. Wenn aber das Wachstum der Ovarien in vollem Gange ist, also das Nahrungsbedürfnis erheblich ist, fällt der Hundertsatz an leeren Mägen und der mittlere Füllungsgrad steigt an. Dies gilt für das Stadium C. (In Rechnung zu ziehen ist der subjektive Fehler bei der Schätzung 
des Reifegrades und der Magenfüllung.) Die beiden Werte des Grades D sind eindeutig. Hier ist das Lumen des Magens eingeengt durch das starke Ovarium.

Da die Weibchen neben den Wachstumshäutungen noch den Begattungshäutungen unterliegen, tritt die Frage auf, ob Weibchen mit Eibehang von solchen ohne Eier durch unterschiedliche Freßtätigkeit getrennt sind, abgesehen davon, daß die Weibchen dann in ihrer Nahrungssuche behindert sind, wenn das Herannahen des Schlüpfens der Larven sie veranlaßt, sich abwechselnd in sauerstoffreiches Wasser und wieder, zum Schutze der Brut, in den Sand zu begeben. Leere Mägen verteilen sich wie folgt:

$\begin{array}{cccccc} & \mathrm{O} & \mathrm{A} & \mathrm{B} & \mathrm{C} & \mathrm{D} \\ \begin{array}{c}\text { Weibchen mit Eiern } \\ \text { in } \%\end{array} & 36 & 7 & 17 & 21 & 69 \\ \begin{array}{c}\text { Weibchen ohne Eier } \\ \text { leere Mägen }\end{array} & 47 . & 53 & 25 & 53 & 69\end{array}$

Wir stellen fest, daß der Durchschnitt der Hundertsätze bei Weibchen ohne Eier höher ist als bei den Weibchen mit Eiern. Das mag seinen Grund in den verschiedenen Häutungen haben, da aber noch eine Reihe von Fragen über das Verhalten der Weibchen bei den verschiedenen Formen der Geschlechtsprodukte offen sind, können keine präzisen Aussagen gemacht werden.

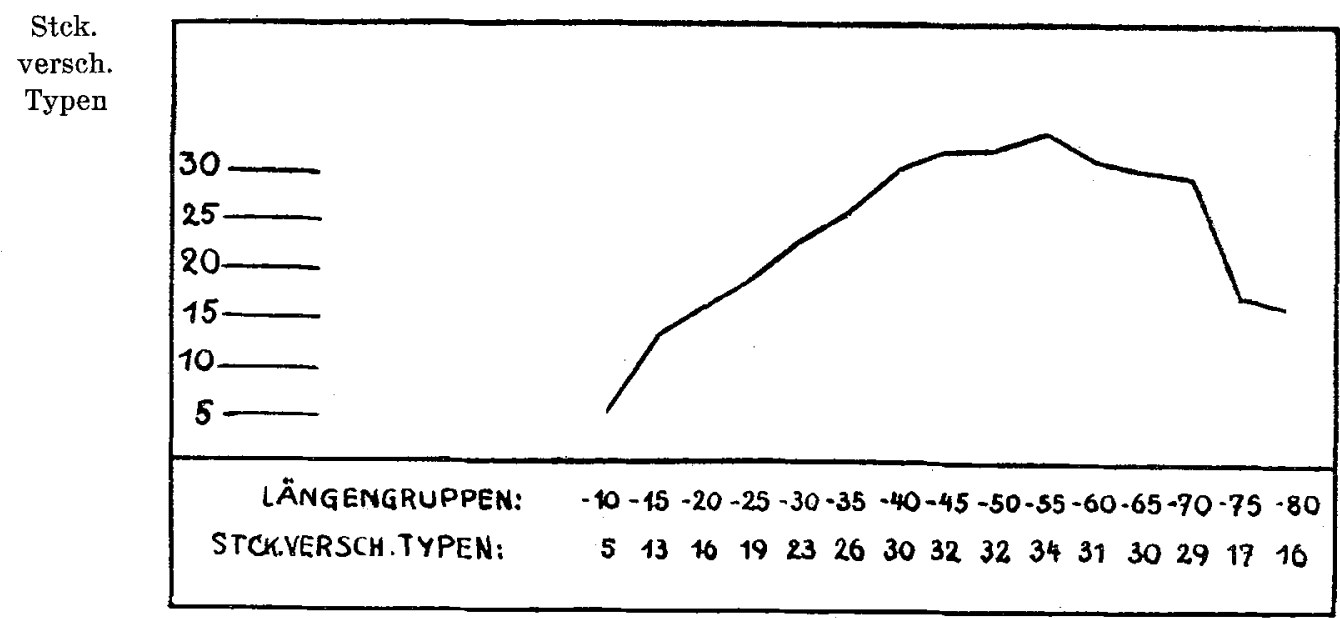

Abb. 1. Nahrungsbreite bei den Größengruppen (gemessen an der Anzahl verschiedener Nahrungstier-Typen).

Im ersten Lebensjahr beträgt das Wachstum der Garnele nach P. F. MEYER etwa $40 \mathrm{~mm}$, nach EhrenBaum und Havinga $40-46 \mathrm{~mm}$. Es ist in seiner Geschwindigkeit abhängig von der Temperatur: Die jungen Garnelen wachsen in drei Sommermonaten nach P. F. MEYER um $16 \mathrm{~mm}$ und in fünf Wintermonaten nur um $7 \mathrm{~mm}$ im Durchschnitt. Die Schnelligkeit des Wachstums ist ja auch eine Funktion der Nahrungszufuhr, und es ist kein Zweifel, daß sich im Sommer ein größerer Nahrungsvorrat findet als im Winter. MEYER's „Wachstumskurve“ (S. 148 B.) besagt, daß das Wachstum der jungen Garnelen bis etwa 30-35 mm schnell ansteigt, um dann nur langsam fortzuschreiten. In welcher Beziehung steht das Wachstum nun zu der Nahrungszufuhr?

Um diese Frage zu prüfen, habe ich erstens die Nahrungsbreite für jede Garnelenlänge, ausgedrückt durch die Anzahl der verschiedenen Gegenstände, die sich überhaupt vorfanden, in der Kurve in Abb. 1. dargestellt. Denn je größer das Nahrungsbedürfnis ist, desto mehr verschiedenen Beutestücken wird sich die Garnele zuwenden. Die Kurve steigt rasch an bis etwa bei $45 \mathrm{~mm}$, hält sich dann auf ziemlich gleicher Höhe bis zum Abfall bei den ganz großen Tieren. Es wird also das Freßbedürfnis bei den jungen Tieren schnell größer, auch die Wachstumgeschwindigkeit ist groß, erreicht das Maximum mit der Geschlechtsreife und behält es, solange die Weibchen noch Eier tragen.

In diese Kurve sind einbezogen alle Gegenstände aus den Garnelenmägen ohne Rücksicht auf ihren Nahrungswert. Ein Nährmittel hat nun einen umso größeren Wert, je mehr abbaufähiges Material es zu liefern vermag. Außerdem aber ist sein Wert für den Fresser noch daran zu erkennen, wie sehr dieser ihm nachstellt und es gegenüber anderen Nährmitteln bevorzugt. Eine solche Wertung hat im ersten Abschnitt Seite 116 durch zwei Momente stattgefunden: einmal durch die Einteilung der Typen in Hauptund Nebennahrung und zum anderen durch die Häufigkeit ihres Erscheinens im Gesamt- 
material, ausgedrückt durch den Hundertsatz. Wenn wir nun diesen Hundertsatz, beispielsweise der Schizopoden von $16.80 \%$, multiplizieren mit dem Schizopoden-Hundertsatz beispielsweise der Größengruppe $36-40 \mathrm{~mm}$ aus der Tabelle V (S. 135) von $20.8 \%$, so erhalten wir einen Wert von 349.44, der unbenannt ist und der, da er das Produkt zweier Hundertsätze ist, eine abstrakte relative Häufigkeit darstellt. Multiplizieren wir nun den Schizopoden-Hundertsatz $16.80 \%$ mit dem Schizopoden-Hundertsatz einer anderen Größengruppe z. B. $51-55 \mathrm{~mm}$ von $31.4 \%$, so bekommen wir mit der Zahl 653.12 einen höheren Wert für diese Längengruppe als für die erste. Diese beiden Werte sagen über das Verhalten der Garnelen der beiden entsprechenden Größengruppen gegenüber der Schizopodennahrung nichts Neues aus; wenn wir aber zu solehen Berechnungen die Hauptnährmittel jeder Längengruppe heranziehen, und zwar nur jene, die in mehr als $20 \%$ der Mägen von Garnelen der betr. Längengruppe vorkommen, so ergibt das arithmetische Mittel der Produkte einen Wert, den man als Maß für die Ernährungsintensität jeder Längengruppe betrachten kann. Dieses Maß gestattet uns also, die Ernährungsintensität der verschiedenen Garnelengrößengruppen untereinander zu vergleichen. Die Durchführung einer solchen Berechnung zeigt das folgende Beispiel der Größengruppe $36-40 \mathrm{~mm}$ :

\begin{tabular}{ll} 
Schizopoden & $20.8 \times 16.8=349.44$ \\
Amphipoden & $29.2 \times 28.0=817.60$ \\
Würmer & $25.1 \times 27.3=685.23$ \\
Muscheln & $23.6 \times 16.4=385.86$ \\
\hline
\end{tabular}

$$
\overline{2238.13}: 4=559.53
$$

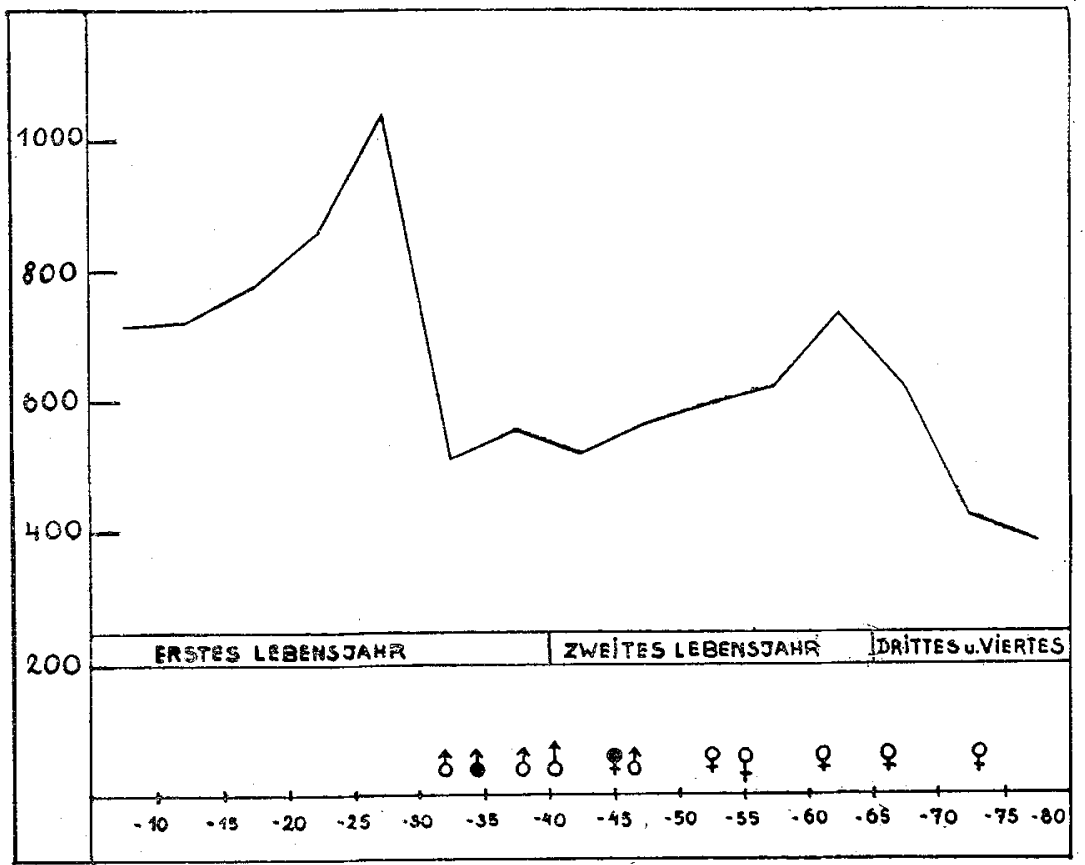

Abb. 2. Ernährungsintensität (Summen von Produkten des Hundertsatzes vom Gesamtmaterial, wo das betreffende Nahrungstier vorkam, und des entsprechenden Hundertsatzes, in welchem dasselbe Nahrungstier in den Mägen der betreffenden Größßengruppe vorkam).

Für alle Größenstufen so berechnet bekommen wir folgende Werte:

$\begin{array}{rrrrrrrrrrrrrrrr}\mathrm{mm} & -10 & -15 & -20 & -25 & -30 & -35 & -40 & -45 & -50 & -55 & -60 & -65 & -70 & -75 & -80 \\ \varnothing & 719 & 727 & 777 & 858 & 1040 & 512 & 560 & 520 & 564 & 595 & 621 & 736 & 618 & 423 & 388\end{array}$

Die Kurve in Abb. 2 stellt diese Werte graphisch dar und läßt eine Reihe von Schlüssen zu.

Da P. F. MeYER mit seiner Wachstumskurve feststellte, daß das Wachstum der kleinen Garnelen bis etwa $30 \mathrm{~mm}$ in erheblicher Schnelligkeit vonstatten geht, muß nicht nur die Anzahl der Nährmittel schnell mehr werden (Abb. 1, Seite 138), sondern auch die Qualität und damit 
auch die Ernährungsintensität groß sein und von steigender Tendenz. Das Kurvenbild liegt im ersten Teil bis $30 \mathrm{~mm}$ erheblich höher als der zweite Teil. Wenn man die dbzgl. Durchschnittswerte errechnet, ist der Unterschied 824.2:553.7. Das zeigt schon, daß die jugendlichen Garnelen sich kräftiger zu ernähren bestrebt sind, indem sie sich vorzüglich an wertvolle Nahrungstiere halten. Außerdem steigt die Kurve ganz in Übereinstimmung mit den Wachstumskurven von P. F. MEYER und Havinga sehr. schnell an, viel schneller als es bei den folgenden Längengruppen wieder vorkommt. Auf der Abscisse bei den Längenangaben sind die Gipfelpunkte für das Erscheinen von Männchen bzw. Weibchen eingezeichnet, wie sie in dem Material von Havinga erschienen sind.

So stellen sich für den Ablauf des Wachstums einer Garnelenpopulation vier verschiedene Ernährungsperioden heraus. Die erste Periode nach dem Larvenleben ist die Jugend mit starker Ernährungsintensität, die zweite die der geschlechtlichen Differenzierung mit dem überwiegenden Vorkommen reifer Männchen, die dritte die Periode der Laichtätigkeit, die wieder durch den Nahrungsbedarf hervorsticht. Die vierte Periode ist die der Laichmüdigkeit und des Absterbens.

Die erste und zweite Periode erfüllt nebst Larvenleben etwa das erste Lebensjahr, die dritte das zweite Lebensjahr und die vierte Periode umfaßt Tiere des dritten und vielleicht noch des vierten Lebensjahres.

In bezug auf die Ernährung stellt die zweite Periode ein Charakteristikum für das Verhalten der aktiven Männchen und der noch vom Laichgeschäft unbeschwerten Weibchen dar. Sie wenden sich vielen verschiedenen Nährtieren zu, ohne eine besondere Auswahl in der Qualität zu treffen. Frst in der dritten Periode hat die Ernährungsintensität wieder ansteigende Tendenz wegen der Laichtätigkeit und dem damit verbundenen größeren Bedarf an Nährstoffen zur Eibildung und Restitution nach der Eiablage.

\section{Die Nahrung an den verschiedenen Örtlichkeiten.}

a) Verbreitung der Nährtiere.

Bevor wir untersuchen, was die Garnelen an den verschiedenen Örtlichkeiten des Gebietes gefressen haben, wollen wir einen Überblick gewinnen über die Besiedlung des Gebietes. Gewiß wäre es ideal, ein Gebiet derartig zu „bonitieren“, daß ein unmittelbarer Vergleich zwischen der vorhandenen Nahrung und der aufgenommenen Nahrung angestellt werden könnte. Ein solches Unternehmen aber ist im Rahmen vorliegender Untersuchungen aus verschiedenen Gründen unausführbar. So mannigfach nämlich die topographische Ausbildung des Gebiets ist, so verschiedengestaltig sind auch die ökologischen Verhältnisse und die sie modifizierenden Umweltsfaktoren. Nicht nur das flecken-, nester- und scharenweise Auftreten der Nährtiere wirkt erschwerend, sondern auch die Frage, ob die Nährtierart in d e $r$ Größe und Lebensform, in der sie vorgefunden wurde, zur Aufnahme geeignet ist. Außerdem finden sich in den Mägen der Zehrer vielfach Arten, die durch Boden- bzw. Netzproben nicht ermittelt werden konnten. In folgender Darstellung nun halte ich mich an die Abstraktionen, die HAGMEIER (1935), WoHLEnBERg (1931), ThAMDRUP (1927) u. a. für die Bodenbesiedlung ähnlicher Gebiete vorgenommen haben, und für das Vorkommen von Plankton an die Untersuchungen von K. THIEMANN (1934) im Mündungsgebiet der Elbe. Die einzelnen Bonitierungsproben, die hier angegeben werden und von mir ausgeführt worden sind, sind nicht paradigmatisch zu werten, sie sollen nur einen Begriff geben vom Vorkommen von Nährtieren. Für weitere Einzelheiten verweise ich auf die Schriften der genannten Autoren; im übrigen müßten Untersuchungen im Ellbmündungsgebiet erst angestellt werden. Darstellungen des Gebietes auf Karten geben K. Thiemann, WulfF und BÜCKMANN u. a., auf die hiermit verwiesen sei.

Die Bodenbesiedlung des Untersuchungsgebietes im Ganzen gehört zu der MacomaGemeinschaft (C. G. J. PETERSEN 1918); das Planktonvorkommen ist als Küstenplankton sehr

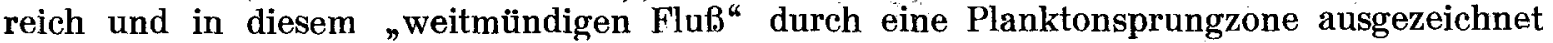
(Thremann).

Die Untergemeinschaften der Bodenbesiedlung zeigen große Anklänge an jene, die HAgmeIER, THAMDRUP und andere für ihre Untersuchungsgebiete aufstellten, sind für die Elbmündung natürlich ebenso durch besondere Verhältnisse modifiziert wie beispielsweise REMANE sie in der Kieler Bucht verändert vorfand. Wie mich eine Reihe von Bonitierungsproben lehrten, können wir die Untergemeinschaften HAGMEIER'scher Prägung im ElbeAestuar wiederfinden: 


\section{Hydrobia-Pygospio-Corophium-Zone \\ 2. Arenicola-Cardium-Macoma-Zone \\ 3. Tapes pullastra-Zone \\ 4. Amphipholis-Zone.}

Die ersten beiden Zonen finden sich auf dem langgestreckten Hochwatt von Kugelbake-Sahlenburg bis Scharhörn vor, streckenweise in konkreter Ausbildung. Im allgemeinen paßt die Einteilung für das ganze Hochwatt. Die südliche Grenze des ersten Gürtels verläuft auf der Wasserscheide Elbe-Weser, die nördliche Grenze in vielen Windungen und Ein- und Ausbuchtungen von der Kugelbake in Richtung der Quellpriele des Buchtloches an der Wasserscheide entlang, die Quellpriele des Eitzenloches überschneidend, um in breitem Gürtel Neuwerk zu umlagern. Hier am nördlichen Vorland deckt sich die Ausdehnung der Zonen mit den Angaben ThamdRuP's über sein Gebiet sehr stark (vergl. Buhnenlinie). Nach Nordwesten verläuft sich dieser Gürtel im Prielsystem der Hundebalje. - Die zweite Zone lagert sich flußwärts vor die erste Zone und reicht bis an die Niedrigwasserlinie, nimmt also einen weit größeren Raum ein. - Von den drei Prielen reichen die Hundebalje und das Buchtloch zu einem großen Teil in den Hydrobia- usw. Gürtel hinein, während das verhältnismäßig flach ausgedehnte Eitzenloch in seinem ganzen Verlauf zu dem Arenicola- usw. -Watt gehört. Die ersteren haben an ihren tiefsten Stellen Biocönosen, die starke Anklänge an die "Tapes-Gemeinschaft" haben. Hier finden wir aber auch einen beweglichen Grund mit großen Schillmengen vor. - Ebenfalls die Abhänge und Sände weisen einen „Tapes-Grund" auf. In den tiefsten Stellen der äußeren Flußmündung und am Ausläufer des Großen Vogelsandes zeigt das Vorhandensein von Sabellaria-Bauten die Ähnlichkeit mit der Amphipholis-Gemeinschaft an.

Hydrobia ulvae ist wohl als Charakterform des höchsten Teiles des Watts anzusprechen, hat aber Wohnstätten auch in den tieferen Teilen des Untersuchungsgebietes (Trusheim (1929), Richter (1929), Thamdrup (1935) usw.). Die 0-Gruppen sind nach Thamdrup zahlreich im äußeren Watt, und nach HeNKING (cit. nach ANKEL 1929) erscheinen sie noch nach Verlust ihres Velums im "Auftrieb".

Würmer kommen überall vor, je nach Bodenbeschaffenheit tubicole oder errante. Pygospio beobachtete ich auf dem ganzen Watt, und auch an den Hängen und Sänden fanden sie sich in wechselnder Dichte. Außerdem kommen in weichem Schlickwatt stellenweise sehr dicht Nereis diversicolor vor, welche anscheinend unter Einwirkung der Sonneneinstrahlung oft ihre Wohnröhren verlassen und moribund den kleinen Wattgarnelen zum Opfer fallen können. Errante Würmer sind sehr zahlreich auf den Sohlen der Priele, sofern nicht Muschelschill einen beweglichen Grund anzeigt. Auch auf dem steinigen Grund in der Nähe der Kugelbake und vor allem zwischen den Sabellaria-Bauten, die auf der Höhe von Scharhörn in einiger Ausdehnung im Flußbett vorkommen und am Ausläufer des Großen Vogelsandes einen größeren Raum einnehmen, erscheinen errante Würmer.

Corophium volutator ist ein ausgesprochener Hochwatt-Amphipode, der dort stellenweise in ungeheuerer Dichte auftritt. Nach Thamdrup lebt er auch in feinem Sand. Im Untersuchungsgebiet ist er fast ganz an das Gebiet mit geringster Wasserbedeckung gebunden, findet sich vereinzelt auch auf dem vorgelagerten Arenicola-Watt, wohin er aber durch Wind und Wellen verschlagen werden kann, ohne sich fleckenweise anzusiedeln. Selbst in einem Brutnetzfang im Fahrwasser habe ich junge Corophien angetroffen.

Die ständig auf dem Watt lebenden autochthonen Tiere des Arenicola-Gürtels spielen für die Ernährung der Garnele eine geringe Rolle, aber ihre Larvenformen und 0-Gruppen, die sich in den Rippeln, Pfützen und Rinnsalen ansammeln.

Einige Proben aus den beiden angegebenen Zonen mögen die Wattbesiedlung veranschaulichen, wie man sie bei Ebbe mit dem Wattstecher feststellen kann:

1.) 7. X. 1933. Nr. $5.7 \mathrm{~cm}$ tief, 25 qcm. Schlickboden:

204 Corophium volutator versch. Größe

236 Nematoden

6 Nereis diversicolor

45 Macoma baltica und Scrobicularia plana

25 Hydrobia ulvae

540 Foraminiferen (fast ausschließlich Polystomella) massenhaft Seeigelstacheln

sehr häufig Kotballen 
2.) 22. III. 1934. Nr. $1.7 \mathrm{~cm}$ tief, $25 \mathrm{qcm}$. Feiner Sand:

1036 Foraminiferen (Polystomella)

225 Hydrobia ulvae ad.

36 " " juv.

145 Ostracoden

135 junge Muscheln

3 Nematoden

massenhaft Seeigelstacheln

Muschelbruchschill, 35 Schuppen (Blütenhüllen) von Zostera, 5 Fischschuppen, 1 Nereiskiefer, 2 Fischwirbel.

3.) 1. V. 1934. Nr. 1-10. Schnitt über den kleinen Vogelsand. $7 \mathrm{~cm}$ tief, $25 \mathrm{qcm}$. Meist grober Sand:

$\begin{array}{lrrrrrrrrrr} & 1 . & 2 . & 3 . & 4 . & 5 . & 6 . & 7 . & 8 . & 9 . & 10 . \\ \text { Corophium } & 1 & 0 & 0 & 0 & 0 & 0 & 0 & 0 & 0 & 0 \\ \text { Bathyporeia } & 0 & 0 & 0 & 1 & 1 & 0 & 1 & 1 & 0 & 1 \\ \text { Hydrobia } & 4 & 7 & 15 & 4 & 5 & 3 & 1 & 4 & 15 & 22 \\ \text { Muscheln } & 3 & 2 & 1 & 0 & 4 & 2 & 10 & 3 & 6 & 1 \\ \text { Würmer } & 2 & 3 & 6 & 0 & 0 & 0 & 7 & 0 & 1 & 0 \\ \text { Harpacticiden } & 4 & 19 & 8 & 0 & 0 & 1 & 10 & 3 & 10 & 17 \\ \text { Ostracoden } & 2 & 1 & 0 & 0 & 4 & 4 & 7 & 4 & 6 & 7 \\ \text { Nematoden } & 493 & 104 & 116 & 80 & 132 & 8 & 95 & 12 & 147 & 34 \\ \text { Foraminiferen } & 32 & 54 & 47 & 45 & 78 & 69 & 247 & 93 & 278 & 391 \\ \text { Pygospio-Röhren } & 70 & 25 & 30 & 10 & 5 & 12 & 50 & 5 & 2 & 2 \\ \text { Arenicola pro qm } & 0 & 30 & 30 & 30 & 25 & 20 & 10 & 15 & 4 & 0\end{array}$

Vereinzelt angetroffen: Bathyporeia, Corophium, Littorina.

Auch Thamdrup(l.c.) hatbeobachtet, daß „die Oberfläche der Sandwatten eine wimmelnde Menge von Copepoden, Ostracoden, Nematoden und Infusorien " enthält; und ReMane (1934) hat die Mikrofauna einer näheren Untersuchung unterzogen. Inbezug auf das Vorkommen weiterer kleiner Nährtiere berichtet Thamdrup (1927 S. 29), daß das lokale Plankton des Wattgebietes sehr dürftig ist, aber das herbeigeschwemmte Meeresplankton zahlreich (ebenso HAGMeIER, 1927 S. 13). Es gelangt viel Plankton aufs Watt und nur wenig kehrt zurück, sodaß "wohl die Annahme begründet ist, daß das zurückgehaltene Plankton in irgend einer Gestalt der Fauna zugute kommt" (Thambrup).

Nach ThiEmann nun besitzt die Elbmündung eine Planktonsprungzone, die ihre stärkste Ausbildung zwischen den Feuerschiffen Elbe III und Elbe IV, etwa 12,8 km von Cuxhaven entfernt, hat. Durch die Tidenbewegungen verschiebt sich dieses Kerngebiet natürlich sowohl flußaufwärts wie auch flußabwärts. Danach stehen folgende Plätze mehr oder weniger unter dem Einfluß dieser Planktonsprungzone: Der Gelbsand bis zum Kratzsand, auf der anderen Seite zwischen Kugelbake und dem Eitzenloch. Folgende Proben mögen ein Bild vermitteln von dem Vorkommen vom Plankton. Die Proben sind mit einem Brutnetz gewonnen, das 15 Minuten fischte und der Fang wurde in gleich großer Wassermenge aufgeschwemmt, sodaß die Zahlen vergleichbar sind:

$\begin{array}{lcc} & \text { Buchtloch } & \text { Eitzenloch } \\ \text { Copepoden } & 54 & 96 \\ \text { Cyprislarven } & 18 & 3 \\ \text { Schneckenlarven } & 70 & 6 \\ \text { Muschellarven } & 17 & - \\ \text { Copep.-Nauplien } & 16 & 9 \\ \text { Cirr.-Nauplien } & 39 & 7 \\ \text { Brach.-Megalopen } & 1 & - \\ \text { Brach.-Zoëen } & 1 & - \\ \text { Echinod.-Larven } & 4 & 1 \\ \text { Nematoden } & - & 1 \\ \text { Spioniden-Larven } & 13 & 17 \\ \text { Medusen } & 13 & -\end{array}$

Außerdem in beiden Proben: Bellerochea, Sagitta; Biddulphia, Coscinodiscus, Melosira, Chaetoceras, Rhizosolenia, Ceratium, Noctiluca, Eucampia. 
Die Planktonten unterliegen den Einwirkungen der Tidenströmungen in ihrer Verteilung über das im Bodenrelief verschieden ausgebildete Gebiet der Sprungzone und zwar "findet augenscheinlich rhythmische, teils passive, teils aktive Auf- und Abbewegung des Planktons in Abhängigkeit vom rhythmischen Wechsel der Stromgeschwindigkeit statt. Außerdem verschieben die Tidenströme die Lage der Planktonvölker im Strom und bewirken Spülung der Planktonbrutstätten" (Hentschel 1923). So erscheinen in der Tat in der unmittelbaren Nähe des Gelbsandes wie auch vor und in den Löchern Buchtloch und Eitzenloch dichte Copepodenansammlungen und sonstige Planktonten zahlreich. Sie sind dichter an den flachen Abhängen als im Fahrwasser. Ebenso ergeht es den Scharen von Schizopoden, die allerdings anscheinend einen größeren Widerstand gegen Stromversetzung leisten, denn in dichten Scharen erscheinen sie zu gewissen Zeiten in den äußeren Stromgebieten beim Großen Vogelsand, wo sie von den Fischern zentnerweise gefangen werden können („Ködergarnelen“); weiter flußaufwärts zerstreuen sich die Scharen und gelangen wohl aktiv in sämtliche Teile des Gebietes. Selbst die Wattpfützen enthalten oft relativ viel Schizopoden. Die Copepoden und (hier besonders beachtenswert) die Cyprislarven von Balanus und die Larvenformen der Schnecken und Muscheln sind von größerer Passivität. Sie werden daher in den Löchern am zahlreichsten angesammelt und besonders zahlreich in jenen, die der Planktonsprungzone am nächsten kommen, dem Buchtloch und dem Eitzenloch. Der im ganzen tiefere Einschnitt des Buchtloches vermag durch Stauungen des Wassers und der Bildung von Stromwirbeln die Anhäufung von Planktonten mehr zu fördern als das flacher ausgedehnte Eitzenloch, wo eine Sedimentation im Spülsaum stärker ist. Wenn man das Gebiet um den Mittelgrund herum befährt, beobachtet man, daß am östlichen Teil das sogenannte „Kabbelwasser" auftritt, und man kann hier eine starke Wirkung der damit verbundenen Stromstauungen, Wirbel und Stromschatten auf das Vorkommen der Planktonten erwarten. Die Menge ist noch umso größer durch die dort vorhandene Planktonsprungzone. Nach HAGMEIER (1927) können gerade Muscheln hier einen geeigneten Ansatzplatz haben, weil die Gefahr der Verschleppung gering ist, hier ist der Typus "Flachsand“. Während die Copepoden und Schizopoden offenbar ihre Verteilung über das ganze Gebiet vom Strom her erfahren, werden die Larvenformen von gewissen Centralstellen ausgeschickt und auch wieder an gewissen geeigneten Orten sich ansammeln. In bezug auf diesen Vorgang sind die Muschelbänke des Hochwatts besonders zu beachten. An den Quellprielen der Baljen und auf der Wasserscheide zur Weser befinden sie sich und liefern, sofern sie nicht nur Muschelschillbänke darstellen, Muschellarven und Balanus-Nauplien, ebenso sind sie wiederum durch ihre für den Ansatz geeignete Lage Ansatzstätten von Muschellarven und Cyprislarven von Balanus. Die Tidenbewegungen erzeugen durch Aufschwemmen der Larven nach dem Brutfall zusammen mit anderen detritusähnlichen Teilen den Biotop des Mulms, den Spülsaum, das Angeschwemmsel in verschiedener Ausbildung, wo sich nach P. F. MEYER die Garnelen bis zum "Wegschwappen" des Wassers mit Vorliebe aufhalten.

Die Amphipoden sind für die Bodenbesiedlung in den beiden folgenden Zonen als Charakterformen anzusprechen, besonders im Hinblick auf die Garnele. Die verschiedenen Arten haben dabei ihre ziemlich bestimmten Wohngebiete. Gammarus locusta hält sich bevorzugt auf den steinigen Gründen auf, wie sie sich um Kugelbake herum finden, ebenso auf den davor im Fahrwasser gelegenen Mytilus-Flecken. Bathyporeia pelagica bevölkert vor allem die tieferen Teile der sandigen Abhänge, während Bathyporeia Robertsoni den Teil der Schorre bewohnt, der etwa zwischen der Niedrigwasserlinie und ca. 5-6 m Tiefe liegt. ERICH ScHuLz (1937) bezeichnet die Zone eben unterhalb der Mittelniedrigwasserlinie als „Bathyporeia-Haustorius-Zone“, die auf die Zone des ArenicolaWatts folgt.

Einige Bodenproben, z. T. mit dem Petersenschen Bodengreifer genommen, mögen ein Bild vermitteln von der gelegentlichen Dichte des Vorkommens von verschiedenen Nährtieren in beiden Zonen :

A. 24. IX. 1933. Abhang des kleinen Vogelsandes querab Tonne KA. $4 \mathrm{~m}$ tief. Fester Sand. $1 / 10$ qm.

Viele leere Hydrobia-Schalen, 7 Bathyporeia Robertsoni, 6 Bathyporeia pelagica, 8 Pygospio elegans, 1 Nephthys hombergi, Kotballen, Cardium-Schill.

B. 1.) 13. VI. 1933. Abhang hinter dem Buchtloch, Sandschicht, darunter schwarzer Schlick, Bruchschill von verschiedenen Muscheln, 1 Bathyporeia Robertsoni, 4 Bathy- 
poreia pelagica, 3 Capitella capitata, Hydrobia-Schalen sehr häufig, Pflanzenreste, Bewuchs mit jungen Mytilus, Seeigelstacheln.

2.) Inhalt der Mägen von 50 Boden-Fischen versch. Art und Größe am selben Ort. 28 Fische mit mehr als 70 Amphipoden

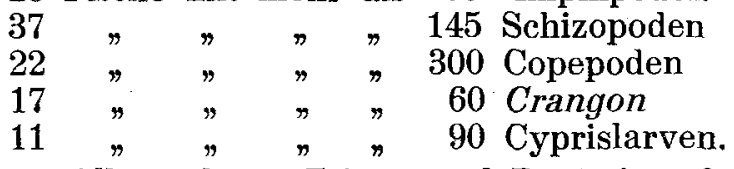

Alle anderen Zehrer und Beutetiere fanden sich in der Einzahl.

C. 23. III. 1934. Abhang vor Buchtloch, $5 \mathrm{~m}$ tief, Sand und Schlick.

1.) 40 Bathyporeia Robertsoni, 15 Bathyporeia pelagica, 5 Nephthys hombergi, 1 Capitella capitata, 1 Spionidenbruchstück, 2 lebende Hydrobien.

2.) 71 Bathyporeia Robertsoni, 2 Corophium juv., 2 Nephthys hombergi, 1 Magelona papillicornis, 1 Paraonis spec., 1 Macoma baltica, Cardium-Schill.

D. 1.) 27. VIII. 1933. Gelbsand (zwischen Tonne 8 und 9), Sand mit festen Schlickklumpen. 12 Macoma baltica $(14-25 \mathrm{~cm}), 9$ Capitomastus minimus, 8 Nephthys hombergi, 1 Pygospio elegans, 3 Gammarus locusta, 3 Hydrobia ventrosa.

2.) Mageninhalte von 57 Stück Carcinus maenas:

21 mit Crangon, 10 mit Muscheln, 10 mit Schizopoden (in einem Magen 2 Stück Praunus flexuosus, in einem anderen 1 Neomysis vulgaris), 3 mit Fischteilen, 4 mit Amphipoden, 2 mit Schnecken, 22 Mägen leer.

E. 10. VI. 1933. Kratzsand. 1 Macoma lebend (2,5 cm), 5 Pygospio elegans, 7 Bathyporeia spec., 1 Polydora caeca, Hydrobia sehr häufig, Muschelschill (auch von jungen, I-Gruppe).

Wir sehen aus Vorhergesagtem, daß die als Nährtiere vor allem in Betracht kommenden Tiere in unserem Brackwassergebiet überall vorkommen können, daß sie aber in der Dichte ihres Vorkommens charakteristische Unterschiede an den verschiedenen Örtlichkeiten aufweisen. Je dichter sie erscheinen, umso mehr werden sie der Garnele zum Opfer fallen, und im folgenden sei untersucht, wie sich die Nahrung in den Mägen der Garnelen von verschiedenen Plätzen voneinander unterscheidet.

b) Mageninhaltsbefunde.

Bei der Auswahl der in Betracht zu ziehenden Örtlichkeiten habe ich mich bemüht, einerseits möglichst gegensätzlich ausgebildete Biotope, andererseits aber auch die Hauptfangplätze der praktischen Garnelenfischerei zu berücksichtigen.

Da nun die Fangzüge, aus welchen ich Stichproben zur Untersuchung entnahm, zumeist über längere Strecken führten, sodaß mehrere Plätze betroffen sein konnten, ist es eine Hauptschwierigkeit, die gewonnenen Proben und ihre Untersuchungsbilder einigermaßen zutreffend auf einen engeren Raum zu begrenzen. Auf Grund folgender Überlegung nun wählte ich die Mitte des Fangzuges als „Fangort“. Der Ort des Einsetzens wie der des Einholens des Netzes sind mir bekannt. Beim Einholen des Netzes wird der Fang auf Deck des Fahrzeuges entleert. Die am Anfang des Zuges gefangenen Garnelen fallen zuerst heraus, weil das Netz ja unten geöffnet wird, während die zuletzt gefangenen Garnelen an den Seiten des Garnelenhaufens herabrieseln, sodaß die Spitze des Hügels, von der durchweg die Stichprobe entnommen ist, aus Garnelen besteht, die etwa von der Mitte des Fangzuges stammen.

Um zu prüfen, wie weit diese Maßnahme berechtigt ist, stelle ich zwei Untersuchungsbilder von Proben einander gegenüber, die beide am 1. XI. 1934, vom gleichen Fahrzeug an fast übereinstimmenden Plätzen genommen worden sind. Der Fangzug der einen Probe verläuft von der Tonne $K$ bis zur Tonne $F$, von der anderen in umgekehrter Richtung von der Tonne F bis zur Tonne K1. Der einzige Unterschied im Verlauf dieser beiden Züge besteht darin, daß ,K-F“ den Ausläufer des Mittelgrundsandes überquert, 
und „F-K1.“ ihm parallel verläuft. Die Untersuchungsbilder geben an, wieviel Stück des betreffenden Beutetieres in 100 Garnelenmägen der Probe enthalten sind:

$\begin{array}{lrr} & \text { K- }-\mathrm{F}^{\star} & \text { "F-K1.“ } \\ \text { Schizopoden } & 111 & \mathbf{1 4 4} \\ \text { Amphipoden } & 48 & 21 \\ \text { Copepoden } & 30 & 33 \\ \text { Hydrobia } & 21 & 18 \\ \text { Fischteile } & 18 & 15 \\ \text { Würmer } & 6 & 6 \\ \text { Muscheln } & 3 & 9\end{array}$

Diese beiden Proben stimmen im wesentlichen miteinander überein; die erste Probe überwiegt im Amphipoden-Vorkommen gegenüber der anderen, die zweite unwesentlich bei Schizopoden gegenüber der ersten. Die Abweichungen sind offenbar eine Folge des Bodenrelief-Unterschiedes, welcher gerade an den Mittelpunkten der Fangzüge hervortritt, während die übrigen Teile ziemlich gleichartig ausgebildet sind: die Garnelen der ersten Probe sind mehr nach dem flacheren Abhang hin orientiert, die der zweiten Probe hingegen nach dem tieferen. Ein dritter Fangzug vom 31. X. 1934 von Tonne J nach dem Feuerschiff Elbe III und wieder zurück nach Tonne $J$ zeigt folgendes Untersuchungsbild:

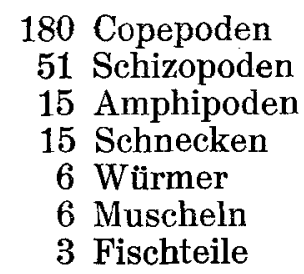

Wenn in diesem Falle die Garnelen der Stichprobe am Anfang oder am Ende der Fangstrecke gefressen hätten, so müßte das Untersuchungsbild dieser Probe denjenigen der beiden anderen Proben sehr stark gleich sein. Sie weicht aber zahlenmäßig von den. beiden anderen stark $a b$ und wird auch in die Nähe des Feuerschiffes lokalisiert.

Nachdem die einzelnen Proben derartig auf einen engbegrenzten Raum bezogen wurden, faßte ich andererseits mehrere nahebeieinanderliegende Proben zusammen, um gewisse Biotope und Örtlichkeiten auf die Verschiedenheiten im Vorkommen der Fresser prüfen $\mathrm{zu}$ können. Jede einzelne Probe zeigt zwei verschieden geartete Untersuchungsbilder. Die eine Art gibt an, wieviel von 100 Garnelen das betreffende Nährtier überhaupt gefressen hatten. Die andere Art stellt die Stückzahl des betreffenden Nährtieres dar, berechnet auf 100 Garnelenmägen der Probe. Die Zahlen der 3 oben herangezogenen Proben sind in letztgenannter Weise gewonnen; die Probe „K-F“ würde in erstgenannter Weise ausgewertet wie folgt aussehen:

$$
\begin{array}{ll}
97 \% & \text { Schizopodenfresser } \\
41 \% & \text { Amphipodenfresser } \\
16 \% \text { Copepodenfresser usw. }
\end{array}
$$

Weiter würden beispielsweise die drei Proben zu der Örtlichkeit „Mittelgrund-West" vereinigt werden. Bei dieser künstlichen Zusammenfassung nahm ich allerdings weder auf die Jahreszeit noch auf die Unterschiedlichkeit der Untersuchungsbilder selbst Rücksicht; denn diese waren in qualitativer und quantitativer Hinsicht bei einer Örtlichkeit oft sehr verschieden. Durch Errechnung aber von Mittelwerten für die Gesamtheit der Proben an einer Örtlichkeit treten deren Merkmale genügend deutlich hervor. Ich addierte also die gleichlautenden Fresser-Hundertsätze bzw. Beutetier-Hundertsätze und dividierte durch die Anzahl der zu der betreffenden Örtlichkeit gehörenden Proben, sodaß der Durchschnitt angegeben wird.

\section{Die verschiedenen Biotope.}

In folgender Tabelle sind die sehr verschieden beschaffenen Lebensräume aufgeführt und die Nährtiere nach gewissen Gruppen zusammengefaß3t. Die Durchschnittswerte gelten für die Anzahl der betr. Nährtiere in 100 Garnelenmägen. 


\begin{tabular}{l|r|r|r|r|r|r}
\hline \hline Nahrungstiergruppen & Strom & Sände & Abhänge & Priele & Watt & M \\
\hline Malakostraken & 94 & 100 & 91 & 49 & 84 & 83.5 \\
Entomostraken & 27 & 104 & 58 & 533 & 72 & 158.8 \\
Würmer & 29 & 22 & 32 & 47 & 37 & 33.4 \\
Mollusken & 32 & 195 & 112 & 211 & 100 & 130.0 \\
\hline Summen & 182 & 421 & 293 & 840 & 293 &
\end{tabular}

Die Summen zeigen an, daß auf den Biotopen "Priele“ und „Sände“ sich Garnelen vorfinden, die die größte Freßtätigkeit entwickelt haben.

Wenn wir die einzelnen Nährtierarten aus dem Verbande der vier Gruppen lösen, bekommen wir folgendes Bild (nächste Tabelle), das uns nicht nur einen Eindruck vermittelt über die Frebtätigkeit der Garnele an den verschiedenen Biotopen, sondern auch von der dortigen Besiedlung mit Nährtieren. [Es sei auch an dieser Stelle darauf verwiesen, daß die Garnelen an Orten, wo sie gefangen worden sind, nicht gefressen zu haben brauchen; sie können zugewandert sein]. In der folgenden Tabelle sind bei Muscheln und Schnecken die Larvenformen einbezogen. "Malakostraken" sind $\mathrm{nur}$ in dieser Tabelle Crustaceen, deren Gattung und Art an den Resten nicht mehr haben erkannt werden können. Es ist aber mit großer Wahrscheinlichkeit anzunehmen, daß es sich in den meisten Fällen um Schizopoden handelte. Bemerkenswert ist noch, daß sich der einzige Rückenschulp eines Tintenfisches, der gefunden ist, im Magen einer "Strom-Garnele" zeigte, und daß die "Muscheln" der „Abhänge" alle aus Muschellarven bestanden. Die Nährtierarten sind in der ersten Spalte der Tabelle so untereinandergestellt, wie die Durchschnittswerte (letzte Spalte unter M) geringer werden.

\begin{tabular}{l|r|r|r|r|r|r}
\hline \multicolumn{1}{c|}{ Nahrungstiere } & Strom & Sände & Abhang & Priele & Watt & M \\
\hline Cyprislarven & 0.4 & 22 & 36 & $\mathbf{3 4 5}$ & 37 & 88.0 \\
Muscheln & 16 & $\mathbf{1 7 5}$ & 16 & $\mathbf{7 2}$ & $\mathbf{7 7}$ & 71.2 \\
Schnecken & 16 & 20 & $\mathbf{9 6}$ & $\mathbf{1 3 9}$ & 23 & 58.8 \\
Copepoden & 8 & $\mathbf{7 4}$ & 17 & $\mathbf{1 6 2}$ & 9 & 54.0 \\
Würmer & 29 & 22 & 32 & $\mathbf{4 7}$ & $\mathbf{3 7}$ & 33.4 \\
Schizopoden & $\mathbf{5 1}$ & $\mathbf{4 5}$ & $\mathbf{3 3}$ & $\mathbf{1}$ & 1 & 26.2 \\
Amphipoden & $\mathbf{1 3}$ & $\mathbf{4 2}$ & $\mathbf{3 2}$ & $\mathbf{2 6}$ & $\mathbf{3}$ & 23.2 \\
Corophium & $\mathbf{2}$ & $\mathbf{5}$ & $\mathbf{1 5}$ & $\mathbf{2}$ & $\mathbf{7 2}$ & 19.2 \\
Harpacticiden & $\mathbf{1 4}$ & $\mathbf{2}$ & $\mathbf{2}$ & $\mathbf{1 8}$ & $\mathbf{2 3}$ & $\mathbf{1 1 . 8}$ \\
"Malakostraken & $\mathbf{1 2}$ & 6 & $\mathbf{7}$ & $\mathbf{1 4}$ & $\mathbf{8}$ & $\mathbf{9 . 4}$ \\
Crangon & $\mathbf{1 6}$ & $\mathbf{2}$ & $\mathbf{4}$ & 6 & - & 5.6 \\
Cirripedien & $\mathbf{2}$ & $\mathbf{5}$ & $\mathbf{3}$ & $\mathbf{4}$ & - & 2.8 \\
Ostracoden & 1 & 1 & - & $\mathbf{4}$ & $\mathbf{3}$ & $\mathbf{1 . 8}$ \\
Cumaceen & $\mathbf{2}$ & 0.2 & - & - & - & 0.4
\end{tabular}

Die einzelnen Biotope enthielten nach dieser Aufstellung Garnelen, die sich in verschiedener Weise den Nahrungstieren zugewandt haben:

Der Biotop des Stromes zeigt eine gewisse Nahrungsarmut; es überwiegen hier: Schizopoden-Crangon-,Malakostraken “-Harpacticiden-Cumaceen.

Die Sände zeichnen sich durch reiche Crustaceen-Nahrung aus, die durch Muscheln eine bedeutende Ergänzung findet. Es überragen hier den Durchschnitt: Muscheln - Copepoden - Schizopoden - Amphipoden - Cirripedien.

Die A bhänge haben ebenfalls eine reiche Crustaceennahrung, die durch. Schnecken vervollständigt wird. Über den Durchschnitt finden sich hier: Schnecken - Schizopoden Amphipoden - Cirripedien. Bemerkenswert ist hier, daß Würmer und Corophium dem Durchschnitt sehr nahe kommen.

Die Priele sind zahlenmäßig das stärkste Freßgebiet, es überwiegen die meisten der Nahrungstiere ganz erheblich gegenüber dem Mittel: Cyprislarven - Muscheln Schnecken - Copepoden - Würmer - Amphipoden - "Malakostraken “ - Crangon - Harpacticiden - Ostracoden - Cirripedien. Schizopoden und Corophium treten stark zurück.

Die Garnelen, die auf dem Watt zurückbleiben und dort gefangen wurden, fressen anscheinend nicht sehr intensiv von dem reichbesetzten Tisch. Es handelt sich allerdings bei diesen Fressern zumeist um kleine Garnelen. Hier werden die Mittel- 
werte von den Anzahlen folgender Tiere übertroffen: Muscheln - Würmer - Corophium - Harpacticiden - Ostracoden.

Zum größten Teil verhalten sich die hier zur Erörterung herangezogenen Nährtiere in bezug auf ihr Vorkommen in den Mägen von Garnelen der verschiedenen Biotope ganz entsprechend den Möglichkeiten ihrer Verteilung. Obwohl die meisten von ihnen über eine starke Euryökie verfügen, treten sie ebenso charakteristisch in den Mägen wie in den Biotopen auf, soweit wir an Hand von ökologischen Untersuchungen schon beurteilen können. Wir haben ständig zu berücksichtigen, daß die Garnelen kleine Wanderungen vornehmen, die sie zu ihrer Nahrung führen. Diese Wanderungen werden von einer großen Reihe von Faktoren beeinflußt, immer aber enden sie an einem ruhigen Verdauungsort, der sich mit dem Fangort wohl in den meisten Fällen deckt, zumal wenn mit einem Grundgeschirr gefangen worden ist. In dieser Hinsicht verdienen die beiden Biotope "Priele" und "Strom" besondere Beachtung. Hier überragen die Durchschnittswerte der "Malakostraken" den Mittelwert, und deswegen können wir an diesen Plätzen Verdauungsorte vermuten; denn als "Malakostrake“ sind ja in diesem Falle solche Teile von malakostraken Krebsen bezeichnet, die schon stark von der Vorverdauung zerstört waren. Die Priele und der Strom sind also Sammelbecken für Garnelen, die nur oder $\mathrm{auch}$ an anderen Orten gefressen haben, sodaß hier die stärkste Untermischung der autochthonen Nahrung durch allochthone vorhanden sein kann.

\section{Die verschiedenen Fangplätze.}

Wenn wir in derselben Weise wie die Biotope die einzelnen Fangplätze der Fischerei behandeln, so bekommen wir folgendes Bild. In der folgenden Tabelle sind die Nahrungstiere wiederum zu gewissen Gruppen zusammengefaßt. Die Reihenfolge der Fangplätze führt von seewärts her in die Flußmündung. In der letzten senkrechten Spalte sind wiederum die Mittelwerte angegeben und in der letzten waagerechten die Summen der Nahrungstiere. Die Karte I auf S. 148 enthält eine graphische Darstellung der Werte.

\begin{tabular}{|c|c|c|c|c|c|c|c|c|c|c|c|c|}
\hline $\begin{array}{l}\text { Nahrungstier- } \\
\text { gruppen: }\end{array}$ & $\begin{array}{l}\text { Vogel- } \\
\text { sand: }\end{array}$ & $\begin{array}{l}\text { Schar- } \\
\text { hörn: }\end{array}$ & $\begin{array}{c}\text { Hunde- } \\
\text { balje: }\end{array}$ & $\begin{array}{l}\text { Eitzen- } \\
\text { loch: }\end{array}$ & $\begin{array}{l}\text { Bucht- } \\
\text { loch: }\end{array}$ & Watt: & $\begin{array}{l}\text { Süder- } \\
\text { fahrw.: }\end{array}$ & $\begin{array}{l}\text { Migrd. } \\
\text { West: }\end{array}$ & $\begin{array}{l}\text { Migrd. } \\
\text { Ost: }\end{array}$ & $\begin{array}{l}\text { Kratz- } \\
\text { sand : }\end{array}$ & $\begin{array}{l}\text { Gelb- } \\
\text { sand: }\end{array}$ & $\mathrm{M}$ \\
\hline $\begin{array}{l}\text { Malakostraken } \\
\text { Entomostraken } \\
\text { Würmer } \\
\text { Mollusken }\end{array}$ & $\begin{array}{l}63 \\
16 \\
49 \\
17\end{array}$ & $\begin{array}{l}49 \\
21 \\
41 \\
34\end{array}$ & $\begin{array}{r}46 \\
84 \\
67 \\
348\end{array}$ & $\begin{array}{r}76 \\
1469 \\
42 \\
455\end{array}$ & $\begin{array}{r}79 \\
561 \\
25 \\
319\end{array}$ & $\begin{array}{r}84 \\
73 \\
37 \\
100\end{array}$ & $\begin{array}{l}93 \\
13 \\
36 \\
43\end{array}$ & $\begin{array}{r}116 \\
79 \\
9 \\
78\end{array}$ & $\begin{array}{r}95 \\
72 \\
29 \\
396\end{array}$ & $\begin{array}{r}109 \\
136 \\
23 \\
28\end{array}$ & $\begin{array}{r}100 \\
52 \\
14 \\
86\end{array}$ & $\begin{array}{r}82.7 \\
234.1 \\
33.8 \\
173.1\end{array}$ \\
\hline ummen & 145 & 145 & 545 & 2042 & 984 & 294 & 185 & 282 & 592 & 296 & 252 & \\
\hline
\end{tabular}

Die Werte dieser Tabelle sind in der Karte I (S. 148) graphisch dargestellt.

Die Größenordnungen der Summen teilen die Fangplätze in drei Gruppen:

I. Hundebalje + Eitzenloch + Buchtloch + Mittelgrund-Ost.

II. Watt + Mittelgrund-West + Kratzsand + Gelbsand

III. Vogelsand + Scharhörn + Süderfahrwasser.

Merkwürdigerweise haben die Mitglieder jeder dieser Gruppen unter sich gewisse charakteristische Ähnlichkeiten in ihrer "Gebietslage“. Die erste Gruppe besteht aus Prielen nebst dem Strominterferenzgebiet "des Mittelgrund-Ost, welches ähnlichen hydrophysikalischen Einwirkungen unterworfen ist wie die Priele, und welches aus diesem Grunde möglicherweise einen bedeutenden Beitrag zur Bildung der ThIEManN'schen Planktonsprungzone leistet. Die zweite Gruppe setzt sich zusammen aus Sänden. Die dritte Gruppe umfaßt Gebiete, die dem starken Tidenstrom ständig ausgesetzt sind. Auf diese Weise also können wir eine weitere Aufteilung des Nährgebietes zu Biotopen vornehmen: Statt der fünf obengenannten Biotope haben wir hier drei, nämlich „Strom“, "Sände“, "Strudelplätze“. Diese drei Biotope unterscheiden sich charakteristisch, in diesem Zusammenhang, in dem mengenmäßigen Auftreten der Nährorganismen für die Garnelen. An erster Stelle mit größter Nahrungslieferung stehen die „Strudelplätze“, dann folgen die „Sände", und das "Strombett" bietet relativ am wenigsten Individuen von Nährorganismen.

Die Variabilität im zahlenmäßigen Vorkommen sowohl der Würmer wie auch der Malakostraken in den Mägen der Garnelen an den verschiedenen Örtlichkeiten ist verhältnismäßig gering. Interessant ist aber, daß im allgemeinen an Orten, wo die Würmer den Durchschnitt überragen, die Malakostraken den ihrigen nicht erreichen. Demnach sind wir 
zu der Aussage berechtigt, die bei der Besprechung der jahreszeitlichen Verhältnisse ihre Bestätigung findet, daß die Garnelen bei Mangel des einen zum anderen Nahrungsmittel übergehen, also von Malakostraken zu Würmern und umgekehrt. Das verschiedenartige Verhalten der Entomostraken und Mollusken zueinander ist anscheinend bedingt durch die besondere - konkrete - Gebietslage der einzelnen Fangplätze. Das gilt besonders für den - ja abstrahierten - Biotop „Strudelplätze“. Während nämlich im Eitzenloch und im Buchtloch sowohl Entomostraken wie Mollusken zahlreich aufgenommen worden sind, sind in der Hundebalje und am Mittelgrund-Ost nu r Mollusken in den Durchschnitt übertreffender Zahl gefressen worden. Um die diese Verhältnisse bewirkenden Faktoren prüfen zu können, müssen wir die Nährtiergruppen in ihre Bestandteile auflösen und die einzelnen Nährorganismen unter Berücksichtigung ihrer Lebensweise gesondert betrachten.

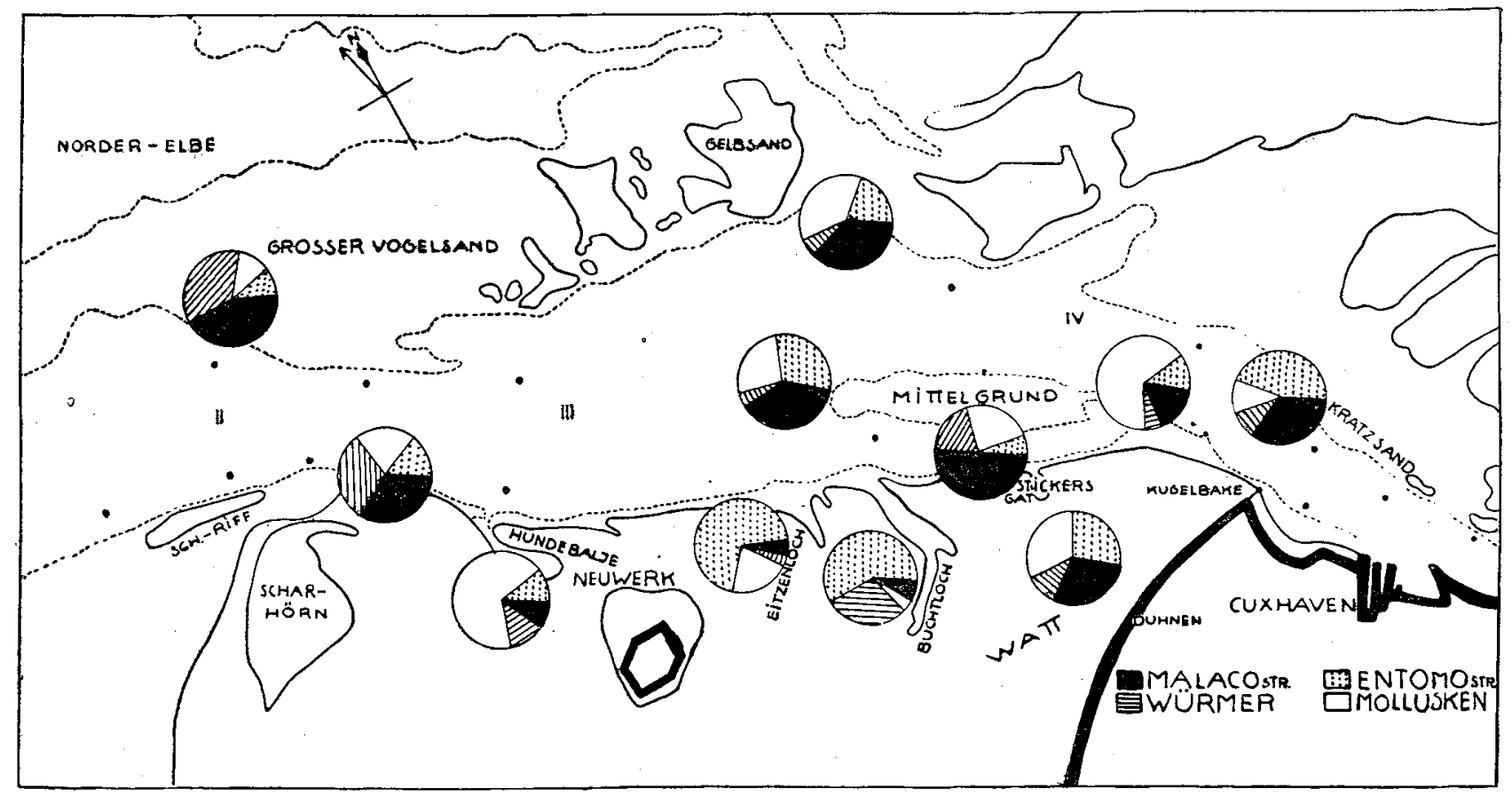

Karte I. Anteil der zu vier Gruppen zusammengefaßten Nahrungstiere an 100 Stück aus Mägen von Garnelen, die dem betreffenden Ort entnommen sind. $5 \mathrm{~m}$ Tiefenlinie:.......... ; Fabrwasserbegrenzungstonnen: ... .; Feuerschiffe I-IV. „Süderfahrwasser“ bei Stickers Gat.

Die folgende Tabelle sei zu diesem Zwecke herangezogen:

\begin{tabular}{|c|c|c|c|c|c|c|c|c|c|c|c|c|}
\hline $\begin{array}{l}\text { Nahrungs- } \\
\text { organismen: }\end{array}$ & $\begin{array}{l}\text { Vogel- } \\
\text { sand: }\end{array}$ & $\begin{array}{l}\text { Schar- } \\
\text { hörn: }\end{array}$ & $\begin{array}{l}\text { Hunde- } \\
\text { balje: }\end{array}$ & $\begin{array}{c}\text { Eitzen- } \\
\text { loch : }\end{array}$ & $\begin{array}{l}\text { Bucht- } \\
\text { loch: }\end{array}$ & Watt: & $\begin{array}{l}\text { Süder- } \\
\text { fahrw.: }\end{array}$ & $\begin{array}{l}\text { Migrd. } \\
\text { West: }\end{array}$ & $\begin{array}{c}\text { Migrd. } \\
\text { Ost : }\end{array}$ & $\begin{array}{l}\text { Kratz- } \\
\text { sand: }\end{array}$ & $\begin{array}{l}\text { Gelb- } \\
\text { sand: }\end{array}$ & M \\
\hline Cyprislarven & - & - & 47 & 1442 & 146 & 37 & 11 & 34 & 41 & 17 & 5 & 197.8 \\
\hline Schnecken & 5 & 23 & 280 & $\mathbf{2 3 7}$ & 285 & 23 & 32 & 26 & 18 & 14 & 32 & 88.6 \\
\hline Muscheln & 12 & 11 & 68 & 218 & 33 & 77 & 12 & 52 & 379 & 15 & 54 & 84.6 \\
\hline Copepoden & 17 & 6 & - & - & 407 & 10 & 18 & 10 & 19 & 113 & 38 & 70.9 \\
\hline Würmer & 49 & 41 & 67 & 42 & 25 & 37 & 36 & 9 & 29 & 23 & 14 & 33.8 \\
\hline Schizopoden & 19 & 17 & 3 & 32 & 47 & 1 & 37 & 70 & 11 & 47 & 70 & 32.2 \\
\hline Amphipoden & 17 & 13 & 22 & 9 & 26 & 3 & 46 & 27 & 45 & 43 & 11 & 23.8 \\
\hline Corophium & - & 6 & - & - & 1 & 72 & 6 & 4 & 28 & 6 & - & 17.6 \\
\hline Algen & 6 & 9 & 37 & 36 & 30 & + & 5 & 21 & 3 & 11 & - & 17.6 \\
\hline Harpacticiden & - & 12 & 28 & 24 & - & 23 & 2 & 25 & - & - & 7 & 17.3 \\
\hline Nematoden & - & 29 & 35 & 12 & 2 & $\mathbf{3 1}$ & 8 & - & - & 1 & - & 16.9 \\
\hline Fischteile & $\mathbf{3}$ & 27 & 7 & 7 & 二 & - & 3 & 10 & - & 5 & - & 15.5 \\
\hline Crangon & 17 & 7 & 7 & 14 & 3 & - & 4 & 5 & 一 & 6 & 6 & 7.7 \\
\hline Nauplien & - & - & - & - & - & 1 & - & -- & 5 & - & 2 & 2.7 \\
\hline Ostracoden & 一 & 2 & 一 & $\mathbf{3}$ & 6 & 3 & 1 & 2 & 1 & 1 & 一 & 2.4 \\
\hline Cumaceen & 1 & - & - & - & - & - & - & 2 & - & - & 2 & 1.7 \\
\hline Summen & 146 & 203 & 601 & 2076 & 1011 & 318 & 221 & 297 & 579 & 302 & 241 & \\
\hline
\end{tabular}

Die Werte dieser Tabelle sind für die ersten sieben Organismen dargestellt in der Karte II. 
Die Cyprislarven überwiegen gegenüber den anderen Örtlichkeiten ganz erheblich in Garnelen aus dem Eitzenloch. Das mag folgende Gründe haben: erstens stellt das Eitzenloch keinen so tiefen Einschnitt in das Watt dar wie das Buchtloch, zweitens breiten sich die Ausläufer des Eitzenloches ebenfalls bis zur Wasserscheide aus, aber in viel breiteren und flacheren. Rinnsalen mit geringerem Gefälle als es das Buchtloch hat; die Möglichkeit der Ansammlung von Cyprislarven während des Brutfalles ist also viel größer beim Eitzenloch als beim Buchtloch, so daß den Garnelen hier viel mehr Cyprislarven zum Fraße geboten werden können. Die Unterschiede im Bodenrelief aber sind offenbar nicht die Ursache allein, die eine Ansammlung von Cyprislarven fördern; denn die Hundebalje ist von ähnlicher flacher, weitreichender Ausbildung wie das Eitzenloch. Das Tidengefälle allerdings ist in der Hundebalje größer. Ein bedeutender Grund dafür, daß nun gerade das Eitzenloch soviel Cyprislarven liefert, ist die Tatsache, daß an den Ausläufern dieses Prieles auf der Wasserscheide ja ausgedehnte Muschelschillbänke liegen, die für den Ansatz der Balanus-Cyprislarven die günstigsten Verhältnisse bieten. Der Einstrom und Abstrom des Wassers vom Hochwatt geht nicht etwa durchaus senkrecht zu dem Verlauf der Elbe, sondern der Einstrom direkt von Norden nach Süden und der Ausstrom von SW

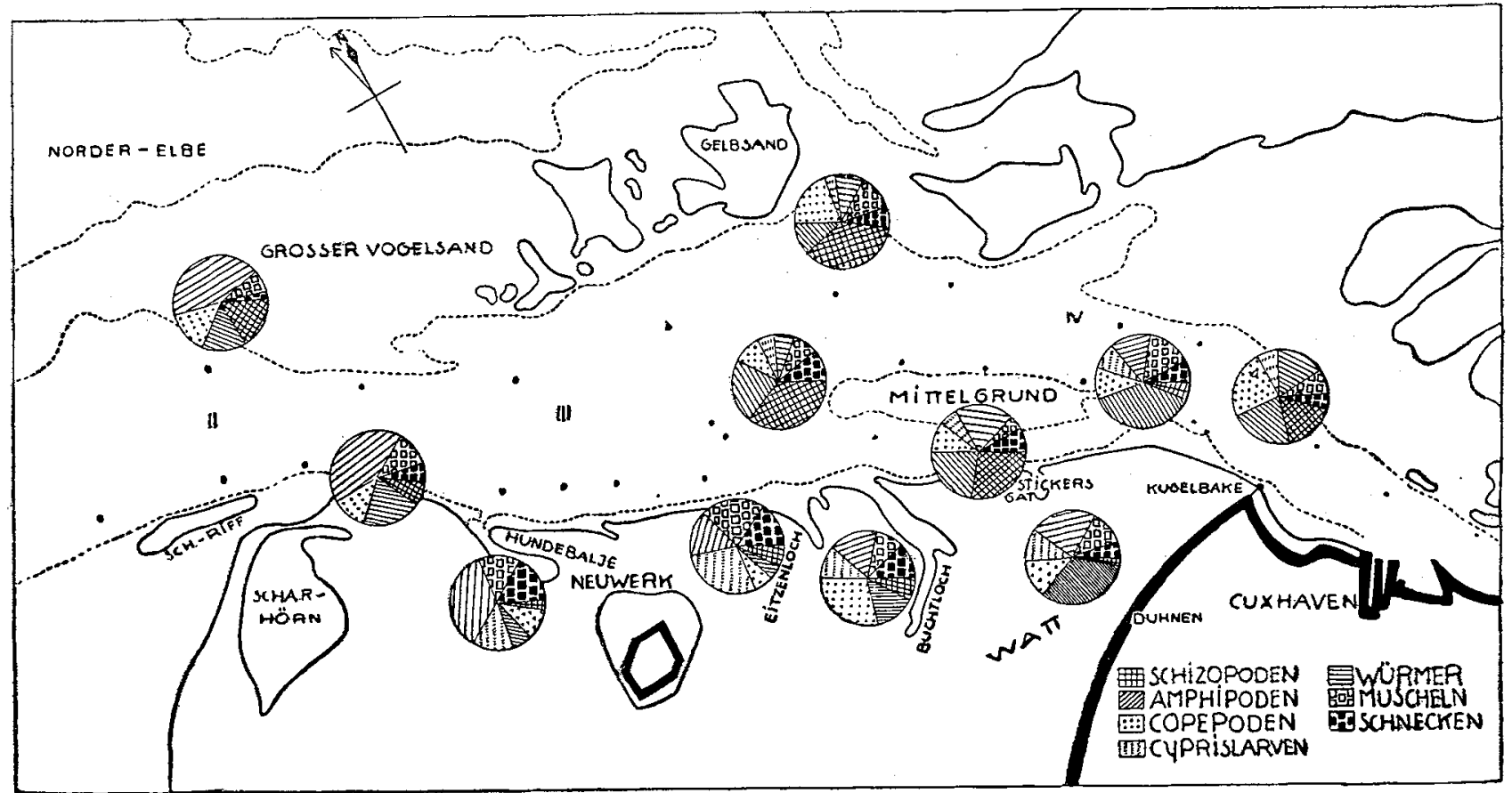

Karte If. Anteil der sieben verschiedenen Nahrungstiere an 100 Stück aus Mägen von Garnelen, die dem betreffenden Ort entnommen sind (vgl. die Tabelle auf S. 148). Zeichenerklärung wie bei Karte I.

nach NO. Die Komponente dieser beiden Stromrichtungen erzeugt die Richtung des Verlaufes der Priele, wobei zu beachten ist, daß die Priele einen umso größeren Neigungswinkel zueinander haben, je weiter sie sich von der Küste entfernen; sie bilden einen Fächer, dessen allerdings ausgedehnter „Drehpunkt“ auf der Wasserscheide liegt, wo die große Muschelbank liegt. Dieser sind die Ausläufer des Eitzenloches am nächsten. Die Reihenfolge der Häufigkeit des Vorkommens von Cyprislarven in Garnelenmägen aus den einzelnen Bestandteilen des „Fächers“ ist daher auch Eitzenloch-Buchtloch-Hundebalje.

Außerdem zeigen dieÖrtlichkeiten Mittelgrund-Ost, dasWatt und Mittelgrund-West noch relativ hohe Zahlen an Cyprislarven. Diese Tatsache veranlaßt uns $\mathrm{zu}$ folgender Überlegung: Die Cyprislarven von Balanus sind h eterotope Organismen, die sowohl als Sedimente wie auch als Planktonten in den Magen der Garnele gelangen können. Als ersteres sind sie wohl ziemlich ausschließlich in den drei Prielen und dem Watt aufgenommen, während sie als letztere wohl vom Mittelgrund-West, Mittelgrund-Ost, Süderfahrwasser, Kratzsand und Gelbsand gewonnen sind. Sie wären also autochthone Nahrungstiere in beiden Gruppen von Örtlichkeiten, sofern sich der Fangort mit dem Freßort deckt.1) Ist

1) Anm. siehe S. 150. 
aber der FreBort ein anderer als der Fangort, wie es durch die kleinen Wanderungen der Garnelen sehr oft möglich ist, so müssen wir die Cyprislarven, die aus Garnelen des Fangortes hervorgeholt werden konnten, als allochthone Nahrungstiere bezeichnen. Eine Entscheidung, ob die Cyprislarven aus Garnelen eines Fangortes autochthon oder allochthon sind, können wir erst fällen, wenn wir den übrigen Mageninhalt auf seine Herkunft geprüft haben. Eine solche Prüfung kann mit ste notop en Nährtieren Erfolg haben. Ein solches ste n otopes Nährtier ist beispielsweise Corophium volutator. Erscheinen Cyprislarven mit Corophium zusammen in Mägen von Garnelen, die an einem Orte gefangen worden sind, der nicht Wohngebiet von Corophium ist, so ist mit größter Wahrscheinlichkeit anzunehmen, daß auch die Cyprislarven allochthon sind. Nun aber besteht die Möglichkeit, daß stenotope Nährtierformen durch Wind, Wellenschlàg, Strömungen usw. physikalisch in einen fremden Biotop verschlagen werden, hier von den Garnelen gefressen werden und als allochthon angesprochen werden, obwohl sich der Fangort mit dem Freßort deckt. Eine solche Fehlschätzung kann vermieden werden durch gleichzeitige Beachtung der Häufigkeit des Auftretens solcher Fälle unter den Mageninhalten von Garnelen einer Population. So können die 72 Stück Corophium, die sich der Tabelle Seite 148 in 100 Mägen von Garnelen des Watts vorfanden; als autochthone Nährtiere bezeichnen, während die 28 Stück Corophium vom Mittelgrund-Ost allochthone Nährtiere sind. Ob diese allochthonen Nährtiere nun in den Mägen von Garnelen, die von dem Freßort herzugewandert sind, an den Fangort verfrachtet worden sind, oder ob sie dorthin als Irrlinge verschlagen worden sind, kann entschieden werden durch die Zusammensetzung der Nahrung mit Hilfe der Berechnung der abstrakten relativen Häufigkeit, sobald wir eine Population beurteilen wollen, wie es auf den Seiten 122 bis 129 geschehen ist.

(Anmerkung: Hier haben wir aus Zweckmäßigkeitsgründen Cyprislarven als selbstständige Organismen betrachtet. Wenn wir sie aber als Entwicklungsstadien von Balanus sp. sp. ansehen, welche Form ja wegen ihrer Larvenformen als h e te r o to $p$ angesprochen werden muß, so müssen die Cyprislarven in den meisten Fällen als all och th o ne Nährtiere bezeichnet werden, weil in den wenigsten Fällen Cyprislarven auf dem eigentlichen Wohngebiet von Balanus gefressen worden sind.)

Wenn wir uns die zahlenmäßige Verteilung der verschieden Nährtiere über die verschiedenen Örtlichkeiten nach der Tabelle Seite 148 weiter ansehen, so stoßen wir auf dieselben Schwierigkeiten wie bei den Cyprislarven und bei Corophium. Die Höchstwerte aber liegen immerhin einigermaßen charakteristisch für die ökologischen Verteilungsformen der Nahrungstiere.

Die Schnecken haben Höchstwerte in Garnelenmägen der Priele, wo sie entweder von der naheliegenden Corophium-Pygospio-Hydrobia-Zone oder auch aus dem Spülsaum stammen können.

Die Muscheln überwiegen stark im Eitzenloch und am Mittelgrund-Ost. An ersterem Orte ist daran möglicherweise die Einwirkung der Planktonsprungzone zu erkennen, wie auch am letzteren, wo die Gebietslage andererseits den Muschelfraß begünstigt.

Die Cope poden haben ebenfalls Höchstzahlen an Orten, die der Einwirkung der Planktonsprungzone unterliegen, nämlich im Buchtloch und am Kratzsand.

Die Würmer und Schizopoden haben wegen ihrer Euryökie keine starke zahlenmäßige Variabilität, im allgemeinen aber überwiegen die ersteren an Orten, wo Schlick vorkommt, während die letzteren an sandigen Stellen ihre mittlere Anzahl überragen.

Die Amphipoden erscheinen dort am zahlreichsten in den Mägen von Garnelen, wo ihr eigentliches Wohngebiet ist, nämlich auf den Sänden und ihren Abhängen.

Ebenso finden sich die meisten der übrigen in der Tabelle Seite 148 angegebenen Nährtiertypen in einer ihrer ökologischen Dichte entsprechenden Anzahl in den Mägen von Garnelen der verschiedenen Fangplätze. Nematoden und Ostracoden verraten ihr wattnahes Wohngebiet, und ebenso die Harpacticiden, während Balanus-Nauplien und Cum a ce en ihren Planktoncharakter vorweisen.

Die folgende Tabelle führt das zahlenmäßige Auftreten einiger Nahrungsorganismen in den Mägen von Garnelen der verschiedenen Orte noch einmal auf durch die Angabe von Durchschnittszahlen, die für e in en Magen errechnet worden sind. Denn wenn, wie wir soeben festgestellt haben, an einem Orte eine Nährtierart relativ individuenreich aus den Mägen der Garnelen' hervorgeholt werden konnte, so ist damit nicht gesagt, daß sich entsprechend viel Garnelen dieser Art zugewandt haben. Beispielsweise haben am Mittelgrund-Ost für 100 Garnelen 379 Stück Muscheln errechnet werden können, welcher Wert den Höchstwert unter allen besprochenen Fangplätzen darstellt. Von diesen 100 Garnelen aber haben nur 33 überhaupt Muscheln aufgenommen, sodaß auf einen Magen, der überhaupt Muscheln enthielt, im Durchschnitt 11.5 Stück kommen. Die Copepoden umfassen 
gleichzeitig Harpacticiden, die Amphipoden auch Corophium, Muscheln und Schnecken auch ihre Larven. Die Werte, die verhältnismäßig weit die 1 überragen, deuten auf das Vorkommen von Flecken, Nestern und Scharen hin.

\begin{tabular}{|c|c|c|c|c|c|c|c|c|c|c|c|}
\hline Nahrungstiere: & $\begin{array}{l}\text { Vogel- } \\
\text { sand: }\end{array}$ & $\begin{array}{l}\text { Schar- } \\
\text { hörn : }\end{array}$ & $\begin{array}{c}\text { Hunde- } \\
\text { balje: }\end{array}$ & $\begin{array}{l}\text { Eitzen- } \\
\text { loch : }\end{array}$ & $\begin{array}{l}\text { Bucht- } \\
\text { loch : }\end{array}$ & Watt : & $\begin{array}{l}\text { Süder- } \\
\text { fahrw.: }\end{array}$ & $\begin{array}{l}\text { Migrd. } \\
\text { West: }\end{array}$ & $\begin{array}{l}\text { Migrd. } \\
\text { Ost: }\end{array}$ & $\begin{array}{l}\text { Kratz- } \\
\text { sand : }\end{array}$ & $\begin{array}{l}\text { Gelb- } \\
\text { sand: }\end{array}$ \\
\hline Schizopoden & $1.06^{\circ}$ & 1.00 & 1.00 & 1.60 & 3.60 & 1.00 & 1.00 & 1.63 & 1.10 & 1.52 & 1.34 \\
\hline Copepoden & 1.13 & 1.80 & 2.80 & 2.00 & 7.54 & 1.52 & 1.33 & 2.70 & 1.12 & 3.24 & 1.67 \\
\hline Cyprislarven & - & - & 2.94 & 19.00 & 6.35 & 2.18 & 2.20 & 5.67 & 4.75 & 2.12 & 1.25 \\
\hline Amphipoden & 1.31 & 1.00 & 1.05 & 1.10 & 1.00 & 1.41 & 1.68 & 1.24 & 1.12 & 1.48 & 1.10 \\
\hline Muscheln & 1.65 & 1.02 & 3.24 & 4.75 & 2.36 & 4.53 & 2.00 & 4.33 & 11.50 & 1.25 & 3.38 \\
\hline Schnecken & 1.67 & 3.80 & 8.20 & 5.15 & 9.84 & 1.92 & 2.90 & 1.73 & 1.63 & 2.00 & 3.20 \\
\hline Würmer & 1.14 & 1.08 & 1.17 & 1.02 & 1.00 & 1.00 & 1.13 & 1.28 & 1.16 & 1.00 & 1.27 \\
\hline
\end{tabular}

3. Qualitätsunterschiede der Garnelen als Handelsware.

Vom Standpunkt der praktischen Fischerei ist die Qualität der Garnelen an den verschiedenen Fangplätzen sehr unterschiedlich. Diese Qualitätsunterschiede beziehen sich nicht nur auf die durchschnittliche Länge der Garnelen, sondern ebenso auf ihre Farbe, wie auf Geruch und vor allem auf die Beschaffenheit des Fleisches, der Abdominalmuskulatur.

Die Wattkrabben sind bekannt wegen ihres „schwarzen oder grünen Kopfes“ und wegen ihres gründigen Geschmacks und Geruchs. Garnelen von schlickigem Grund überhaupt haben nicht den würzigen Geschmack wie die vom Sandgrund. Meist aber sind die ersten durchschnittlich größer und gekocht von leuchtend roter Farbe, während die letzten kleiner zu sein pflegen und blasser und unansehnlicher sind. In der Tat ist das Fleisch der größeren Garnelen blasiger, weicher und wässeriger als das der kleineren vom Sandgrund.

Diese Erscheinungen sind von erheblicher Einwirkung auf die Verwendbarkeit eines Fanges als Handelsware. Die Ursachen dieser verschiedenen Qualität sind in einer Reihe von Faktoren zu suchen. Vornehmlich aber stehen sie anscheinend mit der Qualität der Nahrung im Zusammenhang. So war immer wieder deutlich zu erkennen, daß Garnelen mit starkem Würmerfraß das blasigere Fleisch haben, und daß Crustaceenfresser hingegen das festere Fleisch bekommen. Für die Entschälung zur Konservierung erweisen sich die letzteren als erheblich ergiebiger.

An Hand der folgenden Tabelle, die die durchschnittlichen Hundertsätze der verschiedenartigen Fresser an den verschiedenen Orten aufführt, soll untersucht werden, welche Garnelenqualitäten zu erwarten sind, und in wieweit die Ergebnisse übereinstimmen mit den Erfahrungen der praktischen Fischer, und welche qualitätsbestimmenden Faktoren außerdem in Betracht zu ziehen sind.

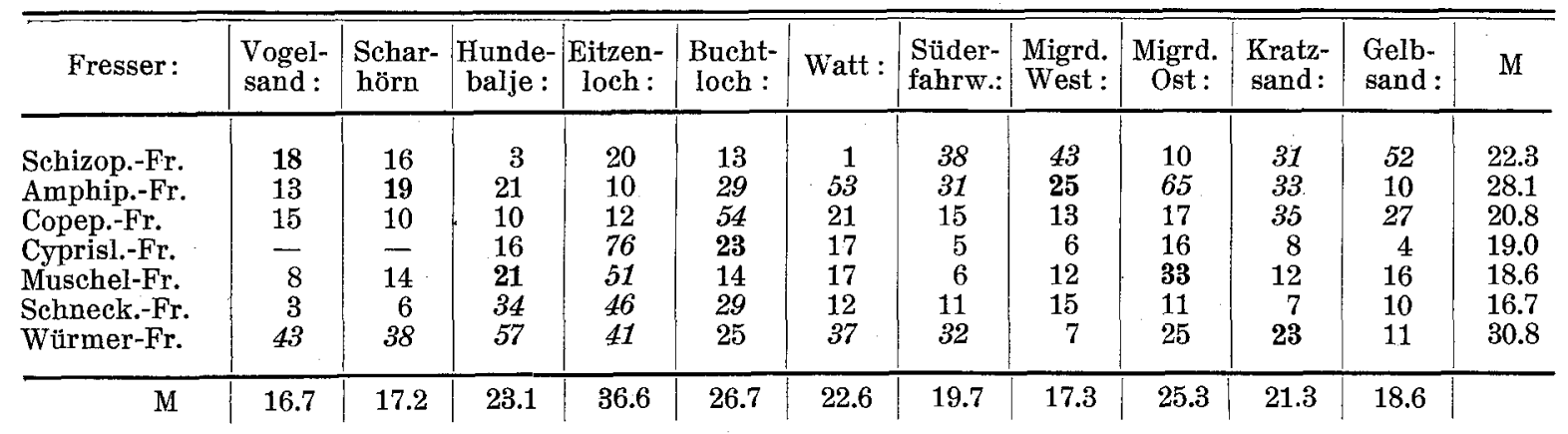

In dieser Tabelle ist $\mathrm{zu}$ beachten, $\mathrm{da} \beta$ die Reihenfolge der verschiedenartigen Fresser von oben nach unten ein Werturteil über die verschiedenen Nahrungstiere enthält. Die Amphipodenfresser umfassen gleichzeitig auch die Corophium-Fresser, die Copepodenfresser auch die Harpacticidenfresser. Die letzte senkrechte und die letzte waagerechte Reihe geben die Mittelwerte der entsprechenden Durchschnittszahlenreihen an. Jene Werte der Tabelle, die sowohl als Mitglied der einen Reihe wie auch der anderen Reihe die 
entsprechenden Mittelwerte überragen, sind in Kursivziffern, solche Werte, die nur einen der beiden dazugehörigen Mittelwerte überragen, sind in fetten Ziffern gedruckt.

In der Karte III sind die Tabellenwerte graphisch dargestellt.

Der Vogelsand liefert eindeutig überwiegend Garnelen, die Würmer gefressen haben, Schizopodenfresser und Amphipodenfresser treten sehr zurück. In der Tat fangen die Fischer hier zwar große Garnelen sehr zahlreich, deren Fleisch aber gekochtweich undwässerig ist.

Ganz ähnlich ist es in der Umgebung von Scharhörn. Auf beiden Fanggründen ist aber die Gebietslage des engeren Fangraumes in Betracht zu ziehen. Die Garnelen des flacheren Teiles sind immer von besserer Qualität als die aus dem tieferen. Gegenüber dem letzteren finden sich mehr Amphipodenfresser als Würmerfresser auf den flacheren Teilen dieses Gebietes, das starken Wasserbewegungen ausgesetzt ist.

Interessant sind die Verhältnisse bei den drei Prielen. Die Hundebalje ist dafür bekannt, daß sie die von den Fischern sogenannten Wattkraben liefert, ebenso das Eitzenloch. Hier, so wie an der ganzen Kante zwischen den Prielen, werden nämlich häufig Garnelen mit "schwarzen Köpfen“ gefangen. Das Buchtloch hingegen beher-

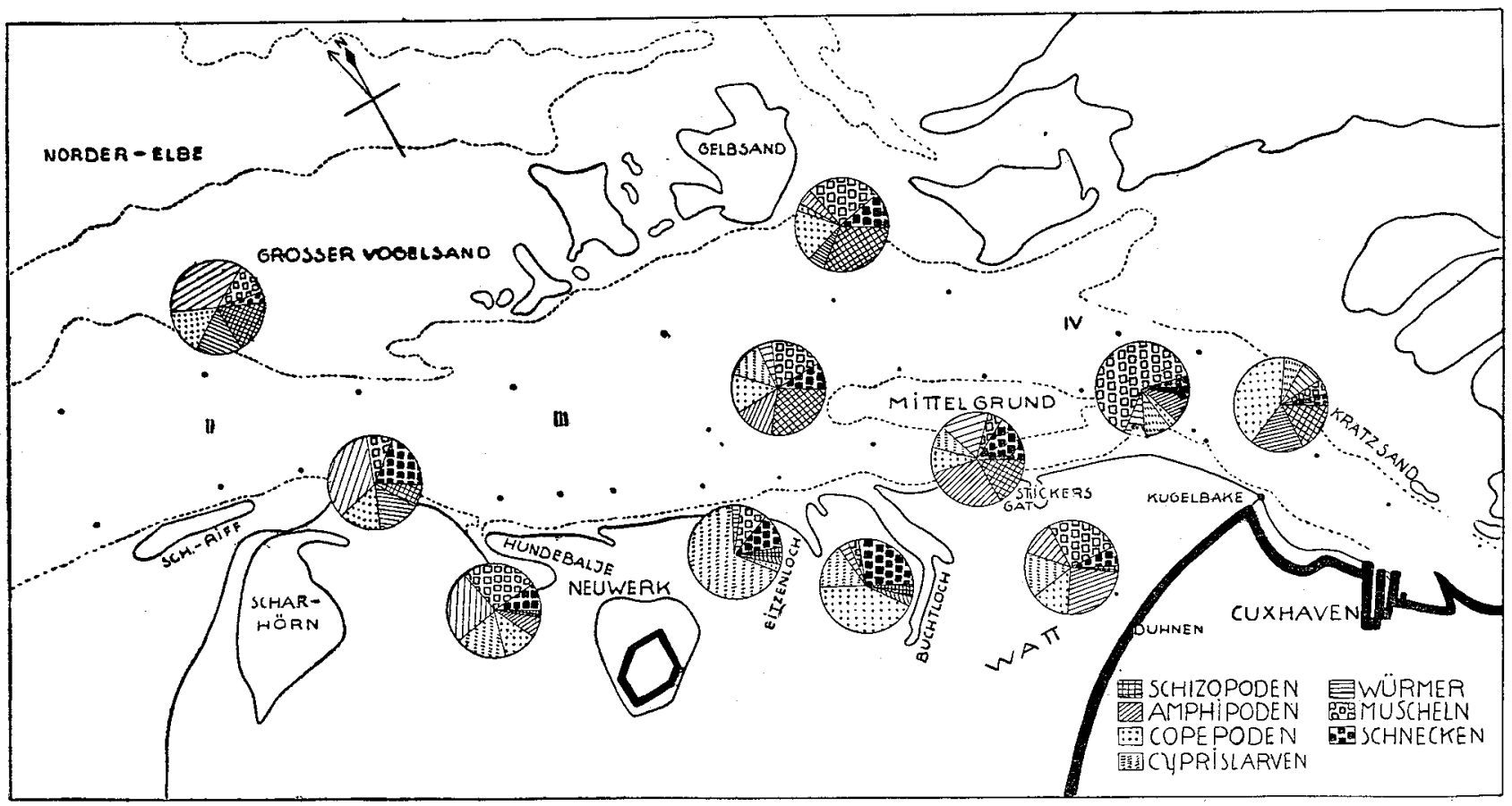

Karte III. Anteil der Fresser von den sieben verschiedenen Nahrungstieren an 100 Garnelen, die an dem betreffenden Ort gefunden worden sind (vgl. die Tabelle a uf S.151). Zeichenerklärung wie bei Karte I.

bergt durchgangs gute Garnelen, die nur durch Umstände wie Springtiden und widrige Windverhältnisse zuweilen mit "schwarzköpfigen" Garnelen untermischt sind. Hier auch finden sich die "grünköpfigen " Garnelen, deren Grünköpfigkeit nicht immer von Grünalgenfraß herrührt, sondern sogar meistens eine Strukturfarbe ist, die durch den Schlickgehalt des Magens hervorgerufen wird. Anscheinend veranlaßt außerdem ein gewisser Schlick die "Leberschläuche " zur Sekretion einer specifischen grüngefärbten Verdauungsflüssigkeit, die die Mitteldarmdrüse und auch besonders Chitinteile des Mageninhaltes grün färbt.

Auf dem Watt handelt es sich fast ausschlieflich um kleine Garnelen, die ohnehin nur zu Gammel-Produkten verarbeitet werden können. Es überwiegen hier CorophiumFresser durchaus; sonst ist die Qualität der Wattgarnelen ebenso verschieden, wie das Watt mit seinen vielen Pfützen, Rinnsalen und Prielchen, die auch während der Ebbe von den kleinen Garnelen bevölkert werden.

Das Süderfahrwasser ist ein Gebiet, daß in eindeutiger Weise Crustaceenfresser liefert, obwohl es so nahe an das Watt reicht. Der hier als Süderfahrwasser bezeichnete Fangplatz erstreckt sich über ein von Osten nach Westen langsam abfallendes Gebiet mit ausgesprochenem Sandboden und starkem Tidenstrom. 
Der M ittelgrund-West schließt sich daran an, und dort überwiegen durchaus Crustaceen-Fresser.

Ebenso verhält es sich mit dem Mittelgrund-Ost, dem Kratzsand und dem Gelbsand. Besonders der Kratzsand ist dafür bekannt, daß die hier gefangenen Garnelen von ausgezeichneter Qualität sind, leider aber wegen ihrer geringen Durchschnittsgröße in der frischversendenden Industrie verpönt sind. Die Feinschmecker unter den Fischern aber ziehen die kleineren Kratzsandgarnelen den größeren Vogelsandgarnelen derartig vor, daß sie behaupten, die kleinen schmeckten immer besser als die großen.

\section{Der Jahresverlauf und die Freßtätigkeit.}

\section{a) Allgemein.}

In verschiedenen Gebieten der Nordseeküste haben die Bearbeiter der Garnelenbiologie ihr besonderes Augenmerk auf die Wander- und Laichtätigkeit der Garnelen im Ablauf des Jahres gerichtet. Wenn wir die Ergebnisse der Untersucher dieser verschiedenen Gebiete miteinander vergleichen, können wir eine grundsätzliche Übereinstimmung feststellen, so daß wir berechtigt zu sein glauben, sie auch für das vorliegende Untersuchungsgebiet im großen ganzen übernehmen zu dürfen. Es liegt zwar ein umfangreiches Untersuchungsmaterial aus dem Gebiete der Elbmündung vor, das der verstorbene Studienrat A. Moltzahn, Cuxhaven, nachgelassen, aber nicht mehr so ausgewertet hat, daß es als Grundlage zur Auffindung von Beziehungen zwischen den verschiedenen Lebensäußerungen der Garnele verwendet werden kann. ${ }^{1}$ ) Da wir nun in folgendem die Freßtätigkeit der Garnelen im Ablauf eines Jahres untersuchen wollen, müssen wir uns vergegenwärtigen, daß nicht nur die Gepflogenheiten des Fressers, sondern ebenso auch die der Nährtiere zur Beurteilung herangezogen wẹden müssen. Der Umfang der Kenntnis, den wir von den Lebensgewohnheiten der Nahrungstiere haben, setzt uns eine Grenze in der Auswertung der Daten vorliegenden Untersuchungsmaterials. Leider liegen über die Bestandsschwankungen nämlich der verschiedenen Nährtiere der Garnele im Laufe des Jahres nur ungenügende Angaben vor. Allgemein wird ausgesagt, daß die Bestände im Winter durch Abwanderung oder Absterben geringer werden. Manche Nahrungstiere hingegen pflegen ihre Bestandsdichte auch im Winter zu halten, sofern nicht ein sehr starker Frost sie dezimiert. Der Sommer weist durchweg für jede Form höchste Bestandsziffern auf. Hier treten besonders die jungen Tiere im Rhythmus der betreffenden Laichzeiten hinzu. Aber gerade die Laichzeiten sind entweder zeitlich so ausgedehnt, oder auch, es folgen schnell mehrere in kurzen Abständen aufeinander, daß sie sich in den Mageninhaltsbefunden von Garnelen aus dem Zeitraum eines Monats nicht charakteristisch widerzuspiegeln vermögen. Wir sind also gezwungen, größere Zeiträume, als es Monate sind, zur Erörterung der Freßtätigkeit der Garnelen im Jahresgang heranzuziehen, obwohl bei der Vielgestaltigkeit des Verhaltens der Fresser und Nahrungstiere sehr kurze

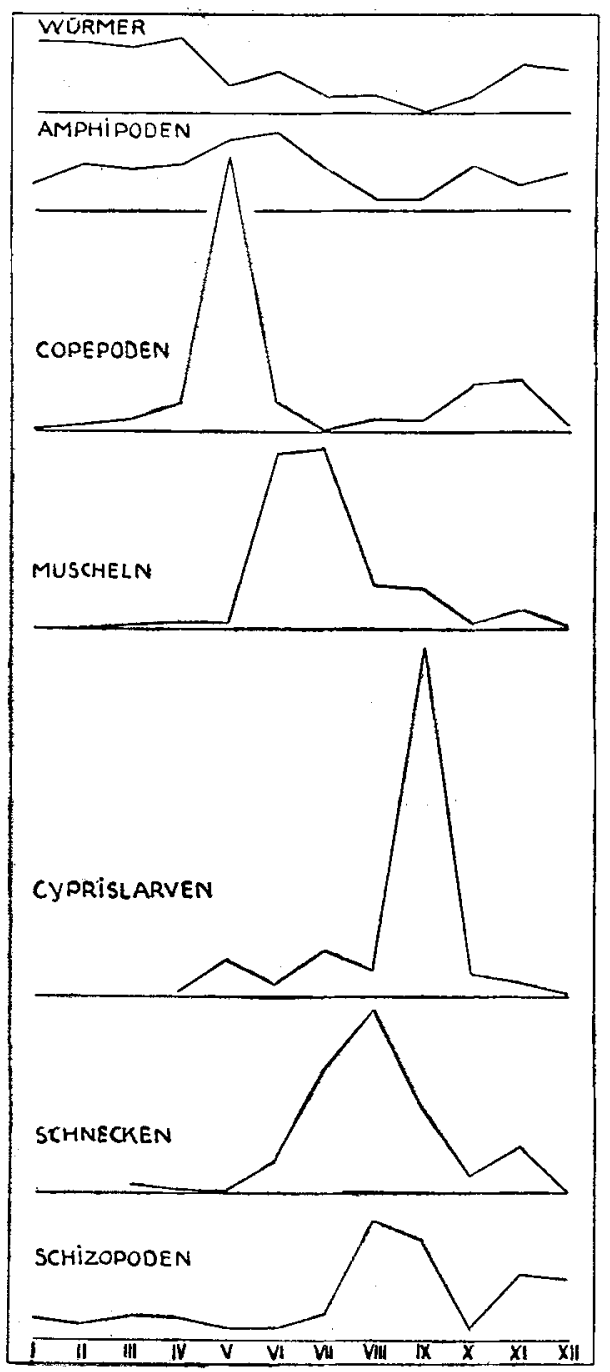

Abb. 3. Zahlenmäßiges Erscheinen der betreffendenNabrungstiere in den Mägen, in Prozent der Jahresgesamtzahl. 
Zeitabschnitte betrachtet werden müßten, wofür uns aber noch die Voraussetzungen fehlen. Diese Bearbeitung gibt somit aber auch den Mittelwerten, die für jeden Monat errechnet worden sind, größere Zuverlässigkeit, sobald wir ganze Jahreszeiten mit mehreren Monaten prüfen wollen. Da nun die Mittelwerte wiederum nach zwei Gesichtspunkten errechnet worden sind, nämlich erstens der Hundertsatz an Fressern und zweitens der Hundertsatz an Nahrungstieren pro Monat, bekommen wir auch Hinweise auf die jahreszeitlichen Veränderungen der Bestandsverhältnisse mancher Nährtiere.

Die Abb. 3 stellt die Verteilung über ein Jahr von sieben ausgewählten Nahrungsorganismen dar, und zwar die Veränderungen im zahlenmäßigen Vorkommen der Organismen in den Mägen von Garnelen.

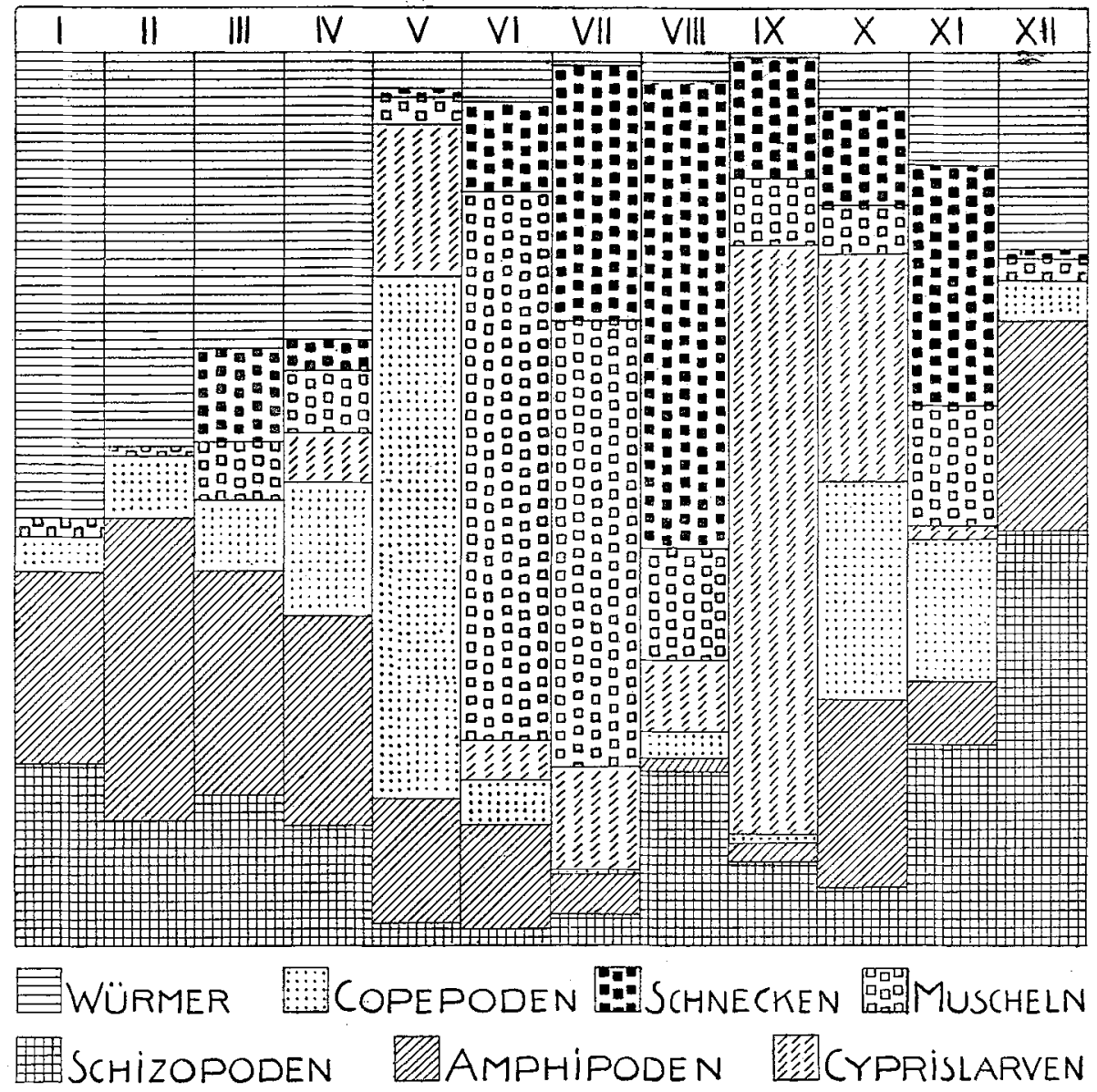

Abb. 4. Prozentanteil der betreffenden Nahrungstiere an der Gesamtzahl des Monats.

Die Würmer zeigen eine relativ gleichmäßige Verteilung über das ganze Jahr. Ihre Maximalwerte haben sie im Winter und ihre Minimalwerte im Sommer.

Auch die A mphipoden sind relativ gleichmäßjig verteilt. Ihre Höchstwerte liegen im Frühjahr, Mai und Juni, während der Spätsommer geringere Häufigkeit aufweist.

Die Mengen der Copepoden verteilen sich über das Jahr dergestalt, daß gegenüber den übrigen Monaten der Mai mit einem ausgeprägten Maximum herausfällt.

Die Muscheln fanden sich am zahlreichsten in den Mägen von Garnelen der Monate Juni und Juli, um dann sehr rasch weniger zu werden.

Die Cyprislarven treten erst im April auf und haben ihr scharf ausgeprägtes Maximum im September.

Schnecken sind zahlenmäßig am häufigsten in den Monaten Juli, August und September gefressen worden. 
Die Schizopoden weisen auch eine relativ gleichmäßige Verteilung auf; sie haben in den Monaten August und September Höchstwerte, wo die Würmer und Amphipoden ihre Mindestwerte haben.

In der Darstellung auf Abb. 4 sehen wir, welchen Anteil unter hundert Nährtieren die verschiedenen Formen monatlich haben. Das Jahr wird so aufgeteilt in zwei große Abschnitte:

\section{Dezember bis April}

II. Mai bis November.

Im ersten Abschnitt überwiegen die großen Nahrungstiere, die in der Einzahl aufgenommen werden und im zweiten Abschnitt die kleinen, welche in der Mehrzahl vorzukommen pflegen. Der Mai erweist sich als Übergangsmonat für die zahlreiche Sommernahrung und der Oktober als Übergangsmonat für die ärmere Winternahrung.

Wir können annehmen, daß die zahlenmäßige Verteilung der besprochenen Organismen über den Zeitraum eines Jahres, wie wir sie durch Untersuchung der Mageninhalte der Garnelen gefunden haben, derjenigen der freien Natur wenigstens dem Rhythmus nach entspricht. Nun tritt die Frage auf, ob in gleichem Rhythmus auch die Fresser der verschiedenen Nahrungetypen mengenmäßig auftreten. Die Kurvenfolge auf Abb. 5 führt zur Untersuchung dieser Frage die durchschnittlichen Hundertsätze der verschiedenartigen Fresser auf.

Wir sehen, daß das „W ü r me r fresser"-Polygon sich durchaus mit dem der Anzahl der Würmer deckt (siehe Abb. 3.); das hat natürlich seinen Grund darin, daß wegen der Größe der Würmer immer nur einer oder höchstens zwei auf einmal gefressen worden sein konnten, es sei denn, daß sich gleichzeitig in einem Magen noch Reste vorhergefressener Würmer vorfinden, die auf einen anhaltenden Würmerfraß schließen lassen. Ganz ähnlich ergeht es den Amphipodenfressern, die allerdings im Mai ihr Maximum haben, während das zahlenmäßige Auftreten von Amphipoden in den Monaten Mai und Juni ist. Im großen Ganzen haben die beiden Kurven dieselbe Tendenz. Auch die Copepodenfresser haben ihr Maximum im Mai wie die Nahrungstiere, aber der März und April weisen ganz im Gegensatz zu dem zahlenmäßigen Vorkommen der Copepoden hohe Werte auf, die zeigen, daß, obgleich wenig Copepoden vorhanden zu sein scheinen, die Garnelen sich ihnen doch mit besonderer Vorliebe zuwenden. Die Muschelfresser haben ebenfalls die zeitlichen Maxima wie bei dem zahlen-

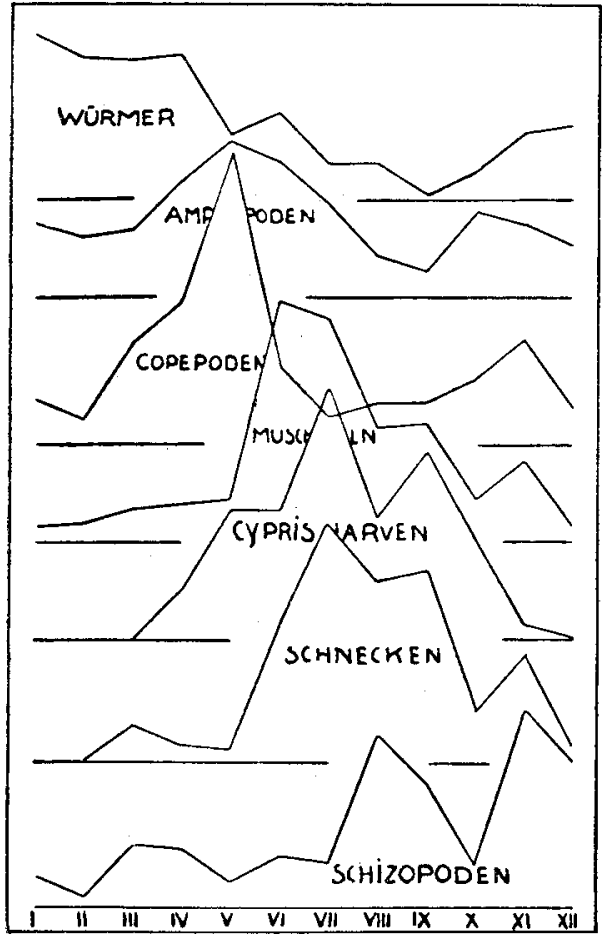

Ȧbb. 5. Prozentuale Verteilung der Fresser des betreffenden Nahrungstieres über das Jahr (Gesamtmaterial). mäßigen Vorkommen der Muscheln, sie überragen hier aber nicht so sehr die Werte des Durchschnitts. Die Fresser der Cyprislarven verhalten sich im Vorkommen in den Monaten stark anders, als diese als Nahrungstiere zahlenmäßig erscheinen. Bei letzteren haben wir ein scharf ausgeprägtes Maximum im September, während die Fresser auch in den Monaten Mai bis Oktober zahlreich vorkommen. Diese Verhältnisse zeigen, daß erstens die Cyprislarven eine beliebte Nahrung für die Garnele darstellen, sonst würden sich ihnen in Zeiten zahlenmäßig geringen Vorkommens nicht soviele Garnelen zuwenden, und daß zweitens, wenn eine Nährtierart zahlreich vorkommt, die Garnelen auch umsomehr nach ihr jagen, wie das zweite Maximum der Fresserkurve zutage legt. Ein starker Schnecken fraß findet vom Juni bis September statt, obwohl zahlenmäßig die Schnecken den Durchschnitt nur im Juli bis September überragen. Die Maxima liegen ebenfalls keineswegs korrespondierend. Im August kommen die meisten Schnecken in den Mägen der Garnelen vor, während im Juli sich die meisten Garnelen den Schnecken zuwenden. Außerdem zeigt sich ebenso wie für die Cyprislarven, daß der Schneckenfraß erst im März beginnt. Der Schizop odenfraß hat im August-September und November-Dezember seine Maxima. Das deckt sich aus denselben Gründen wie bei den Würmern mit dem zahlenmäßigen Vorkommen in den Mägen der Garnelen. Merk- 
würdigerweise hat der Oktober einen Mangel an Schizopodenfraß, und auch in bezug auf die übrigen Nährtiere zeigt dieser Monat einen eigenen Charakter. Spätere Untersuchungen mögen hier Aufklärung bringen.

Die Polygone der verschiedenen Fresser-Häufigkeiten sind derartig untereinandergestellt, wie sich ihre Maxima etwa vom Anfang des Jahresverlaufes auf das Ende hin verlagern. Ein Nahrungswechsel geht also in folgender Reihenfolge im Gang des Jahres vonstatten:

Würmer / Amphipoden / Copepoden / Muscheln/Cyprislarven/Schnecken / Schizopoden.

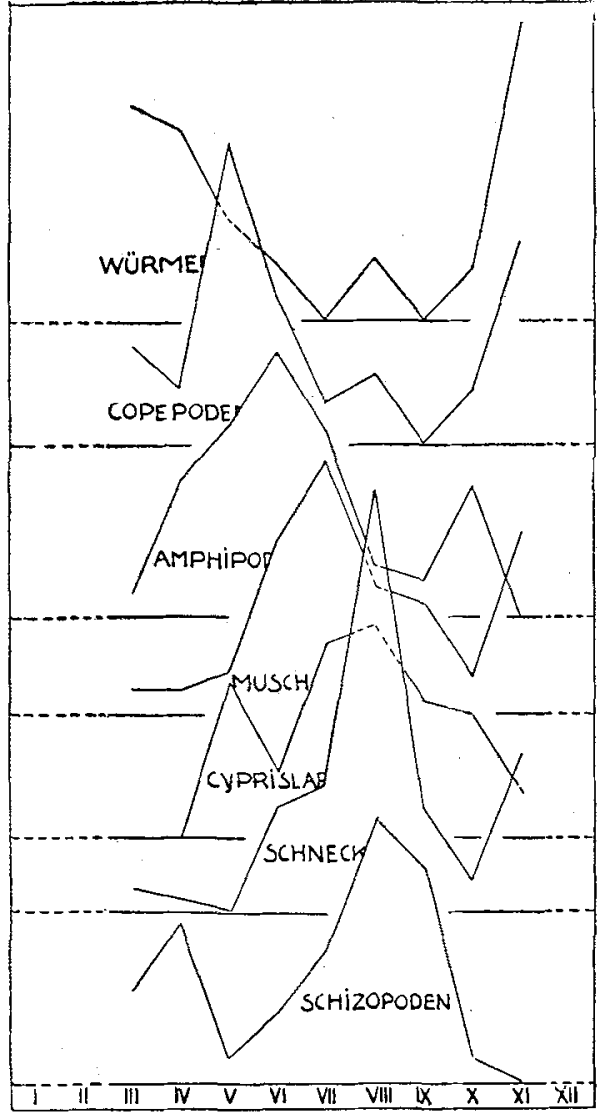

Abb. 6. Prozentuale Verteilung der Fresser der betreffenden Nahrungstiere über das Jahr 1933.

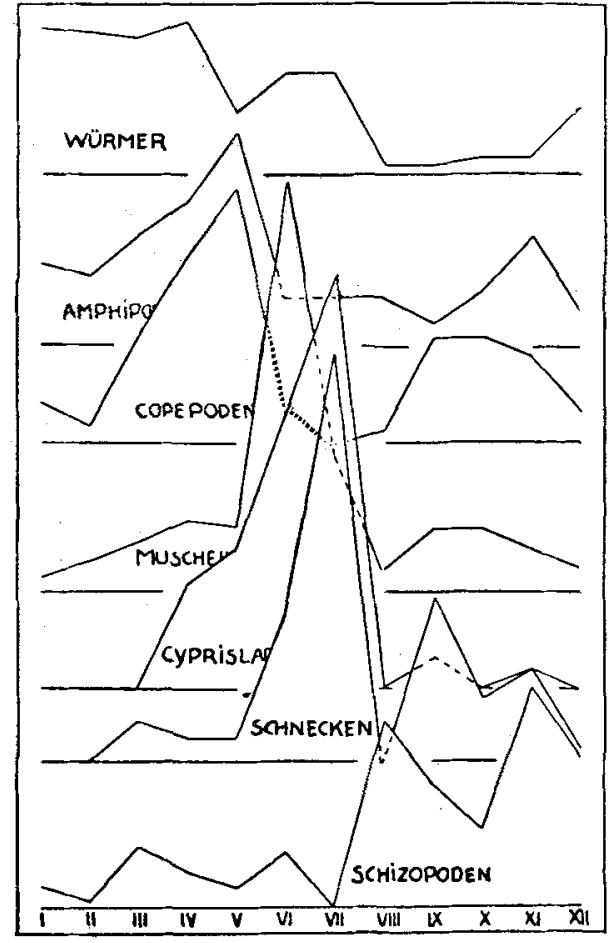

Abb. 7. Prozentuale Verteilung der Fresser der. betreffenden Nahrungstiere über das Jahr 1934.

ln den Abbildungen 6 und 7 sind die Jahre 1933 und 1934 gesondert behandelt, und wir sehen, daß der Nahrungswechsel im großen ganzen dieselbe Reihenfolge hat, bis auf den Wechsel zwischen Copepoden- und Amphipodenfraß. Die beiden Jahre unterscheiden sich im wesentlichen darin, daß folgende Fresser um einen Monat später im Jahre 1933 als im Jahre 1934 auftreten:

Amphipodenfresser, Muschelfresser und nach der Lage der Maxima vielleicht auch die Cyprislarvenfresser und Schneckenfresser. Im übrigen können wir feststellen, daß zum mindesten die Jahreszeiten in den einzelnen Jahren ihre ähnlichen Verhältnisse haben, zu Zeiten sogar die einzelnen Monate verschiedener Jahre.

Nach der Abb. 8 können wir die Monate wie folgt zusammenfassen und die Zusammenfassung durch die Qualität der Nahrung charakterisieren:

Die erste Gruppe reicht von Januar bis Mai, die zweite Gruppe vom Juni bis September, die dritte von Oktober bis Dezember. In der ersten Gruppe ist der Crustaceenfraß konstant, der Würmerfraß tritt zurück gegenüber dem zunehmenden Copepodenfraß. Die zweite Gruppe weist die sehr gemischte Sommernahrung auf. Die dritte Gruppe zeigt einen starken Übergang zur Malakostrakennahrung unter Rückgang der Sommernahrung. 


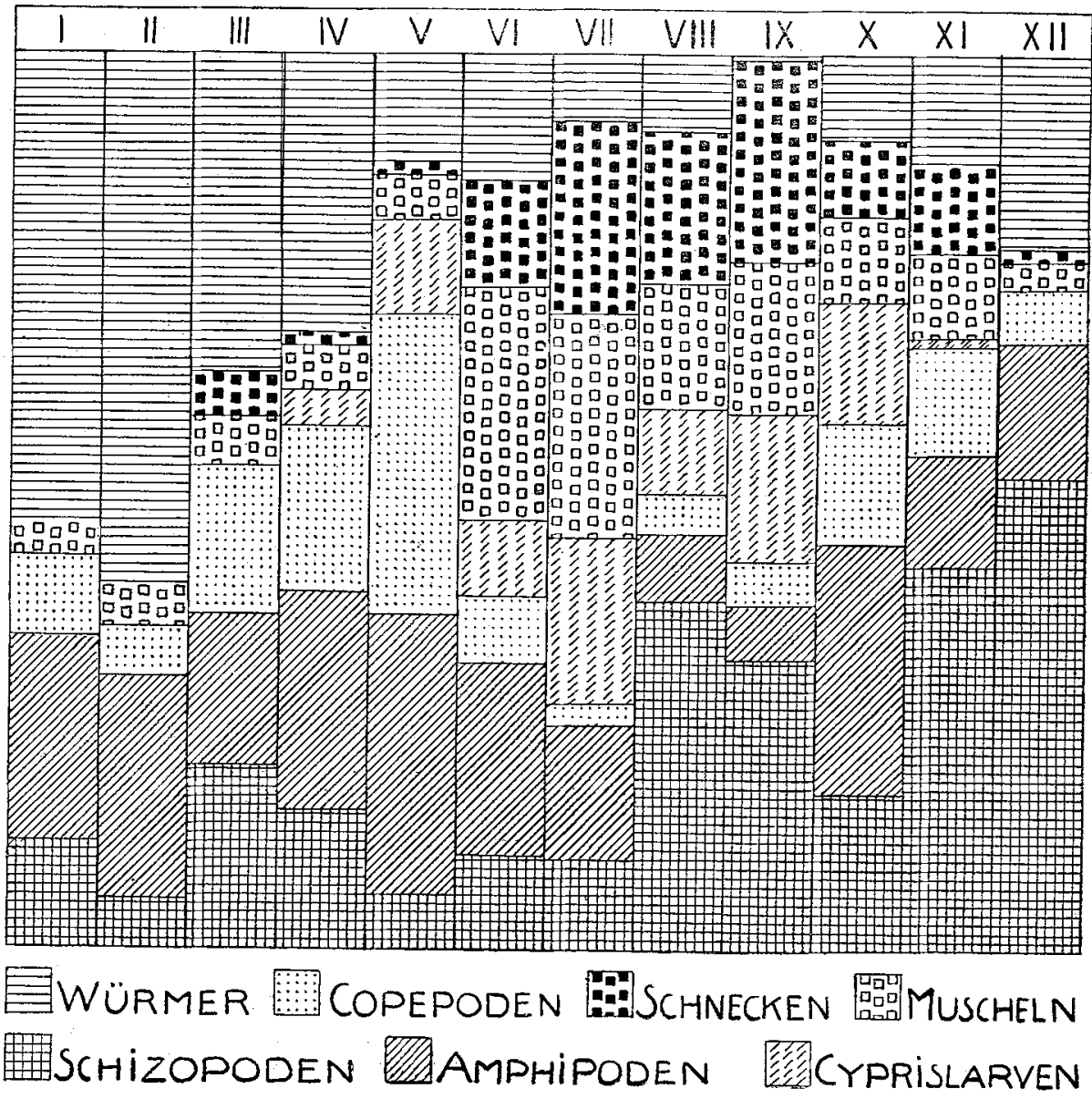

Abb. 8. Prozentanteil der Fresser der verschiedenen Nahrungstiere in jedem Monat.

b) Das Verhältnis der Geschlechter zur Nahrung im Jahresverlauf.

Für beide Geschlechter ist die Verteilung der verschiedenartigen Fresser über das Jahr, wie die Abb. 9 (S. 158) zeigt, im großen ganzen ziemlich gleichartig. Dennoch sind einige beachtliche Unterschiede da, die der Erwähnung wert scheinen.

Wir haben oben erfahren, daß die Männchen eine besondere Vorliebe haben für planktonische und kleinere Nährorganismen. So sind beispielsweise von den hier herangezogenen Männchen $18.7 \%$ Copepodenfresser gegen $8.8 \%$ von den Weibchen. Das Maximum der Kurven liegt für beide in den Monaten April und Mai, hier handelt es sich vor allem um die planktonisch lebenden Centropagiden und Cyclopiden, die, da sie um diese Zeit offenbar in Massen erscheinen, sich den Weibchen geradezu aufdrängen, während der Jagdeifer der Männchen immer in einer gewissen Höhe bestehen bleibt. Die Cyprislarvenfresser bestehen bei dieser Aufstellung aus fast gleichgroßem Anteil an Männchen und Weibchen im Jahresdurchschnitt. Während die Männchen schon im April Cyprislarven zu fressen beginnen, fangen die Weibchen erst einen Monat später damit an. Diese Tatsache scheint ein Beweis zu sein für die Annahme, daß die Männchen sich eher pelagischen Formen zuwenden als die Weibchen; denn die Nauplien von Balanus balanoides beispielsweise schwärmen am Anfang oder Mitte März, die Cyprislarven haben sich nach etwa 15 Tagen gebildet und setzen sich nach weiteren 15 Tagen an. $\mathrm{Ob}$ die übrigen Maxima, die in der Männchenkurve auftreten, auf andere Laichperioden hindeuten, muß noch untersucht werden. Die Muschelfresser kommen unter den Männchen wie unter den Weibchen in ähnlicher Häufigkeit im Verlaufe des Jahres vor. Wie weit hier von dem einen oder dem anderen Geschlecht die pelagischen Formen bevorzugt werden, kann nicht entschieden werden, weil, wie KäNDLER 1926 mitteilt, Mytilus-Larven sich im Plankton 


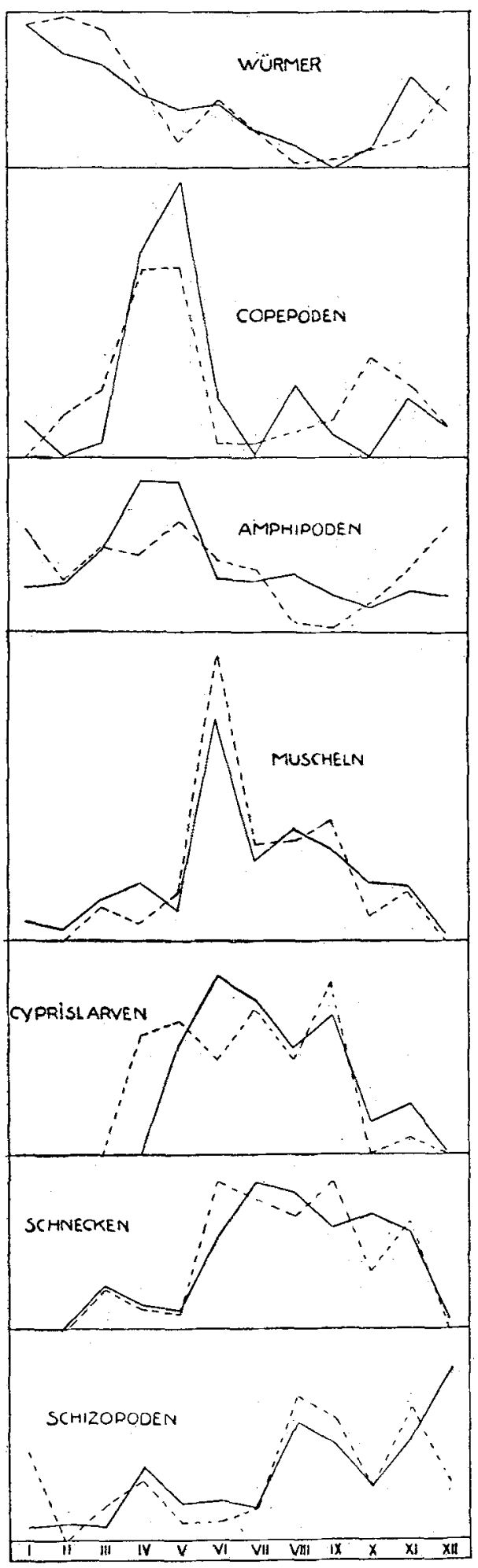

Abb. 9. von April bis Dezember vorfinden, also ein so scharf abgegrenztes Erscheinen, wie es die Fresserkurve aufzeigt, nicht haben.

\section{c) Laichzeiten, jahreszeitliche Wanderungen und Freßtätigkeit.}

Um evtl. Beziehungen zwischen den verschiedenen Lebensäußerungen der Garnelen aufzudecken, stellen wir verschiedene Momente aus dem Leben der Garnele einander gegenüber. Die Kurve der Abb. 10 gibt uns ein Bild von der FreBintensität der Garnele im Verlauf des Jahres, gemessen an der Häufigkeit dès Auftretens von Tieren mit leeren Mägen. Es sind zu dieser Darstellung nur die Weibchen herangezogen, weil das allgemeine Verhalten der Weibchen von anderen Untersuchern relativ eingehend studiert worden ist. Wenn wir den Verlauf der Kurve verfolgen, sehen wir, daß im Durchschnitt die erste Hälfte des Jahres mehr leere Mägen aufweist als die zweite Hälfte. Die Laichzeiten der Garnelen laufen nun im Jahresgang zusammengefaßt etwa wie folgt ab. Aus P. F. MeYER's Untersuchungen (1935, S. 35) läßt sich entnehmen, „daß die geschlechtsreife weibliche Garnele, allgemein gesprochen, dreimal im Jahre zur Eiablage schreitet und zwar im Sommer zweimal und im Winter einmal. Die sommerliche Periode wird von der winterlichen durch eine Zwischenperiode scharf getrennt, in der eine ausgesprochene : : Laichmüdigkeit :: herrscht. Die Eiablage findet in der Sommerperiode von März bis Juli statt. Die Eiablage in der Winterperiode ist von Anfang September bis Ende Februar zu rechnen. Bei Berücksichtigung der Eierstockverhältnisse beginnt die Sommerperiode bereits im Januar (mit der Entwicklung des Eierstocks), die

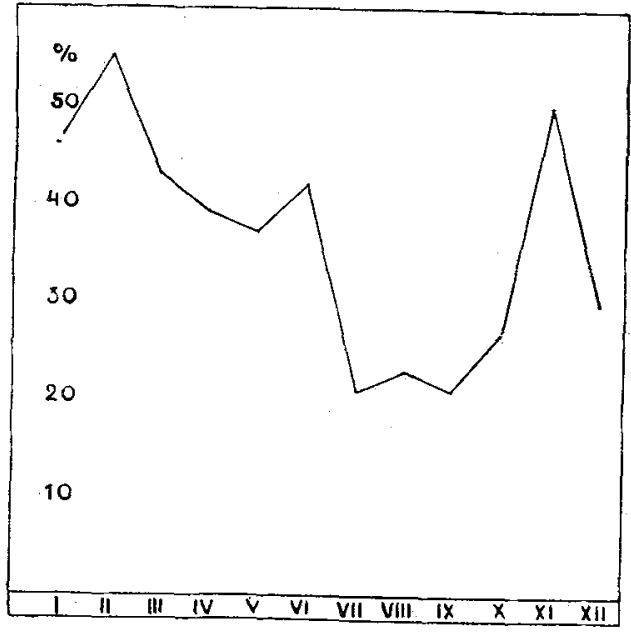

Abb. 10.

Abb. 9. Prozentuale Verteilung der Fresser der betr. Nahrungstiere über das Jahr; Fresser getrennt nach Geschlechtern: Männchen gestrichelte Linie, Weibchen ausgezogene Linie.

Abb. 10. Hundertsatz an Weibchen mit leeren Mägen im Jahresgang. 
Winterperiode dagegen schon Anfang September“. Zur Wandertätigkeit können wir aussagen, daß die Abwanderung in die Winterquartiere Anfang Oktober erfolgt. Nach Havinga verhalten sich dabei die verschiedenen Geschlechter verschieden und auch die Jahrgänge. So beginnt von den am weitesten flußaufwärts liegenden Fangplätzen die Abwanderung der größeren schon im Juni oder Juli (je nach Beschaffenheit des Gebietes). Im Spätherbst und Winter erfolgt dann die große Wanderung seewärts. Die großen Garnelen gehen den kleineren voran und ihre Wanderungen setzen sich noch bis spät in den Winter hinein fort. Zurück bleiben immer nur die kleinen. Aber auch diese suchen tiefste Stellen wie Rinnen und Baljen auf, in Zeiten strengen Frostes wandern auch sie wie die großen noch weiter ab. Anfang März setzt wieder die Anwanderung ein, bei der die kleinen voranziehen. Diese findet man noch im Frühsommer an den Wattinseln, und während sie heranwachsen, ziehen sie noch weiter land-bzw. stromaufwärts. Sobald im Juni die Anwanderung ihren Höhepunkt erreicht hat, beginnt auch schon wieder der Abzug und der Kreislauf von neuem. Im Gange der Besprechung dieser Vorgänge haben wir schon feststellen können, daß die verschiedenartigen Ereignisse im Leben der Garnelen zueinander in Abhängigkeit stehen. Naturgemäß findet eine Verzögerung oder Beschleunigung statt, je nachdem wie Verinderungen der Umweltsbedingungen eintreten (vergl. PlagmanN, 1937). Bei einer Gegenüberstellung der verschiedenen Lebenserscheinungen in ihrem Jahresverlauf, müssen wir berücksichtigen, daß die einzelnen Erkenntnisse in verschiedenen Gebieten und in verschiedenen Jahren gewonnen wurden. Wenn dennoch sinngemäß gleiche Tendenzen vorhanden sind, ist das Ergebnis einer Gegenüberstellung umso verläßlicher. So sahen wir, daß die Vielseitigkeit der Nahrung größer wird mit der Erhöhung der Freßtätigkeit: Die Monate Juli, August und September haben nämlich relativ wenig leere Mägen, und um diese Zeit finden sich mehrere Maxima in der jährlichen Verteilung der Nahrungstiere auf die Fresser, allerdings ausgenommen im Oktober, der anscheinend unter dem Einfluß der beginnenden Abwanderung steht. Weiter haben wir erfahren, daß die Häufigkeit des Auftretens von Weibchen mit Eiern in denselben eben aufgezählten Monaten geringer wird, bzw. am geringsten ist. Ganz offenbar also folgt auf die große sommerliche Laichtätigkeit eine Periode der "Laichmüdigkeit“, welche „in ausgiebigstem Maße fast ausschließlich der Nahrungsaufnahme gewidmet ist, und in der für die Herstellung eines guten Ernährungszustandes für den Beginn des Winters Sorge getragen wird" (FHRENBaUm, S. 93). Besonders gilt dies nach Ehrenbaum für die Monate August und September und in der Tat sind nach unserer Darstellung in diesen Monaten eindeutig die drei Maxima der weiblichen Fresser vereint (Äbb. 9). Die erhöhte Freftätigkeit beginnt aber schon, wie die Kurve der leeren Mägen aufzeigt, im Juli, wo ja auch die Häufigkeit der Weibchen mit Eiern geringer wird. Die Periode erhöhter Freßtätigkeit wäre also für unser Untersuchungsgebiet etwa wie folgt abzugrenzen :

$$
\text { : : Juli-August-September : : }
$$

Die Periode der starken sommerlichen Laichtätigkeit bedarf einer erhöhten „Ernährungsintensität“, und ihr Qualitätsbedürfnis wird durch überwiegenden Amphipodenfraß und Copepodenfraß befriedigt, und zwar im nahrungsreichen Wattenmeer, während die Periode der Winterlaichzeit ihre erhöhte Ernährungsintensität durch überwiegenden Schizopodenfraß bewerkstelligt, welcher die in ihren tiefen Winterquartieren wohnenden Weibchen zur Wanderung in Küstennähe veranlaßt, sofern tiefe Rinnen im Bodenrelief ihnen den Rückzug in ihr Temperaturoptimum garantieren.

\section{Zusammenfassung der Ergebnisse.}

Die vorliegende Arbeit ist von vornherein in der Hoffnung unternommen worden, durch Vertiefung unserer Kenntnis über die Lebensgewohnheiten der Garnele die Grundlage für eine Beurteilung der starken Schwankungen in den befischbaren Beständen zu verbreitern.

Durch Untersuchung der Mageninhalte der Garnelen wurde versucht, die Wechselwirkung zwischen den Nährorganismen und Zehrern zu erkennen.

Da das Elbe-Ästuar fast alle jene Biotope aufweist, die in geringen Abwandlungen auch an allen anderen Garnelenfangplätzen der deutschen Nordseeküste erscheinen, wurde das Material zur Untersuchung nur von hier genommen.

In den beiden ersten Abschnitten wird näher auf Arten, Anzahl und Größe der Nahrungstiere eingegangen, wie sie in den Mägen der Garnelen vorkamen, um einen Einblick in die Küstenlebensgemeinschaften zu vermitteln. 
Es stellt sich heraus, daß die Garnele wohl als omnivor zu bezeichnen ist, daß aber die Nahrung überwiegend aus Würmern, Amphipoden, Schizopoden, Copepoden, Cyprislarven von Balanus, Schnecken und jungen Muscheln besteht.

Die Variabilität im Zusammentreffen von verschiedenen Nährtierformen in den Mägen der Garnelen ist sehr groß, und es wird versucht, durch Einführung des Begriffes „abstrakte relative Häufigkeit" solche „Mageninhaltsgesellschaften“ zu isolieren, die Nährtierbiocönosen der freien Natur entsprechen.

Die Nahrungsmittel werden von der Garnele in charakteristischer Weise in einer ruckartigen Rückwärtsbewegung ergriffen, meist ganz verschlungen und im Vorverdauungsraum zerkleinert. Mechanische Beihilfe leisten Sandkörnchen, die von der Garnele successive zur Nahrung hinzugenommen werden, sodaß ein Ersatz der "Magenmühle" von Potamobius geschaffen ist.

Im Laufe ihres Lebens nimmt die Garnele einen allmählichen Nahrungswechsel vor. Für die jungen Garnelen unter $30 \mathrm{~mm}$ Länge steht Corophium an erster Stelle, von 30-45 mm Würmer und Amphipoden, dann wechseln ab, bis zu den größten, Würmer mit Schizopoden. Bei den größten tritt ein starker Kannibalismus auf. Die Größen 30 bis $45 \mathrm{~mm}$ haben die größte Nahrungsbreite.

Die Männchen sind unter den beiden Geschlechtern am aktivsten in ihrer Sammeltätigkeit. Beide Geschlechter wenden sich denselben Nährtierformen zu. Durch die Einführung eines Wertes für die Ernährungsintensität können vier verschiedene Ernährungsperioden herausgestellt werden: Die erste Periode nach dem Larvenleben ist die Jugend mit stärkster Ernährungsintensität, die zweite, die der geschlechtlichen Differenzierung, die dritte die Periode der Laichtätigkeit, die wieder durch erhöhten Nahrungsbedarf hervorsticht, während die vierte Periode unter der Einwirkung der Laichmüdigkeit und des Absterbens steht.

Bevor die Freßtätigkeit der Garnele an den verschiedenen Örtlichkeiten des Untersuchungsgebietes besprochen wird, wird ein Überblick über die Besiedlung des Gebietes mit Nahrungstieren gegeben.

Die verschiedenen Örtlichkeiten sind nach zwei Gesichtspunkten behandelt: erstens nach Biotopen mit den Typen Strom, Sände, Abhänge, Priele, Watt, und zweitens nach elf verschiedenen Fangplätzen der praktischen Fischerei, nämlichVogelsand, Scharhörn, Hundebalje, Eitzenloch, Buchtloch, Watt, Süderfahrwasser, Mittelgrund-Ost, Mittelgrund-West, Kratzsand und Gelbsand. Während hier die Örtlichkeiten nach dem zahlenmäßigen Vorkommen der Nahrungstiere in den Mägen der Garnelen charakterisiert werden, behandelt ein weiterer Abschnitt Qualitätsunterschiede der Fresser, die durch Qualitätsunterschiede der Nahrungsmittel bedingt sind, unter dem Gesichtswinkel der Garnelen als Handelsware.

Im Verlauf eines Jahres nehmen die Garnelen im allgemeinen einen Nahrungswechsel vor, der folgende Veränderung vom Anfang des Jahres bis zum Ende aufweist: Würmer / Amphipoden / Copepoden / Muscheln / Cyprislarven / Schnecken / Schizopoden. Vom Januar bis Mai ist ein gleichbleibender Crustaceenfraf $\mathrm{zu}$ verzeichnen, der Copepodenfraß nimmt auf Kosten des Würmerfraßes zu. Vom Juni bis September findet sich eine sehr gemischte Sommernahrung, und vom Oktober bis Dezember tritt die. Sommernahrung zugunsten von Malakostrakenfraß in den Hintergrund.

Ein Vergleich zwischen Laichzeiten, Wanderungen, Freßtätigkeit und Nahrungsqualität fördert zutage, daß die Monate Juli-August-September eine Periode erhöhter Freßtätigkeit ausmachen, die auf die Periode der sommerlichen Laichtätigkeit folgt. Die jahreszeitlichen Wanderungen der Garnelen werden mitbestimmt durch das Auftreten der Nährorganismen; der Ausschlag aber ist in anderen Faktoren zu suchen. 


\section{Schriftenverzeichnis.}

1. ANkel, W. E.: Hydrobienschill und Hydrobienkalk. - Natur und Museum, 59. H. 1. 1929.

2. BaLss, H. : Über die Chemoreception bei Garnelen. - Biol. Centralblatt 33. 1913.

3. Blegvad, H.: On the Biology of some Danish Gammarids and Mysids. - Rep. Dan. Biol. Stat., $22,1922$.

4. BRoch, Hj.: Die Bedeutüng der Drobak-Schwelle für die Bodenfauna der Garnelenfelder. Oslo 1935.

5. BURCKHARDT, A.: Die Ernährungsgrundlagen der Copepodenschwärme der Niederelbe. Intern. Revue der ges. Hydrobiol. und Hydrog., Bd. 32. Heft 6. 1935. Dissertation. 1935.

6. DAHL, F.: Untersuchungen über die Tierwelt der Unterelbe. - 6. Ber. der Comm. zur Unters. d. deutschen Meere. XVII-XXI. 3. Kiel 1891.

7. Depdolla, Ph.: Nahrung und Nahrungserwerb von Praunus flexuosus Müll. - Biol. Centralblatt Nr. 43. 1923.

8. - : Biologische Notizen über Praunus flexuosus Müll. - Zoologischer Anzeiger, 47. 1916.

9. Ehrenbaum, E. : Zur Naturgeschichte von Crangon valgaris Fabr. - Mitt. der Sektion für Küsten- und Hochseefischerei. Berlin 1890.

10. Giesbrecht, W.: Crustacea in Lang, A.: Handbuch der Morphologie. Bd. IV. 1913.

11. HAGMEIER, A. u. KÄNDLER, R.: Neue Unters. im nordfriesischen Wattenmeer und auf den fiskalischen Austernbänken. - Wiss. Meeresunters. N. F. Abt. Helgoland, XVI. Abh. Nr. 6. 1927.

12. HaRt, T. J.: Preliminary Notes on the Bionomics of the Amphipod Corophium volutator Pallas. - Journ. Marine Biol. Ass. N. S. Bd. 16. 1930.

13. Havinga, B.: Der Granat (Crangon vulgaris Fabr.) in den holländischen Gewässern. - Journal du Conseil. Bd. V. No. 1. 1930.

14. Hecht, F. u. MAtern, H.: Zur Ökologie von Cardium edule L. - Senckenbergiana Bd. 12.1930

15. Hentschel, E.: Biologische Wirkungen der Gezeiten im Süsswasser der Niederelbe. - Verh. d. intern. Komm. f. Limnologie. Kiel. 1923.

16. - : Der Detritus als Nahrung der Meerestiere. - Der Fischerbote 1915.

17. Hertling, H.: Unters. über die Ernährung von Meeresfischen. I. Quantitative Nahrungsuntersuchungen an Pleuronektiden und einigen anderen Fischen der Ostsee. - Ber. D. W. K. N. F. IV. 1928.

18. Hoek, P. P. C. u. ReDeCKe, H. C.: Über Mytilus edulis. Der Fischerbote 1915.

19. JoHANNSEN, W.: Elemente der exakten Erblichkeitslehre Jena 1926.

20. Jordan, H. J. u. Hirsch, G. Chr.: Einige vergl.-physiol. Probleme der Verdauung bei Metazoen. - Handbuch der norm. und pathol. Physiol. III. 1927.

21. KändLer, R.: Muschellarven aus dem Helgoländer Plankton. - Wiss. Meeresunters. N. F. Abt. Helgoland XVI, Abh. Nr. 5. 1926.

22. - : Unters. über die Biologie der Auster. Nr. 3. Verbreitung und Wachstum der Austernbrut. - Wiss. Meeresunters. N. F. Abt. Helgoland XVII. 1928.

23. LAdigES, W.: Über die Bedeutung der Copepoden als Fischnahrung im Unterelbegebiet. - Dissertation. Zeitschrift für Fischerei, Neudamm. 1934.

24. Marcus, K.: Zur Lebensgeschichte der Miesmuschel (Mytilus edulis). Der Fischerbote 1915.

25. MC INTosh, W. C.: The British Annelids. Polychaeta. Bd. I-IV. London 1900-1923.

26. MeIerJÜrgen, G.-A.: Zur Ernährungsbiologie der Bergbachfauna. - Dissertation. Aus der Preuß. Lehrund Versuchsanstalt. Veröff. Nr. 13. 1935. Münster i. W.

27. MeschKat, A.: Untersuchungen über den Aufbau der Kabeljaunahrung im Bereiche der Vestmannainseln. Rapports et Procès verb. XCIX. III. 1936.

28. MIELCK, W. u. KÜNNE, C.: Fischbrut- und Planktonuntersuchungen auf dem Reichsforschungsdampfer „Poseidon“ in der Ostsee, Mai-Juni 1931. - Wiss. Meeresunters. N. F. Abt. Helgoland XIX, Abh. N. 7.1935.

29. MEyeR, P. F.: Ein Beitrag zur Eiablage der Nordseekrabbe (Granat) Crangon vulgaris Fabr. - Zoologischer Anzeiger. Bd. 108. Heft 7/8. Leipzig 1934.

30. - : Wachstum- und Altersuntersuchungen an der Nordseekrabbe (Granat) Crangon vulgaris Fabr. Zoologischer Anzeiger Bd. 111. Heft 5/6. Leipzig 1935.

31. - : Ein Beitrag zur Frage der Laichperiodizität bei der Nordseekrabbe (Granat) Crangon vulgaris Fabr. - Zoologischer Anzeiger Bd. 109. Heft 1/2. Leipzig 1935.

32. - : Die Nordseekrabbe (Granat, Garnele) Crangon vulgaris Fabr. im Jadebusen. - Zeitschrift für Fischerei, Neudamm. 1936.

33. - : Ein Beitrag zur Frage der Brutbiologie der Ostseekrabbe Leander adspersus (Rathke) var. fabricii Rathke in der Wismarschen Bucht. - Zoologischer Anzeiger. Bd. 117. Heft 7/8. Leipzig 1937.

34. Nienburg, W. u. Kolumbe, E.: Zur Ökologie der Flora des Wattenmeeres II. Das Neufelder Watt im Elbmündungsgebiet. - Wiss. Meeresunters. N. F. Abt. Kiel. Bd. XXI. H. 1. 1931.

35. Petersen, C. G. J.: The necessity for quant. methods in the investig. of the animal life on the sea -bottom. - Proceed. Zool. Soc. London. 24. 1924.

36. - : The sea-bottom and its production of fish-food. - Rep. Dan. Biol. Stat. Vol. XXI. 1918.

37. Plagmann, J.: Hydrographische Einflüsse auf die Lebensweise der Garnelen. - Der Fischmarkt, Febr. 1937.

38. Rauschenplat, E.: Über die Nahrung von Tieren aus der Kieler Bucht. Dissertation Kiel 1901.

39. Remane, A.: Verteilung und Organisation der benthonischen Mikrofauna der Kieler Bucht. - Wiss. Meeresunters. Abt. Kiel. Bd. 21. 1933.

40. Ringleb, F.: Mathematische Methoden der Biologie. Leipzig 1937.

41. SARS, G. O.: An account of the Crustacea of Norway. Bd. I, Amphipoda. Kopenhagen 1895.

42. ScHLIENz, W.: Verbreitung und Verbreitungsbedingungen der höheren Krebse im Mündungsgebiet der Elbe. - Arch. f. Hydr. XIV. 1924 
43. Schulz, ERrch.: Beiträge zur Kenntnis mariner Nematoden. - Zool. Jahrb. Syst., Bd. 62. 1932.

44. - : Das Farbstreifen-Sandwatt und seine Fauna. - Kieler Meeresforschungen Bd. I. Heft 2. Nr. 19.1937.

45. SchuURmans-StekhoveN jr., J. H.: Ökol. und morphol. Notizen über Zuiderseenematoden. I. Die westl. Hälfte der Zuidersee. - Zeitschrift für Morphol. und Ökol. der Tiere. Abt. A der Zeitschrift für wissenschaftl. Biologie. Bd. 20. Heft 4. 1931.

46. Schwartz, AlBERT: Die Ausbreitungsmöglichkeiten der Hydrobia. - Natur und Museum. 59. H. 1.1929.

47. SpIEGEL, A.: Chemoreception von Crangon vulgaris. - Zeitschr. für vergl. Physiologie. VI. 1927.

48. STEbBing, O.: Gammaridea. Das Tierreich, 21. Liefg., Berlin. 1906.

49. ThamDRuP, H.: Die marinbiol. Unters. des Skalling-Labor. in der Ho-Bucht. - Rapports et Procès verbaux Vol. XCIV. 3. 1934-1935.

50. - : Beiträge zur Ökologie der Wattenfauna auf experimenteller Grundlage. - Meddelelser fra Komm. for Danm. Fiskeri og Havunders. Ser. Fis. X. 2. Kopenhagen. 1935.

51. ThIemanN, K.: Das Plankton der Flußmündungen. - Dissertation. Wiss. Ergebnisse der Deutschen Atlantischen Expedition auf dem Forschg.- und Vermessungsschiff "Meteor" 1925-1927. Bd. XII. Hamburg 1934.

52. TrusherM, F.: Trockenrisse mit Hydrobienfülle im Schlickwatt. - Natur und Museum, 59. H. 1. 1929.

53. - : Massentod von Insekten. - Natur und Museum 59. H 1. 1929.

54. WohlEnBerg, E.: Die grüne Insel der Eidermündung, eine entwicklungs-physiologische Untersuchung. - Aus dem Archiv der Deutschen Seewarte. Bd. 50. Nr. 2. Hamburg 1931.

55. —: Die Wattenmeer-Lebensgemeinschaften im Königshafen von Sylt. — Helgoländer. Wiss. Meeresunters. Bd. 1. Heft 1. 1937.

56. Wulff, A. u. BüCKMANN, A.: Der Gammelfang der Garnelenfiseher. - Wiss. Meeresunters. N. F. Abt. Helgoland XIX. Abh. Nr. 1. 1932. 